\title{
Herstellung von katalytischen monoklonalen Antikörpern
}

Dissertation zur Erlangung des Doktorgrades

der Mathematisch-Naturwissenschaftlichen Fakultäten

der Georg-August-Universität zu Göttingen

vorgelegt von

Farrokh Djalali Bazzaz

aus Teheran/Iran

Göttingen 2000 
D7

Referent: Prof. Dr. U. Grossbach

Korreferent: Prof. Dr. F.-W. Schürmann

Tag der mündlichen Prüfung: 31.10.2000 
Mènen zwè KleinenEngdn, Darren und Pejvak 
Die vorliegende Arbeit wurde in der Zeit von Dezember 1997 bis September 2000 in der Abteilung für Immunologie der Georg-August-Universität zu Göttingen angefertigt. 
Der Schlaf der Vemunft

gabiet Ungeherer 


\section{INHALTSVERZEICHNIS}

INHALTSVERZEICHNIS I

ABKÜRZUNGSVERZEICHNIS $\quad$ V

I EINLEITUNG 1

$1.1 \quad$ Allgemein 1

$1.1 \quad$ Monoklonale Antikörper 2

1.1.1 Cat-mAk 3

1.2 Vitamin E 5

1.2.1 Die Eigenschaften 7

1.2.2 Vitamin E im Körper 8

$\begin{array}{lll}1.3 & \text { Ziel und Planung } & 12\end{array}$

II MATERIALIEN und METHODEN 15

2.1 Materialien 15

2.1.1 Kulturgefäße und Präparationsmaterialien 15

2.1.2 Pipetten und Pipetterhilfen 16

2.1.3 Zentrifugen und Rotoren 17

$\begin{array}{lll}\text { 2.1.4 Weitere Geräte und Laborinstallationen } & 18\end{array}$

$\begin{array}{llr}2.2 & \text { Methoden } & 19\end{array}$

$\begin{array}{lll}2.2 .1 & 19\end{array}$

2.2.2 Immunisierung 20

2.2.2.1 Auswahl der Tiere zur Immunisierung 20

a) $\mathrm{MRL}_{\mathrm{lpr} / \mathrm{lpr}} \quad 20$

b) SJL/Hsp $\quad 20$

2.2.2.2 Optimierung der Antikörperproduktion durch Adjuvantien 21

2.2.3 Fusionvorbereitung 25

$\begin{array}{lll}2.2 .4 & \text { Fusion } & 27\end{array}$ 
2.2.5 Screening 28

2.2.6 Selektion 30

2.2.7 Aufbau eines cat-ELIS 31

2.2.8 Reklonierung und Hybridome 32

2.2.9 Etablierung und Kultivierung der Hybridome 33

2.2.10 Bestimmung der Antikörperkonzentration mittels ELISA 34

2.2.11 Antikörperproduktion der Hybridome 36

2.2.11.1 Antikörperproduktion in einem Minibioreaktor 37

2.2.12 Gefrierkonservierung von Zellen 38

2.2.13 Auftauen 39

2.2.14 Mykoplasmentest 40

a) Behandlung Mykoplasmeninfizierter Kulturen $\quad 42$

2.2.15 Antikörper-Isotypisierung 42

2.2.16 Aufreinigung der mAk mittels Protein A-Affinitätschromatographie 43

2.2.17 Aufreinigung muriner Antikörper mittels

2.2.18 Aufreinigung muriner Antikörper mittels

Sephacryl 300HR-Säulenchromatographie $\quad 46$

2.2.19 Herstellung von antigenbindenden Fragmenten $\mathrm{F}_{(\mathrm{ab}) 2} \quad 48$

a) Aufreinigung vom Fab 49

2.2.20 Dialyse und Anreicherung von Proteinlösungen 49

a) Dialyseschläuche $\quad 50$

b) Dialyse mit Dialysekassetten $\quad 50$

c) Dialyse mit Konzentratoren $\quad 51$

2.2.21 Proteinfällung 51

a) Fällung mit TCA 52

b) Fällung mit Ammuniumsulfat $\quad 52$

c) Fällung mit Aceton- $\mathrm{HCl}$

2.2.22 SDS-PAGE 53

a) Herstellung eines Gradientengels $\quad 54$

b) Herstellung der Gele nach LÄMMLI 55

c) Elektrophorese $\quad 55$

2.2.23 Proteintransfer mittels Elektroblotting 56 
2.2.24 Anfärbung der Proteine 57

a) Im Gel 58

b) Auf der Membran $\quad 58$

2.2.25 Nachweis von Proteine mittels ECL „enhanced chemiluminiescence“ $\quad 58$

2.2.26 Untersuchung zur Kreuzreaktion von mAk Ing-1 und cat-mAk Doro-1 60

2.2.26.1 Präparation der Monozyten 60

a) Isolierung mononukleärer Leukozyten des periphären menschlichen Bluttes (PBMNL) 61

b) Isolierung der Monozyten von MNL durch Adhärenz 62

c) Differenzierung der Monozyten zur dendritischen Zellen in vitro 63

d) Differenzierung der Monozyten zur Makrophagen 63

e) Kultivierung der humanen Permanentlinien $\quad 64$

2.2.27 Färbung membranständiger Antigene für die

Durchflußzytometrische Analyse $\quad 64$

2.2.28 Epitop-Charakterisierung und Kreuzreaktion des mAk Ing-1 66

2.2.29 Berechnung der Dissoziationskonstanten $\left(K_{D}\right)$ des mAks Ing-1 67

$\begin{array}{ll}\text { III ERGEBNISSE } & 70\end{array}$

3.1 Immunisierung, Fusion und Screening 70

$\begin{array}{lll}3.2 & \text { Cat-ELISA }\end{array}$

$3.3 \quad$ Vitamin E-bindender mAk Ing-1 75

3.4 Antikörperproduktion der Hybridome 76

$\begin{array}{lll}3.5 & \text { Mykoplasmentest } & 77\end{array}$

$3.6 \quad$ Isotyp-Bestimmung 77

$\begin{array}{lll}3.7 & \text { Antikörper-Aufreinigung } & 78\end{array}$

$\begin{array}{lll}\text { 3.7.1 Antikörperaufreinigung mittels Sephacryl } 300 \mathrm{HR} & 79\end{array}$

3.8 Untersuchung der katalytischen Aktivität der monoklonalen

Antikörpers Doro-1 zur Bildung von Vit. E aus 3,5,6-Trimethyl-2-

$\begin{array}{lr}\text { Phytylhydrochinon } & 80\end{array}$

$3.9 \quad$ Untersuchung des optimierten Vit. E-ELISA 81

$3.10 \quad$ Nachweis von Vitamin E im Biotin-Streptavidin-System 83 
3.11 Kristallographische Strukturanalyse des Substrates, des

Biotin-Vit. E-Esters und des antigenbindenders Fragment

(Fab) von Ing-1

3.12 Lokalisation des Epitops vom mAk Ing-1 innerhalb des Vit. E-Moleküls 87

3.13 Nachweis von natürlichem $\alpha$-Tocopherol mittels einer hydrophobe

$\begin{array}{ll}\text { Oberfläche } & 88\end{array}$

3.14 Berechnung der Dissoziationskonstante des mAks Ing-1 mittel ELISA 90

$3.15 \quad$ Untersuchung zur Kreuzreaktion der mAk Doro-1 und Ing-1 93

IV DISKUSSION 94

4.1 Das Hapten und seine Eigenschaften $\quad 94$

4.1.1 Design des Haptens $\quad 97$

$\begin{array}{lll}4.2 & \text { Auswahl der Tiere } & 98\end{array}$

$\begin{array}{lll}4.3 & \text { Auswahl der Adjuvantien } & 99\end{array}$

4.4 Auswahl des Haptens 99

$\begin{array}{lll}4.5 & \text { Auf des cat-ELISA } & 102\end{array}$

4.6 Nachweis der katalytischen Aktivität des mAks Doro-1 105

4.6.1 Die niedrige Umsatzrate von Doro-1 106

4.7 Der Vit. E bindende Ak Ing-1 107

4.7.1 Epitopbestimmung durch Biotin-Vit. E-Ester 108

4.7.2 Die Reaktion der Mak Ing-1 und Doro-1 mit verschiedenen

$\begin{array}{lll}\text { 4.7.3 Praxisbezogene Anwendung von Ing-1 } & 109\end{array}$

$\begin{array}{llr}\text { V ZUSAMMENFASSUNG } & 110\end{array}$

VI LITERATURVERZEICHNIS 113 


\section{ABKÜRZUNGSVERZEICHNIS}

\begin{tabular}{|c|c|}
\hline ABTS & 2,2-Azino-di(3-ethylenbenzthiazolinsulfonsäure) \\
\hline $\mathrm{Ag}$ & Antigen \\
\hline Ak & Antikörper \\
\hline APC & Antigenpräsentierende Zelle(n) \\
\hline BSA & Rinderserumalbumin \\
\hline cat-ELISA & Katalytischer ELISA \\
\hline cat mAk & katalytischer monoklonaler Antikörper \\
\hline $\mathrm{DC}$ & Dendritische Zelle(n) \\
\hline DMSO & Dimethylsulfoxid \\
\hline ECL & Enhanced Chemiluminescence \\
\hline EDTA & Ethylendiamintetraacetat \\
\hline $\mathrm{Ee}$ & enantiomeric excess \\
\hline ELISA & Enzyme Linked Immuno Sorbent Assay \\
\hline FACS & Fluoreszenz-aktiver Zellsorter \\
\hline FCS & fötales Kälberserum \\
\hline $\mathrm{g}$ & Gravitation $\left(9,81 \mathrm{~m} / \mathrm{s}^{2}\right)$ \\
\hline GM-CSF & Granulozyten/Monozyten-koloniestimulierender Faktor \\
\hline HAT & Hypoxanthin-, Aminopterin- und Thymidin-Zusatz \\
\hline HAT-Az & HAT-Azaserin-Zusatz \\
\hline HGPRT & Hypoxanthin-Guanin-Phosphoribosylteranferase \\
\hline $\mathrm{HuS}$ & humanes Serum \\
\hline i.p. & intraperitoneal \\
\hline IFN- $\gamma$ & Interferon $\gamma$ \\
\hline $\operatorname{Ig}$ & Immunglobulin \\
\hline IL & Interleukin \\
\hline $\mathrm{K}_{\mathrm{a}}$ & Assoziationskonstante (Affinitätskonstante) \\
\hline $\mathrm{K}_{\mathrm{D}}$ & Dissoziationskonstante \\
\hline KÜ & Kulturüberstand \\
\hline $\mathrm{M} \varphi$ & Makrophag(en) \\
\hline mAk & monoklonaler Antikörper \\
\hline
\end{tabular}


MMP Magermilchpulver

NMR Nuclear Magnetic Resonance

OD optische Dichte

PBL periphere Blut Leukozyten

PEG Polyethylenglycol

SDS Natriumdodecysulfat

PAGE Poly Acrylamid-Gelelektrophorese

TCA Trichloressigsäure

TCR T-Zellrezeptor

TEMED N,N,N`,N`-Tetramethylethylendiamin

Tris Tetrahydroxymethylaminomethan

Vit. E Vitamin E 


\section{I $\quad$ Einleitung}

\subsection{Allgemein:}

Das Immunsystem schützt den Organismus vor Infektionen durch Viren, Bakterien, Pilze und Parasiten. Zur Aufrechterhaltung der Integrität des Organismus stellt das Immunsystem ein wirkungsvolles Netzwerk aus löslichen Faktoren, Zellen und Organen bereit, die auf eindringende Fremdstoffe reagieren.

Die spezifische Immunabwehrreaktion besteht aus zwei verschiedenen Mechanismen, die sehr intensiv miteinander kommunizieren. Diese Mechanismen, die T-Zell vermittelte und die humorale Immunantwort, werden trotz ihrer unterschiedlichen Abläufe gleichermaßen von Antigen-präsentierenden Zellen (APC) unterstützt.

Die Antigen-Präsentation wird durch "professionelle" APC, die Dendritischen Zellen (DC) mit sehr hoher akzessorischer Aktivität, gesteuert. Zu den APC gehören noch weitere Immunzellen, wie z.B. Monozyten und Makrophagen.

Die Hauptakteure der humoralen Immunantwort sind die B-Zellen, die nach einer erfolgreichen Antigenpräsentation aktiviert werden. Nach der Aktivierung beginnen die ruhenden BZellen ihre Differenzierung durch mehrere Reifungsstadien und bilden die Plasmazellen, die spezifische Antikörper serzernieren.

Das B-Zell-System verfügt über ein sehr großes Repertoire an potentiellen Immunglobulinen (Ig) und ist dadurch in der Lage, gegen fast jedes Antigen (Ag) einen spezifischen Antikörper (Ak) produzieren zu können. 


\subsection{Monoklonale Antikörper}

EMIL VON BEHRING und SHIBA SABURO KITASATO entdeckten 1890, daß das Blutserum einer geimpften Person Ak enthält, die spezifisch an einem bestimmten Krankheitserreger binden (JANEWAY \& TRAVERS, 1995). Circa 70 Jahre später, im Jahr 1959, stellten P. MEDAWAR und F. MACFARLANE BURNET ihre Theorie zur klonalen Selektion der B-Zellen vor und erklärten so die Bildung der monospezifischen Antikörper.

Bevor die Methode der Hybridomtechnologie entwickelt wurde, war es nur möglich, gewünschte Antikörper in Form von polyklonalen Antiseren, einem Gemisch von Ak verschiedener Spezifität, zu gewinnen. 1975 publizierten KÖHLER und MILSTEIN (KÖHLER \& MILSTEIN, 1975) eine neue Methode zur Herstellung monoklonaler Antikörper (mAk). Erst durch diese Methode wurde der Wunsch nach mAk höchster Reinheit und Spezifität realisiert. Die beiden Forscher fusionierten murine Myelomzellen mit Ak-produzierenden BZellen aus immunisierten Tieren. Das Fusionat einer Hybridzelle gewährleistete zum einen permanentes Wachstum und zum anderen die Bildung von mAk. Die Anwendung dieser Methode war so erfolgreich, daß trotz der Entwicklung weiterer neuer Methoden, wie z. B. des Phagen-Display-Systems (WINTER et al., 1994), immer noch ein Großteil der mAk durch Zellfusion hergestellt wird.

Aufgrund des unerschöpflichen Repertoires der B-Zellen bei der Produktion von Antikörpern postulierte schon KARL LANDSTEINER (JANEWAY \& TRAVERS, 1995), daß Ak gegen eine uneingeschränkte Zahl von Molekülen möglich sein müßten. Um das Spektrum an Spezifitäten ermitteln zu können, untersuchte LANDSTEINER die Immunantwort auf kleine organische Moleküle wie Arsenate und Nitrophenyle. Solche einfachen Strukturen lösten allein keine Antikörperproduktion aus. Er entdeckte jedoch, daß eine Reaktion dann eintritt, 
wenn diese Moleküle kovalent an ein Trägerprotein gebunden sind und deshalb bezeichnete er die kleinen Moleküle als Haptene (von griechisch Haptein für "Haften”).

Immunglobuline sind nicht nur ein Forchungsobjekt, sondern gleichzeitig ein optimales Hilfsmittel zur Untersuchung verschiedener Objekte in der modernen bio-medizinischen Forschung. Die Anwendung von Ak nimmt beinahe täglich zu.

Eines der neuesten Anwendungsgebiete von mAk ist deren Einsatz als Katalysatoren, sogenannten katalytischen monoklonalen Antikörpern (cat-mAk), nachdem die Idee, die molekulare Diversität des Immunsystems zur Herstellung von Enzymen zu benutzen, zum ersten Mal im Jahre 1948 von L. PAULING (PAULING, 1948) geäußert wurde.

\subsubsection{Cat-mAk}

1986 haben zeitgleich LERNER und SCHULTZ zum ersten Mal zwei mAk (6D4, ein Maus IgG, generiert von Lerner et. al. und MOPC167, ein Maus IgA, generiert von Schultz et al.) vorgestellt, die katalytische Aktivität aufwiesen (LERNER et al., 1986; SCHULZ et al., 1986). Seit 1986 sind viele chemische Reaktionen mit Hilfe von katalytischen monoklonalen Ak (cat-mAk) beschrieben worden. Bei den ersten Versuchen handelte es sich um einfache Transformationen, deren Mechanismen wohlbekannt waren, z. B. Esterhydrolysen. Nach den ersten Erfolgen wurden jedoch weitere anspruchsvollere Transformationen allgemeiner Art vorgenommen, wie z. B. Bildung von Säuren, Basen oder nukleophile Reaktionen (SCHULTZ \& LERNER, 1993). Es wurden auch Reaktionen mit mAk durchgeführt, die einer Katalyse ähnlich verliefen (LERNER \& BENKOVIC \& SCHULTZ, 1991).

Bei diesen Reaktionen wurde die Bindungsenergie der cat-mAk in einer hoch spezifischen Weise benutzt, um die Aktivierungsenergie zu überwinden und so die Transformation zur 
Bildung eines Zielmoleküls zu begünstigen. Ein Unterschied zwischen cat-mAk und Enzymen ist unter anderem die hohe Bindungsenergie, die zwischen Substrat und mAk spezifisch wirken kann.

In den letzten Jahren beschränkte sich der Einsatz von cat-mAk auf chemische Reaktionen, deren Durchführung mit mAk im Vergleich zu bekannten chemischen Methoden keine Verbesserung erbrachten. Allerdings dienten diese Katalysatoren als Modell, um nun die Reaktionen durchführen zu können, für die nur beschränkt Enzyme existieren. Ein Beispiel dafür ist die Aldolase-Reaktion, die von cat-mAk 38C2 oder $33 \mathrm{~F} 12$ bechleunigt wird (ZHONG et al., 1998). Diese beiden mAk katalysieren sowohl die Aldol- als auch die Retroaldolreaktion (Abb. 1).

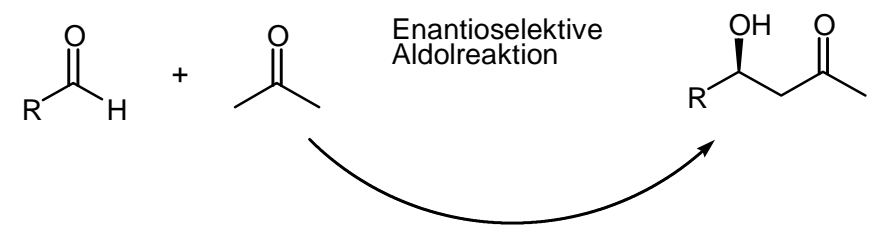

mAk 38C2 oder 33F12

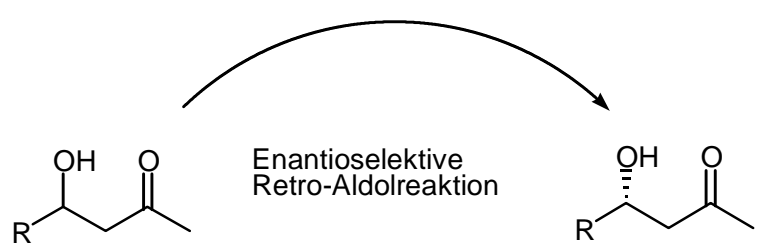

\section{Abbildung 1: Die Aldolase-Reaktion sowie Retro-Aldolreaktion mit den cat-mAk 38C2 oder $33 F 12$.}

Eine in der Naturstoffsynthese oft genutzte Transformation ist die intramolekulare Ringschlußreaktion. Diese Art der Verknüpfung gelingt oft gut durch Addition eines Nukleophils an ein Elektrophil. So wird die Zahl der Atome vor und nach der Transformation konstant gehalten werden, so daß man von Atomökonomie spricht. Die atomökonomischen Reaktionen (TROST, 1995 a) sind ressourcenschonend, da keine andere Verbindung als 
Atom-Transporter benötigt wird. Ein Beispiel für eine intramolekulare Cyclisierung ist die Biosynthese von Vitamin E (Vit. E). Dabei wird nach Protonierung der Doppelbindung durch das Enzym Tocopherol-Cyclase das entstandene Carbokation enantiofacial differenzierend von der freien phenolischen Hydroxylgruppe unter Ausbildung des Chromansystems selektiv angegriffen (WOGGON \& STOCKER, 1994).

\subsection{Vitamin E}

1929 haben EVANS und BISHOP (EVANS und BISHOP, 1922) Reproduktionsstörungen bei Ratten festgestellt, in deren Futter bestimmte Fette fehlten. Damit lieferten die beiden Forscher die ersten Hinweise auf den essentiellen fettlöslichen Charakter eines bis dahin unbekannten Elements, das später isoliert und als Vitamin E deklariert wurde (nach HORWITT, 1986).

Vitamin E gehört neben Vitamin A, D und K zur Gruppe der fettlöslichen Vitamine. Vitamin E ist ein Sammelbegriff für alle Tocopherol- und Tocotrienolderivate, eine Gruppe von acht natürlichen Verbindungen: $\alpha-, \beta-, \gamma$ - und $\delta$-Tocopherol sowie $\alpha-, \beta-, \gamma$ - und $-\delta$-Tocotrienol (Abb. 2). Unter allen acht Stereoisomeren besitzt $\alpha$-Tocopherol mit der absoluten $2 R-4^{\prime} R-8^{\prime} R$ Konfiguration die höchste biologische Aktivität (Tab. 1). 

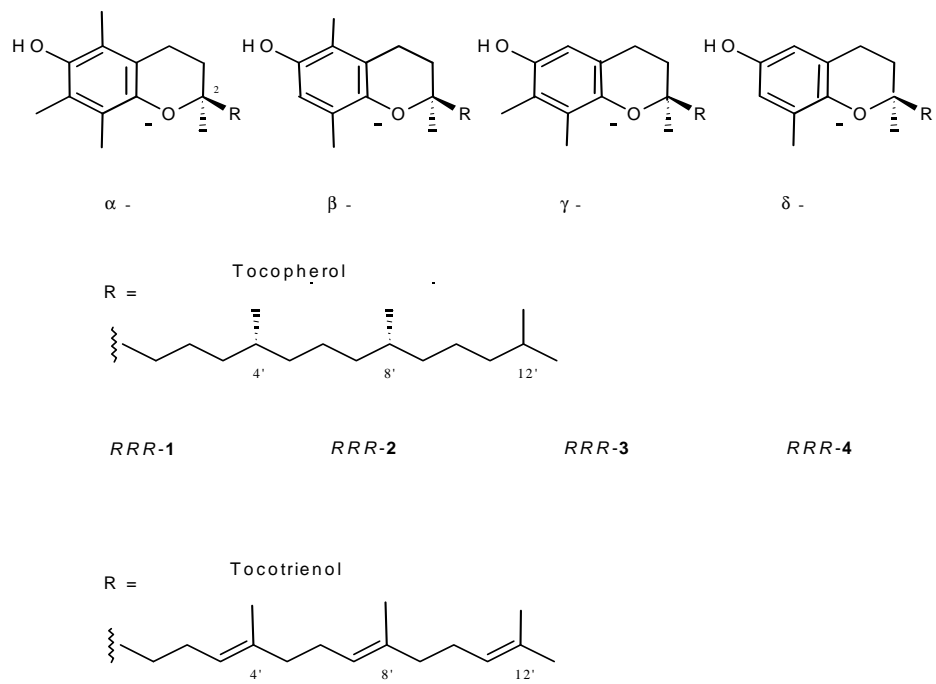

$\begin{array}{llll}R-5 & R-6 & R-7 & R-8\end{array}$

Abbildung 2: Die Strukturen aller 8 natürlichen Vitamin E-Isomere. (Nomenclature of Tocopherols and related componds, 1982).

Tabelle 1: Die relative Aktivität von natürlichem $\alpha$-Tocopherol mit absoluter $\left(2 R, 4{ }^{\prime} R, 8 R^{\prime}\right)$ Konfiguration und 7 möglichen Stereoisomeren.

\begin{tabular}{|c|c|}
\hline \multicolumn{2}{|l|}{ Relative Vitamin E-Aktivität* } \\
\hline Tocopherol-Acetat-Derivate & Tocopherole/Tocotrienole \\
\hline 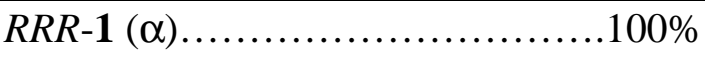 & 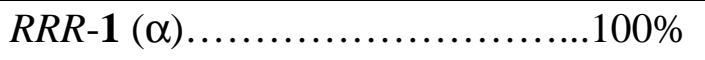 \\
\hline 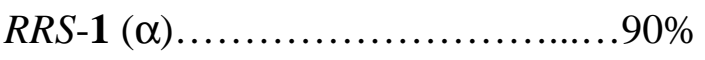 & 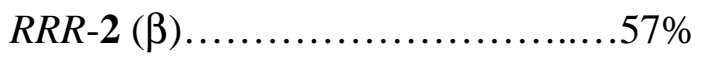 \\
\hline 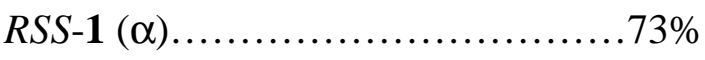 & 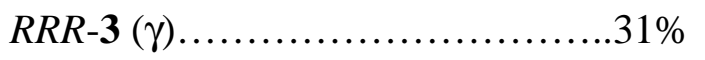 \\
\hline 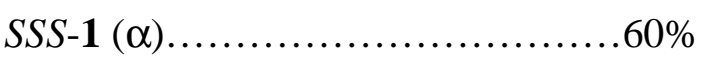 & 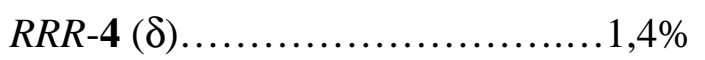 \\
\hline 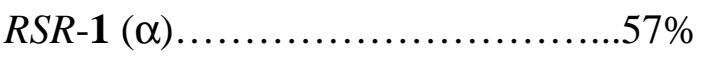 & 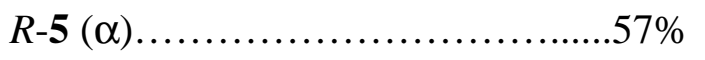 \\
\hline 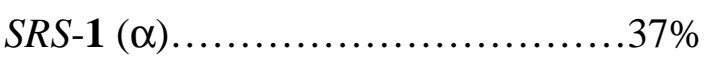 & Konzentrat aus Palmenöl und............30\% \\
\hline 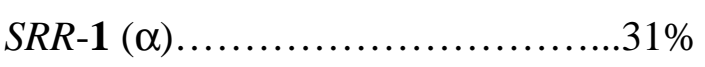 & Fettsäuren Rückstand..................35 - 47\% \\
\hline 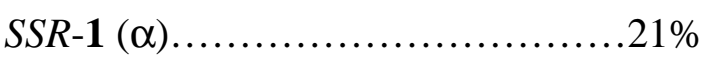 & \\
\hline
\end{tabular}

*Ermittelt durch Fetal Resorption Gestation Test bei Ratten (modifiziert nach WEIMANN \& H. WEISER, 1991). 
Da synthetisch hergestelltes Vitamin E alle 8 Stereoisomere von $\alpha$-Tocopherol (all-rac- $\alpha$ Tocopherol) beinhaltet, bleiben die pflanzlichen Ölen die einzige Quelle zur Gewinnung von enantiomerenreinem Vitamin E (Tab. 2).

Tabelle 2: $\quad$ Vitamin E-Gehalt in pflanzlichen Ölen

\begin{tabular}{|lccc|}
\hline $\begin{array}{l}\text { Vitamin E-Verbindung } \\
{[\mathrm{mg} / 100 \mathrm{~g} \text { Öl }]}\end{array}$ & Sonnenblumenkerne & Sojabohnen & Palmen \\
\hline$\alpha$-Tocopherol & 59,5 & 11,0 & 18,3 \\
$\beta$-Tocopherol & 0 & 0 & 0 \\
$\gamma$-Tocopherol & 3,54 & 62,4 & 0 \\
$\delta$-Tocopherol & 0 & 20,4 & 0 \\
$\alpha$ - $+\gamma$-Tocotrienol & 0 & 0 & 17,2 \\
\hline
\end{tabular}

(Modifiziert nach NETSCHER et al., 1996).

\subsubsection{Die Eigenschaften}

Vitamin E dient im Körper als Antioxidans und Radikalfänger. Diese hoch reaktiven Moleküle werden kontinuierlich im Körper gebildet, sowohl als Nebenprodukte des oxidativen Stoffwechsels als auch durch Umwelteinflüsse wie ionisierende Strahlungen. Durch ihr hohes Reaktionspotential reagieren die freien Radikale spontan mit verschiedenen Molekülen und verursachen dadurch irreversible Schäden wie Mutationen. Da das Vit. E mit freien Radikalen reagiert, steht es mit ca. 50 verschiedenen Krankheiten in Verbindung. Es gibt zahlreiche Studien sowohl Langzeit- epidemologische (LUBIN et al., 2000) wie auch experimentell-analytische Studien (PATHANIA et al.,1999; FACTOR et al.,2000), in denen das Vit. E entweder präventiv oder therapeutisch untersucht wurde. Es gibt neben den Krank-heiten, bei denen Vit. E involviert, jedoch nicht die Ursache ist, noch eine Reihe von 
Erkrankungen, die direkt auf den Mangel dieses Vitamins zurückzuführen sind. Dazu gehört der chronische Vitamin E-Mangel bei Patientinnen mit Fettmalabsorption, der ein progressives neurologisches Syndrom verursacht. Zu den Symptomen dieser Krankheit gehören die Reflex- und Bewegungsstörungen (Ataxien) sowie die Empfindungsstörungen in den Extremitäten, die durch progressive Neuropathie verursacht werden (SATYA-MURTI et al., 1986).

\subsubsection{Vitamin E im Körper}

Das im Dünndarm absorbierte Vitamin E gelangt über die Lymphsystem-Passage ins Blut, und es erreicht so die Gewebe. Da ca. 87\% der Gesamtmenge von Vitamin E im Körper mit $2 R, 4^{\prime} R, 8^{\prime} R$ - $\alpha$-Tocopherol-Konfiguration im Blut zirkulieren (GONZALES, 1990), wird am häufigsten die Vitamin E-Konzentration im Blut bestimmt. Sie liegt zwischen 11,6 und 37,1 $\mu \mathrm{mol}(0,5$ und 1,6 mg/dl). Das entspricht einer täglichen Zufuhr von 10 bis $30 \mathrm{mg}$ Vitamin E (WILLETT et al.,1983). Der individuelle Bedarf an Vitamin E unterliegt vielen variablen Parametern und ist vor allem von Ernährungsgewohnheiten abhängig. Da die Konzentration von Vitamin E im Blut mit der Lipidkonzentration im Blut korrespondiert, wird die Relation der Vitamin E-Konzentration zu dem Gesamtlipid als Standardmaß gewählt, wobei ein Verhältnis von $0,8 \mathrm{mg}$ Vitamin E pro $1 \mathrm{~g}$ Lipid als unterste Grenze des Normalbereiches gilt (WILLETT et al.,1983).

Das Vitamin E im Blut wird von LDL (Low density Lipoprotein) geschützt und von TTP (Tocopherol Transfer Protein) zu den Geweben transportiert. Dieser Transport verhindert einerseits die spontanen Schwankungen der Vitamin E-Konzentration im Blut, so daß bei 
10facher Vitamin E Zufuhr die Konzentration im Blut verdoppelt wird (KIYOSE et al., 1997), und andererseits verteilt es sich nach gewebespezifischem Bedarf (Tab. 3).

\section{Tabelle 3: Vitamin E-Konzentrationen in verschiedenen Geweben beim Menschen}

\begin{tabular}{|c|}
\hline Gewebe* \\
\hline 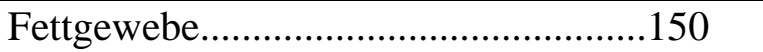 \\
\hline 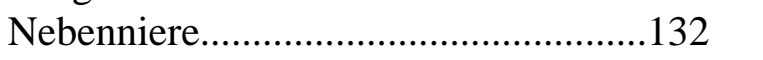 \\
\hline 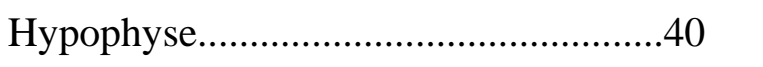 \\
\hline Hoden $\left(0^{\star}\right) \ldots \ldots \ldots . . .$. \\
\hline 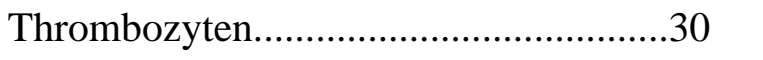 \\
\hline 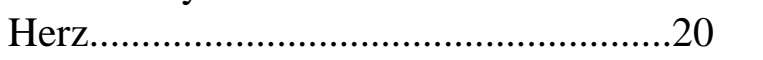 \\
\hline 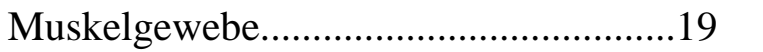 \\
\hline 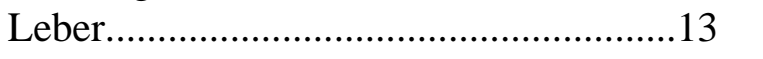 \\
\hline Eierstöcke ( ( ) ..........................................11 \\
\hline Plasma...................................................., \\
\hline 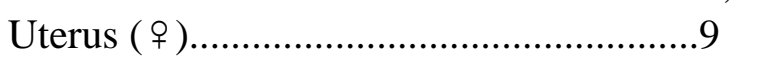 \\
\hline Nieren.............................................. \\
\hline 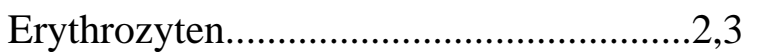 \\
\hline
\end{tabular}

*)Es handelt sich um Frischgewicht (modifiziert nach CARPENTER et al., 1985)

Vitamin E wird in Gewebe in der Zellmembran und membranreichen Zellorganellen wie in Mitochondrien mit einer Dichte von 1 Molekül Vitamin E auf tausend Phospholipidmoleküle eingebaut und schützt vor allem die mehrfach ungesättigten Fettsäuren (PUFA) vor dem Angriff von Radikalen (SIMON et al., 1956; BURTON et al.,1982). Für die Lokalisation von $\alpha$-Tocopherol in der Membran ist die lange hydrophobe Seitenkette am C-2 verantwortlich (Abb.3a), während das Chroman-Ring-System die freien Radikale entsprechend dem Mechanismus aus Abbildung 3 neutralisiert (Abb.3b). 
a)

Innen

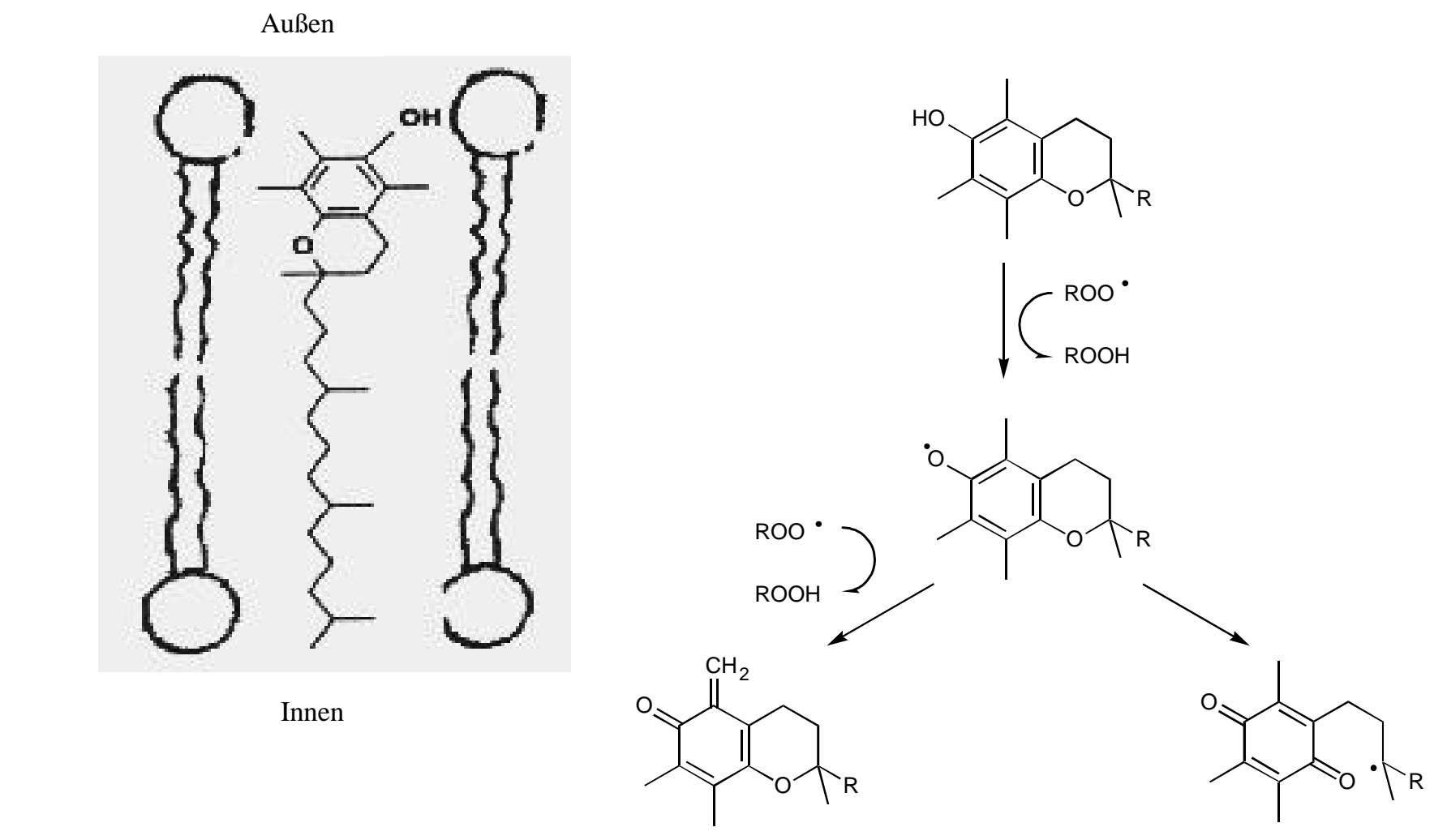

b)

Abbildung 3: a) Die Lokalisation von Vit. E innerhalb der Phospholipidmembran.

b) Die Funktion des Tocopherols als Antioxidans (modifiziert nach VATASSERY, 1989).

Nach der Reaktion mit radikalischen Substanzen übernimmt das Vitamin E das einzelne freie Elektron und wird dadurch selbst radikalisch. Die sofortige Konfigurationsänderung neutralisiert den radikalischen Sauerstoff (Abb.3b). Diese Moleküle werden von Vitamin C später regeneriert (Abb.4).

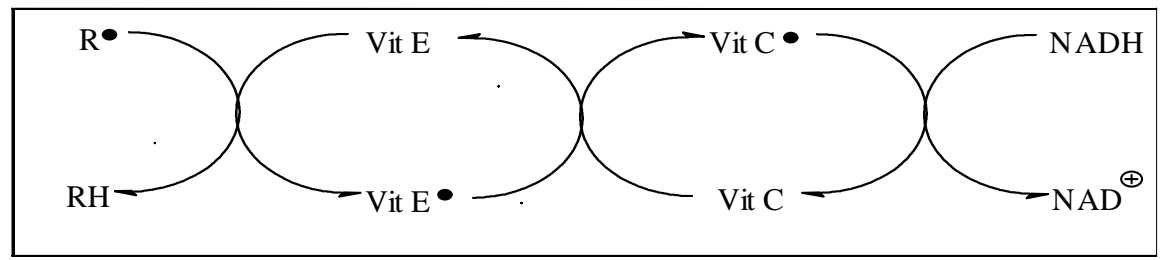

Abbildung 4: Die Regenerierung des Vitamin E durch Vitamin C (modifiziert nach PACKER, 1979). 
Dank dieser effektiven Schutzmechanismen ist Vitamin E das wichtigste Antioxidans im Körper (BURTON, JOYCE \& INGOLD, 1983). So wird neben vielen Substanzen das Vitamin A auch vor Oxidation geschützt, darüberhinaus bestehen weitere funktionelle Verbindungen zwischen diesen beiden Vitaminen (CHENG et al., 1987; INGOLD et al., 1987).

Zudem reguliert Vitamin E die Thrombozytenaggregation, indem es die Aktivität von Cyclooxigenase hemmt und dadurch die Synthese von Prostaglandin minimiert. Es wurde auch nachgewiesen, daß Vitamin E die Aktivität von Proteinkinase $\mathrm{C}$ hemmt (MAHONEY \& AZZI, 1988).

Die biologisch-physiologische Aktivität von Vitamin E natürlicher Herkunft ist höher als die von synthetischem Vitamin E. Da die Vitamin E-Konzentration in Relation zum Gesamtlipid im Blut gemessen wird, wird die Bioverfügbarkeit verschiedener Formen von Vitamin E ( $\alpha-$, $\beta$-, $\gamma$ - und $\delta$-Tocopherol) unterschiedlicher Herkunft über den Anstieg der Tocopherolkonzentration im Blut extrapoliert.

Studien über die Aktivität verschiedener Vitamin E-Konfigurationen haben gezeigt, daß die Bioverfügbarkeit von $100 \mathrm{mg} / \mathrm{Tag}$ natürlichem Vitamin E ca. $300 \mathrm{mg} / \mathrm{Tag}$ synthetischem Vitamin E entspricht (KIOSE et al., 1997; ACUFF et al., 1998). Die Unterschiede zwischen synthetischem und natürlichem Vitamin E sind auf die Spezifität des Transportproteins (- $\alpha-$ Tocopherol-Transferprotein) zurückzuführen, welches vorzüglich an $2 R, 4^{\prime} R, 8^{\prime} R$ - $\alpha$ Tocopherol bindet (CHENG et al., 1987; INGOLD et al., 1987). 


\section{4 $\underline{\text { Ziel und Planung }}$}

Im Rahmen dieser Arbeit sollten murine monoklonale Antikörper produziert werden, die die Synthese von $\alpha$-Tocopherol katalysieren. Diese Antikörper sollen in der Lage sein, eine intramolekulare Cyclisierung durchzuführen und von zwei möglichen Enantiomeren nur die Transformation einer Konfiguration zu begünstigen (Abb.5).

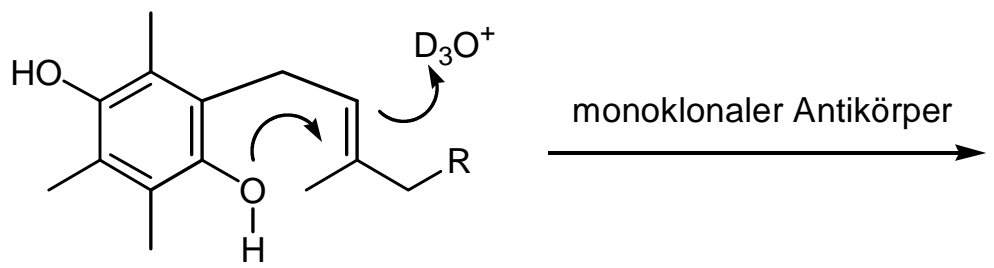<smiles>[R]C[C@]1(C)Oc2c(C)c(C)c(O)c(C)c2C[C@H]1[2H]</smiles><smiles>[R]C[C@H](C)CCC[C@H](C)CCCC(C)C</smiles>

\section{Abbildung 5: Schema der enantioselektiven Synthese von Vitamin E mit Hilfe eines katalytischen monoklonalen Antikörpers.}

Zur Immunisierung wurden zwei autoimmunkranke Mäusestämme (SJL und MRL/lpr) gewählt, die aufgrund ihrer aggresiven Krankheit verstärkt katalytische Antikörper produzieren (TAWFIK et al., 1995).

Diese Tiere sollten mit dem enantiomerenreinen Hapten (Abb.6) immunisiert werden, welches an KLH-Maleimid als Träger-Protein gekoppelt war, sowie ohne Träger-Protein mit einem Lipopeptid-Adjuvans appliziert werden, das in der Arbeitsgruppe von Prof. W. G. BESSLER (HOFFMANN \& BESSLER, 2000) hergestellt und uns freundlicherweise zur Verfügung gestellt wurde. 


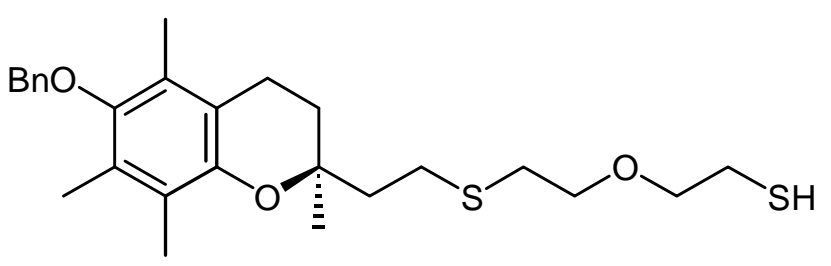

Abbildung 6: Das enantiomerenreine Hapten.

Zur Bestimmung der katalytischen Reaktionsbedingungen (Substrate, Lösungsmittel, Temperatur und Reaktionsdauer sowie möglichst viele verschiedene Antikörpern) sollte ein effizientes Nachweissystem entwickelt werden.

Da die gewünschte Reaktion der natürlichen Biosynthese von Vitamin E entsprechen sollte, sollten drei verschiedene Substrate synthetisiert werden. Nach der Protonierung sollte sich in allen drei Substanzen ein tertiäres Carbokation ausbilden, welches von der phenolischen Hydroxylgruppe unter Ausbildung des Chromangerüstes angegrifen wird (Abb.7).<smiles>Cc1c(C)c2c(c(C)c1O)CC[C@](C)(CCC[C@H](C)CCC[C@H](C)CCCC(C)C)O2</smiles>

$\alpha$-Tocopherol<smiles>[R]C=C(C)CCc1c(C)c(O)c(C)c(C)c1O</smiles>

A<smiles>[R7]CC(=C)CCc1c(C)c(O)c(C)c(C)c1O[R17]</smiles>

B
C

Abbildung 7: Substrate, die durch retrosynthetische Spaltung des $\alpha$-Tocopherols zum Testen der cat-mAk eingesetzt werden sollen.

Ferner sollten monoklonale Antikörper generiert werden, die an Vitamin E binden können. Die Vitamin E-bindenden Eigenschaft dieser Antikörper sollten dazu benutzt werden, ein sowohl qualitatives als auch quantitatives Testverfahren von Vitamin E zu entwickeln. 
Da viele Substanzen, die zur Durchführung dieser Arbeit essentiell waren (GÖRLITZER, 1997; SEIBEL, 1997), in der Arbeitsgruppe von Prof. L. F. TIETZE im Institut für Organische Chemie synthetisiert werden konnten, schien eine interdisziplinäre Arbeit in Kooperation mit der genannten Arbeitsgruppe unabdingbar zu sein. Die Durchführung dieser Arbeit ist abhängig von enger Kooperation mit Herrn J. SEIBEL, der den organisch-chemischen Teil übernahm (SEIBEL, 1997).

Zusätzlich sollten röntgen-kristallographische Strukturanalysen von cat-mAk und antiVitamin E-Ak im Rahmen einer Kooperation mit der AG von Prof. G. M. SHELDRICK im Institut für Anorganische Chemie dazu beitragen, daß das aktive Zentrum und die Bindungsstellen beider Antikörper charakterisiert werden können. Über diese Versuche wird in diese Arbeit nicht berichtet. 


\section{MATERIALIEN und METHODEN}

\subsection{Materialien}

Da die benötigten Materialien und Reagenzien im Zusammenhang mit ihrem Verwendungszweck im Methodenteil erwähnt sind, werden hier nur allgemeine Reagenzien, Materialien und Laborinstallationen sowie Geräte aufgelistet.

\subsubsection{Kulturgefäße und Präparationsmaterialien}

- Filter

- Handschuhe

- Kryoröhrchen
Sartorius Minisart NML,

Filtriereinheit zum Einmalgerauch,

$0,2 \mu \mathrm{m} / 6$ bar max.,

Best. Nr.: 16534 K

Sartorius GmbH, Göttingen, (D)

Einmal-Untersuchungs-Handschuhe

aus reinem Latex,

Best. Nr.: 942 785/4

Hartmann

Cryotube, $48 \times 12,5, \mathrm{~W} /$ base,

Best. Nr.: 3-68632

Nunc GmbH, Wiesbaden, (D) 
- Mikrotiterplatten

- Petrischalen mit Teflonmembran

- Petrischalen

- Zentrifugenröhrchen

- Zentrifugenröhrchen

\subsubsection{Pipetten und Pipetterhilfen}

- Eppendorf-Varipetten
Mikrowellplatte 96f mit Deckel,

Nunclon Delta SI (für Zellkultur);

Best. Nr.: 1-67008

Nunc GmbH, Wiesbaden, (D)

Petriperm hydrophob

Fa. Bachhofer, Reutlingen, (D)

für Zellkultur, $\varnothing 100$ x 20 mm,

Best. Nr.: 639160

Greiner GmbH \& Co. KG,

Nürtingen, (D)

10 ml, Best. Nr.: 3-47856

Nunc GmbH, Wiesbaden, (D)

50 ml, Best. Nr.: 210261

Greiner, Nürtingen, (D)
1-10 $\mu \mathrm{l}, 10-100 \mu \mathrm{l}, 100-1000 \mu \mathrm{l}$,

Eppendorf-Gerätebau, Northeler

und Hinz GmbH, Hamburg, (D) 
- ED-Pipetten

- Octapetten

- Pipettboy

- Pipettenspitzen

\subsubsection{Zentrifugen und Rotoren}

- Tischzentrifugen
Electronic Digital Pipette, mit

Adaptern für $100 \mu \mathrm{l}$ und $1000 \mu \mathrm{l}$,

Fa. RAININ, Instrument Co. Inc.

Woburn, (USA)

8-Kanal-Pipetten, $100 \mu \mathrm{l}, 200 \mu \mathrm{l}$,

Costar, Cambridge, Massachusetts, (USA)

automatische Pipetterhilfe

Tecnomara Deutschland GmbH,

Fernwald, (D)

blau: Best. Nr.: 70.762

gelb: Bestl. Nr.: 70.760

Sarstedt, Nümbrecht, (D);

weiß: Best. Nr.: 40500000

Dunn, Asbach, (D)
Heraeus Christ Difuge GL,

Labofuge M,

Heraeus GmbH, Hanau, (D) 
- Kühlzentrifuge

- Schwenkbecherrotor

- Plattenrotor
Minifuge GL,

Heraeus GmbH, Hanau, (D)

Nr.: $2150, \mathrm{r}_{\mathrm{m}}=16,2 \mathrm{~cm}$ mit

den Einsätzen Nr.: 5322 und 5226,

Heraeus GmbH, Hanau, (D)

Nr.: $3471, r_{m}=17,5 \mathrm{~cm}$,

Heraeus GmbH, Hanau, (D)

\subsubsection{Weitere Geräte und feste Laborinstallationen}

- Brutschrank

- Sterilbank Kl. II
Heraeus $\mathrm{CO}_{2}$-Auto Zero,

Sollwerteinstellung:

$\mathrm{CO}_{2}: 5 \%, \mathrm{~T}: 37^{\circ} \mathrm{C}, \mathrm{RH}: 95 \%$

Heraeus GmbH, Hanau, (D)

Heraeus-Lamin Air, HLB 2472,

Heraeus GmbH, Hanau, (D) 


\subsection{Methoden}

\subsubsection{Haptenvorbereitung}

\section{$\underline{\text { Material }}$}

- Trägerprotein

Imject Maleimide Activated Keyhole Limpet

Hemocynin (KLH), Pierce-Kfm; Best. Nr.: 77106

Ampuwa

Fresenius AG, Bad Homburg

Zwischen 7 synthetisierten Haptenen, die im Institut für organische Chemie in der Arbeitsgruppe von Prof. Dr. Dr. h.c. L.F. Tietze synthetisiert wurden (GÖRLITZER, 1997; SEIBEL, 1997), wurde Hapten I (Abb.8) als geeignet zur Immunisierung ausgewählt.

2 mg KLH-Maleimid (Sulfo-SMCC) (BARTEL und CAMPBELL, 1959) (Pierce; Deutschland) wurden in $200 \mu \mathrm{l}$ Wasser (Ampuwa) gelöst. Zur KLH-Lösung wurden 2 mg Hapten, gelöst in $500 \mu \mathrm{l}$ PBS (HERSCKOVITS, 1988) und ca. $20 \mu \mathrm{l}$ DMSO gegeben und 2 Stunden bei RT inkubiert (SENOZAN und LANDRUM, 1981). Anschließend wurde die Lösung portioniert und bei $4^{\circ} \mathrm{C}$ gelagert.<smiles>Cc1c(C)c2c(c(C)c1OCc1ccccc1)CC[C@@](C)(CCSCCOCCS)O2</smiles>

Abbildung 8: Enantiomerenreines Hapten als Antigen zum Immunisieren. 


\subsubsection{Immunisierung}

\subsubsection{Auswahl der Tiere zur Immunisierung}

Zur Immunsierung wurden zwei Mausstämme (MRL lpr/pr und SJL/Hsp) ausgewählt, die im Vergleich zu Mäusen des BALB/c-Stammes mehr katalytische Antikörper produzieren (Tawfik et al., 1996).

\section{a) MRL $_{\text {pr } / p r}$}

Die genetischen Untersuchungen an den Mäusen aus dem MRL-Stamm zeigen eine spontane, autosomale, ressesive Mutation in der lpr (Lymphproliferation)-Region. Die Tiere mit dem Genotyp lpr/lpr besitzen ein massiv vergrößte Lymphknoten (MURPHY und ROTHS, 1977), die auf die ressesive lpr-Mutation zuruckzuführen sind. Im Alter von 16 Wochen tragen über $90 \%$ der Zellen in den Lymphknoten das Thy-1.2-Protein, ein membranständiges Alloantigen. In dieser Zeit erscheinen im Serum zwei antinukleare Autoantikörper der Subklassen IgG1 und 2a, welche sogar an dsDNA binden (MURPHY and ROTHS 1978).

Aufgrund pathologischer Entwicklung (Immunkomplex Glomerulonephritis) sterben die weiblichen Tiere im Durchschnittsalter von ca. 17 und die Männchen von ca. 22 Wochen.

Die Phenotypisierung der Oberflächen-Antigene zeigte folgende Alloantigene (EISENBERG et al., 1978): $\mathrm{H}^{2 \mathrm{k}}$, Ly-1.2, Ly-2.1, Ly-3.1, Thy-1.2 und $\mathrm{TL}^{-}$.

Die Tiere sind Albino (c/c), größer als BALB/c-Mäuse (Körpergröße: LG/J) und sehr ruhig.

\section{b) $\underline{\text { SJL/Hsp }}$}

Ca. $90 \%$ der Tiere dieses Stammes entwickeln das Retikulum-Zell-Sarkom (Hodgkinähnlich) im Alter von 13 Monaten. Die Krankheit entwickelt zuerst in Peyersche Plaques 
(SANTOS et al., 1994), mesynschymatischen Lymphknoten und metastasiert in Milz, Leber, Thymus und andere Lymphknoten. Ungewöhnlich bei der Entwicklung des Sarkoms dieser Tiere ist die Regula-tion des Tumors und seine sehr frühe Entwicklung, nämlich im Alter von 22 Tagen. Im Alter zwischen 1. bis 7. Monat entwickeln ca. $83 \%$ der weiblichen Tiere Leukämie (TONG et al., 1998).

Die Tiere des SJL-Stammes produzieren nur $5 \%$ ihrer normalen Menge an $\lambda$-Leichtekette im Serum ( SATOH et al., 1996) und überdurchschnittliche Mengen an anti-NP (Nukleoprotein)-Antikörper.

Die Tiere sind Albino mit MHC von $\mathrm{H}-2^{\mathrm{S}}$-Phenotyp, so groß wie BALB/c-Mäuse und aggressiv.

\subsubsection{Optimierung der Antikörperproduktion durch Adjuvantien}

Da die Haptene aufgrund ihrer niedermolekularen Strukturen sehr schwache Antigenität besitzen und dementsprechend eine schwache Immunantwort auslösen, erfolgt die Immunisierung mit einem Hapten als Antigen in der Regel mit Adjuvantien (von Lateinisch adjuvare für "helfen") als Begleitsubstanz. Die meisten Adjuvantien werden vor allem aus Pflanzen und aus bakteriellen Zellwänden isoliert oder durch chemische Synthese hergestellt.

FREUND stellte 1956 sein Adjuvans vor (FREUND, 1956) und manifestierte unter anderen die Verstärkung der Antikörperbildung, Empfindlichkeitserhöhung gegen das Antigen sowie gegen einfache chemische Komponenten. Adjuvantien werden mit Antigenen in gemischter Form appliziert und verstärken die Immunantwort gegen das Antigen. Daher kann die 
notwendige Antigendosis bzw. die Anzahl von Injektionen reduziert werden oder überhaupt erst eine meßbare Immunantwort induziert werden (PETERS und BAUMGARTEN, 1992).

Die Wirkung von Adjuvantien kann viele Ursachen haben, z. B. Anlocken der Lymphozyten. Eine der wichtigsten Ursachen ist dennoch die costimulierende Aktivität der Makrophagen.

Durch die Mischung der Adjuvantien mit dem Antigen stimulieren die bakteriellen Substanzen, aus dem Adjuvans, die Makrophagen zur Freisetzung der costimulierenden Signale für CD4 $4^{+}$-T-Zellen, die nicht bakterielles Antigen erkennen (JANEWAY \& TRAVERS). Eines des meist verwendeten Adjuvans ist die von FREUND vorgestellte Mischung, die nach ihm bezeichnet wurde und in zwei Formen eingesetzt wird: 1.) einfache Wasser-in-Öl Emulsion, als inkomplettes FREUNDsches Adjuvans (iFA), und 2.) komplettes FREUNDsches Adjuvans (cFA), daß zusätzlich hitzeinaktivierte Mykobakterium tuberklosum Organismen in der Ölphase der Wasser-in-Öl Emulsion beinhaltet.

Neben den klassischen Adjuvantien gehören weitere definierte Substanzen zu dieser Familie. Dazu gehören Aluminium-Hydroxyde, deren Wirkung durch Zugabe von abgetöteten Bordetella pertussis Bakterien verstärkt wird, N-acetyl-muramyl-L-alanyl-D-isoglutamin (Muramyl-di Peptid = MDP), ein Dipeptid mit L-Konfiguration der ersten und D-Konfiguration der zweiten Aminosäure, und Bestatin, ein chemisch genau charakterisiertes Bakterienprodukt (PETERS und BAUMGARTEN, 1992).

Da die Immunsierung in dieser Arbeit mit einem Hapten durchgeführt werden soll, werden die Injektionen mit Adjuvantien erfolgen, um die Immunantwort und dementsprechen die Antikörperbildung positiv zu beeinflussen. 


\section{$\underline{\text { Material }}$}

- $\quad M R L_{\text {lpr/lpr }}$ Mäuse

- SJL/Hsp Mäuse

- TiterMax-Adjuvans

- P3CSK4-Adjuvans
Harlan, Borchen

Harlan, Borchen

Boehringer Ingelheim,

AG. von Prof. W.Bessler, Freiburg

Um die Immunantwort zu verstärken (PETERS und BAUMGARTEN, 1992), wurde die Immunisierung mit Adjuvantien durchgeführt. Zur Immunisierung wurden 2 Mausstämme (MRL $L_{\text {lpr/lpr }}$ und SJL/Hsp) ausgewählt, die in einer ausgeprägten aggressiven Form autoimmun erkrankt sind.

Zur Immunisierung wurden 2 Adjuvantien verwendet. Acht Tiere wurden mit "TiterMax" und vier Tiere mit einem speziellen Lipopeptid-Adjuvans immunisiert (Tab.4).

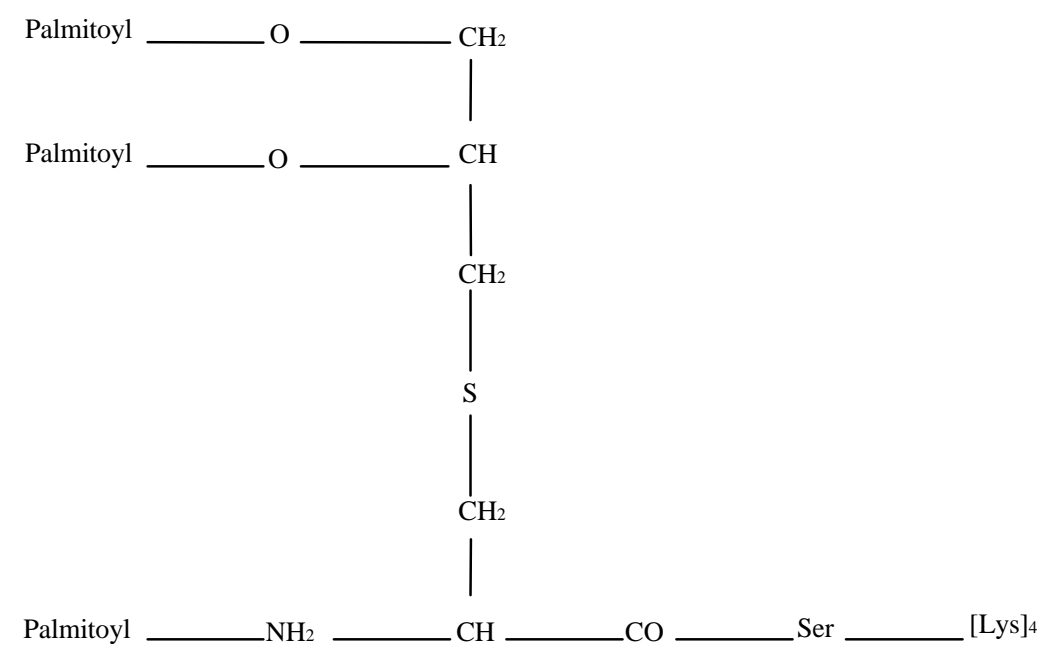

Abbildung 9: a) Lipopeptid-Adjuvans P3CSK4. 
Tabelle 4: Immunsierungsschema der $6 \mathrm{MRL}_{\mathrm{lpr} / \mathrm{pr}}$ und $6 \mathrm{SJL} / \mathrm{Hsp}$ Mäuse mit TiterMax und P3CSK4-Adjuvans*.

\begin{tabular}{|c|c|c|c|}
\hline $\begin{array}{c}\text { ZEIT } \\
\text { (Tage) }\end{array}$ & IMMUNISIERUNGSSCHRITTE & $\begin{array}{l}\text { INJEKTIONSVOLUMEN } \\
(\mu \mathrm{I} / \mathrm{Maus}) \& \\
\text { IMMUNISIERUNGSART }\end{array}$ & $\begin{array}{l}\text { ANTIGEN: } \\
\text { KLH- } \\
\text { HAPTEN }\end{array}$ \\
\hline 1 & Priming & $\begin{array}{l}200 \mu \mathrm{l} \\
(100 \mu \mathrm{l} \mathrm{Ag}+100 \mu \mathrm{l} \text { Adjuv. }) \\
\text { i.p. }\end{array}$ & $100 \mu \mathrm{g}$ \\
\hline 35 & 1. Auffrischung mit Adjuvans & $\begin{array}{l}150 \mu \mathrm{l} \\
(75 \mu \mathrm{l} \mathrm{Ag}+75 \mu \mathrm{l} \text { Adjuv. }) \\
\text { i.p. }\end{array}$ & $75 \mu \mathrm{g}$ \\
\hline 42 & 2. Auffrischung mit Adjuvans & $\begin{array}{l}150 \mu \mathrm{l}, . \\
(75 \mu \mathrm{Ag}+75 \mu \mathrm{l} \text { Adjuv. }) \\
\text { i.p }\end{array}$ & $75 \mu \mathrm{g}$ \\
\hline 49 & 3. Auffrischung ohne Adjuvans & $75 \mu \mathrm{Ag}$, i.p. & $75 \mu \mathrm{g}$ \\
\hline 50 & 4. Auffrischung ohne Adjuvans & $75 \mu \mathrm{l} \mathrm{Ag}$, i.p. & $75 \mu \mathrm{g}$ \\
\hline 51 & 5. Auffrischung ohne Adjuvans & $75 \mu \mathrm{l} \mathrm{Ag}$, i.p. & $75 \mu \mathrm{g}$ \\
\hline 52 & \multicolumn{3}{|c|}{ FUSION } \\
\hline
\end{tabular}

*) Von jedem Stamm wurden 4 Tiere mit TiterMax und 2 Tiere mit P3CSK4 immunisiert.

Das zweite Adjuvans bestand aus zwei Faktoren, einem Lipopeptid, P3CSK4 (Abb. 9a), und einem T-Zell-Epitop, die extra für die beiden Mäusestämme in Arbeitsgruppen von Prof. W.G. Bessler hergestellt worden. Der Vorteil des zweiten Adjuvans bestand darin, daß die Immunisierung mit Hapten allein und ohne Träger-Protein erfolgte (Abb. 9b). 


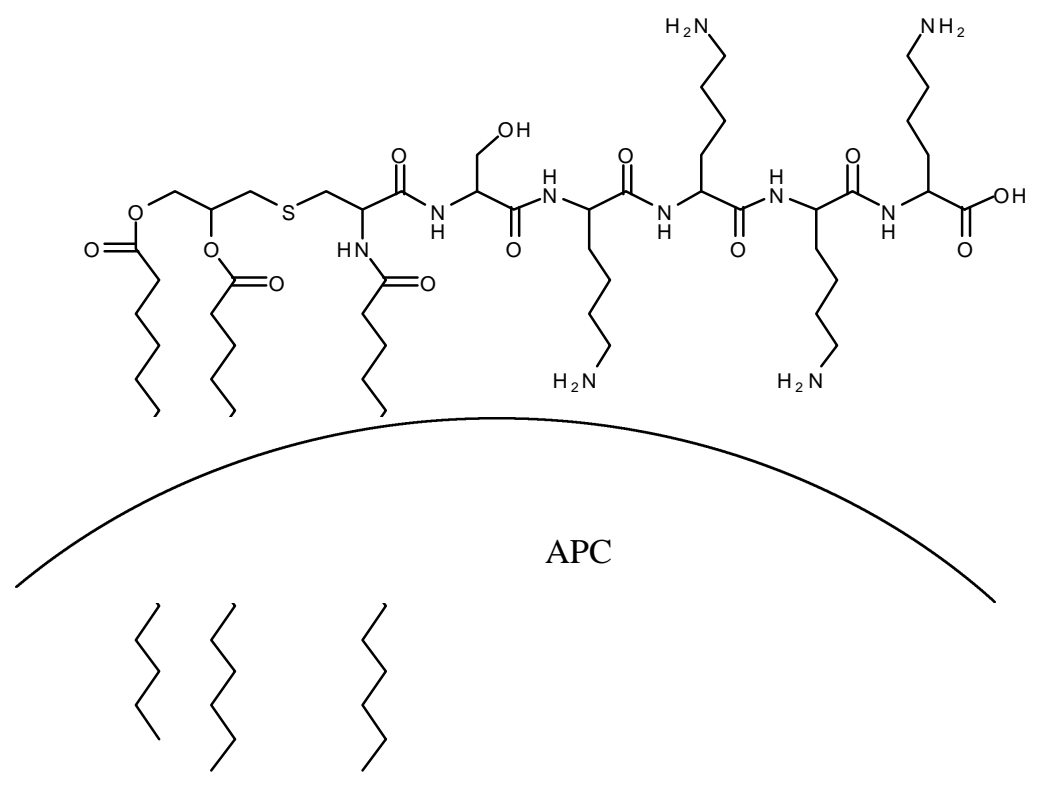

Abbildung 9:b) Die schematische Darstellung der Bindung der P3CSK4-Verbindung an APC.

Es wurden insgesamt 12 Tiere im Alter von 8 Wochen immunisiert. Alle Injektionen wurden intraperitoneal durchgeführt.

\subsubsection{Fusionvorbereitungen}

\section{$\underline{\text { Material }}$}

- BALB/c Mäuse

- $\quad$ P3 x 63 Ag8.653

- 8-Azaguanin
Zucht aus hauseigenem Tierstall

Myelomzellinie (nicht Antikörper produzierend) aus der BALB/c Maus; ATCC: P3 x 63 Ag8.653

Sigma, Deisenhofen 
- Selektionsmedium: HATAz (50 x):

Hypoxanthin

Aminopterin

Thymidin

Azaserin

- Mikrotiterplatte (96 Näpfe)
680,50 $\mu \mathrm{g} / \mathrm{ml}$; Serva, Heidelberg

$0,88 \mu \mathrm{g} / \mathrm{ml}$; Serva, Heidelberg

193,80 $\mu \mathrm{g} / \mathrm{ml}$; Sigma, Deisenhofen

$0,25 \mu \mathrm{g} / \mathrm{ml}$; Sigma, Deisenhofen

TC Qualität; Nunc GmbH, Wiesbaden

40 Tage vor der Fusion wurden die HGPRT ${ }^{(-)}$Maus Myelomzellen P3 x 63 Ag 8.653 (KEARNEY et al., 1979) aufgetaut und im Hybridomkulturmedium kultiviert. Eventuell entstandene Revertanten, die nicht mehr HAT sensitiv waren, wurden durch eine 10tätige Behandlung mit 8-Azaguanin $(20 \mu / \mathrm{ml})$ abgetötet. Desweitern erfolgte eine HATAz Selektionskontrolle durch 14tätige Kultur in Selektionsmedium A sowie ein Mykoplasmentest. Anschließend wurden die Myelomzellen auf Bakterienschalen expandiert. Bei der Expansion wurden nur die suspendierten Zellen kultiviert, um die Adhärenz der Myelomzellen zu minimieren. Für jede Fusion wurden ca. 2 × $10^{8}$ vitale Zellen vorbereitet. Um die eventuellen Probleme, wie z.B. Mykoplasmenkontamination, zu umgehen, wurden mit einem Tag Ab-stand mehrere Ampullen von Myelomzellen aufgetaut und die Kulturen getrennt voneinander behandelt.

Drei Tage vor der Fusion wurden Peritoneal-Makrophagen einer BALB/c Maus als Feederzellen steril präpariert. Dazu wurden die Mäuse durch $\mathrm{CO}_{2}$-Begasung getötet und die Bauchhöhle unter aseptischen Bedingungen mit einem kleinen Schnitt geöffnet. Mittels einer sterilen Pasteurpipette mit $10 \mathrm{ml}$ eiskalter PBS wurden die Peritoneal-Makrophagen ausgespült. Anschließend wurden die Makrophagen gezählt und mit Selektionsmedium in mittleren Näpfen einer 96-Napf Mikrotiterplatte mit einer Konzentration von 1 x $10^{3}$ Zellen/Napf kultiviert. 


\subsubsection{Fusion}

\section{$\underline{\text { Material }}$}

- Präparierbesteck

- Fusionsmedium

- Polyethylenglykol (PEG)

- Hybridom-Kulturmedium
Brand $\mathrm{GmbH}+\mathrm{Co} . \mathrm{KG}$, Wertheim

RPMI-1640 mit 50\% PEG 4.000, sterilfiltriert

fusionsgetestet (MW 4.000), Merk, Darmstadt

RPMI- $1640+20 \%$ FCS

24 h nach der letzten Injektion wurden die Tiere unter Narkose Herz-punktiert, Blut gewonnen und anschließend getötet. Ca. $400 \mu$ Blut wurden bei 2600 x g für 10 min bei RT zentrifugiert und das Serum in $10 \mu \mathrm{l}$ Portionen bei $-20^{\circ} \mathrm{C}$ für spätere Tests kryokonserviert. Unter sterilen Bedingungen wurde die Milz präpariert. Mittels einer Einmalspritze mit $10 \mathrm{ml}$ $37^{\circ} \mathrm{C}$ warmem Medium 80/20 wurden die Milzzellen in einer Bakterienschale ausgespritzt, bis ein heller Bindegewebesack zurückblieb. Die gewonnenen Milzzellen wurden anschließend gezählt, mit den Myelomzellen im Verhältnis $1: 2$ gemischt und einmal mit Medium 80/20 proteinfrei gewaschen. Danach wurde der Überstand vollständig abgesaugt und das Zellpellet sanft resuspendiert.

Die PEG-Fusion wurde unter permanenter, sanfter Agitation wie folgt durchgeführt (PETRES und BAUMGARTEN):

a) Zugabe von $1 \mathrm{ml}$ Fusionsmedium innerhalb von $1 \mathrm{~min}$ bei $37^{\circ} \mathrm{C}$,

b) 1 min sanftes Schütteln bei $37^{\circ} \mathrm{C}$,

c) Zugabe von $1 \mathrm{ml} \mathrm{PBS}\left(37^{\circ} \mathrm{C}\right)$ innerhalb von $1 \mathrm{~min}$, 
d) Zugabe von $3 \mathrm{ml} \mathrm{PBS}\left(37^{\circ} \mathrm{C}\right)$ innerhalb von $1 \mathrm{~min}$ und

e) Zugabe von $16 \mathrm{ml} \operatorname{PBS}\left(37^{\circ} \mathrm{C}\right)$ innerhalb von $1 \mathrm{~min}$.

Anschließend wurde die Fusionsausbeute durch Auszählung von asymmetrischen, großen, mehrkernigen Zellen bestimmt. Die Zellsuspension wurde dann für 5 min bei $600 \mathrm{x}$ g und RT zentrifugiert. Die pelletierten Zellen wurden für 5 min bei RT inkubiert. Danach wurde der Überstand vollständig abgesaugt, die Zellen in Hybridom-Medium vorsichtig resuspendiert und einmal gewaschen. Ausgehend von der Gesamtzellzahl (Myelom- + Milzzellen) wurden $1,8 \times 10^{5}$ Zellen in $18 \mathrm{ml}$ HATAz-Selektionsmedium aufgenommen und in mit PeritonealMakrophagen beschichteten Näpfen ausplattiert.

\subsubsection{Screening}

\section{$\underline{\text { Material }}$}

- ELISA-Platte

- Aktiviertes BSA

- Substrat

- Waschpuffer
MaxiSorp; Nunc GmbH, Wiesbaden

Imject Maleimide Activated Bovine Serum

Albumin; Pierce-Kfm; Best. Nr.: 77116

2,2-Azino- [3-ethylbenzthiazolinsulfonat]

(ABTS) Boehringer, Mannheim

PBS mit 0,05\% Tween $20(\mathrm{v} / \mathrm{v})$ 
- Substrat-Lösung

$10 \mathrm{ml}$ von $2 \mathrm{mM}$ ABTS, $100 \mathrm{mM} \mathrm{CH}_{3} \mathrm{COONa} \mathrm{x}$

$3 \mathrm{H}_{2} \mathrm{O}, 50 \mathrm{mM} \mathrm{NaH}_{2} \mathrm{PO}_{4} \times \mathrm{H}_{2} \mathrm{O}, \mathrm{pH} 4,2+50 \mu \mathrm{l}$

$30 \% \mathrm{H}_{2} \mathrm{O}_{2}$

Das Screening dient dem Aufspüren von Klonen, die Antikörper mit der erwünschten Funktionalität produzieren. Da ein katalytisches Testsystem erst entwickelt werden sollte, wurden die Antikörper zuerst anhand ihrer Spezifität gegen Hapten getestet.

Ausgehend vom Antigen (KLH-Hapten-Komplex) wurden die Hybridomüberstände an BSAHapten-Komplex getestet. Dazu dienten die gewonnenen Mausseren als Positivkontrolle. Da theoretisch Kreuzreaktionen zwischen KLH-Maleimid und BSA-Maleimid existieren können, wurden die zu testenden Antikörper zuerst für 30 min bei RT auf BSA präabsorbiert. Die getesteten Überstände wurden aus den Näpfen ausgewählt, deren Klone mindestens 1/3 des Napfbodens ausgefüllt haben. Nach der Präabsorption wurden die zu testenden Kulturüberstände für $2 \mathrm{~h}$ bei $37^{\circ} \mathrm{C}$ auf BSA-Hapten-Komplex in einer Mikrotiterplatte inkubiert und anschließend drei Mal mit je $200 \mu l$ Waschpuffer/Napf gewaschen. Als Nachweis-Antikörper wurden $100 \mu$ Peroxidase-konjugierter Kaninchen anti-Maus Antikörper (1:1000 in PBS verdünnt) in die Näpfe pipettiert und $1 \mathrm{~h}$ bei RT inkubiert. Nach dreimaligem Waschen (siehe oben) wurden $100 \mu$ l Substrat-Lösung (50 $\mu \mathrm{H}_{2} \mathrm{O}_{2}$ in $10 \mathrm{ml}$ ABTS) zu den Näpfen pipettiert. Nach ein bzw. drei Minuten wurden dann die optischen Dichten unter Ver-wendung eines 405 nm Meßfilters und eines $490 \mathrm{~nm}$ Referenzfilters in einem Platten-photometer gemessen. 


\subsubsection{Selektion}

\section{$\underline{\text { Material }}$}

- Selektionsmedien (50 x konzentrierte Stammlösung):

HAT-Mediumzusatz

Hypoxanthin: 680,50 $\mu \mathrm{g} / \mathrm{ml}(500 \mu \mathrm{M})$

Aminopterin: $8,80 \mu \mathrm{g} / \mathrm{ml}(8 \mathrm{mM})$

Thymidin: $193,80 \mu \mathrm{g} / \mathrm{ml}(800 \mu \mathrm{M})$

In Aqua bidest., sterilfiltriert;

Zur Entfernung nicht gewünschter Fusionsprodukte (Myelom/Myelom) sowie nicht fusionierter Myelomzellen wurde eine Positivselektion durchgeführt.

Dazu wird ein Enzymdefekt ausgenutzt, den die zur Fusion angesetzten Myelomzellen in der Hypoxantin-Guanin-Phosphoribosyl-Transferase (HGPRT) besitzen. Da die HGPRT ${ }^{(-)}$Myelomzellen den Azaserin- und Aminopterin-Block des DNA-Hauptsyntheseweges durch den Einbau von supplimentiertem Hypoxantin und Thymidin nicht umgehen können, werden die im Selektionsmedium kultivierten unerwünschten Myelomzellen sterben.Überleben können nur die Hybridome, die eine intakte HGPRT durch Fusion mit einer Milzzelle erhalten haben.

Es war darauf zu achten, daß durch spontane Rückmutation mit einer Frequenz von $1 \times 10^{-5}$ Myelomzellen die HAT-Selektion überleben können. Da Azaserin in der Purinsynthesekaskade die Bildung von 5-Amino-Imidozol-4-Carboxy-Ribonukleotid blockiert, wird der Haupt Syntheseweg doppelt blockiert.

Daher wurde dem HAT-Selektionsmedium zusätzlich Azaserin zugesetzt, wodurch sich die spontane Rückmutation auf eine Frequenz von $1 \times 10^{-10}$ reduziert (PETERS \& BAUMGARTEN, 1992). 
Es wurden zur Selektion der Fusionate 50fach konzentrierte HATAz Stammlösung angesetzt und nach Bedarf entsprechend verdünnt. Diese Stammlösung ist bei $-20^{\circ} \mathrm{C}$ nur für 6 Monate haltbar.

\subsubsection{Aufbau eines cat-ELISA}

\section{$\underline{\text { Material }}$}

- ELISA-Platte

Maxi Sorp; Nunc GmbH, Wiesbaden

- Coating-Puffer (Lösungen A \& B in Aqua bidest.):

Stammlösung A: $10,6 \mathrm{~g} \mathrm{Na}_{2} \mathrm{CO}_{3} / 500 \mathrm{ml}$

Stammlösung B: $8,4 \mathrm{~g} \mathrm{NaHCO}_{3} / 500 \mathrm{ml}$

Gebrauchlösung: 8,5 ml Stammlösung A

4,0 ml Stammlösung B

37,5 ml Aqua bidest., pH 10,5

- Fang-Antikörper:

Kaninchen anti-Maus-Antikörper,

Dako; Best. Nr.:Z259

- Waschpuffer

PBS mit 0,05\% Tween $20(\mathrm{v} / \mathrm{v})$

Zum Monitoring der ausgewählten Klone wurde ein auf dem Enzyme Linked Immuno Sorbent Assay (ELISA) basierendes Test-System entwickelt. Da die enzymatische Aktivität sehr geringfügig sein kann, wurde eine längere Reaktionsdauer von 3 Tagen bevorzugt.

Das synthetisierte Substrat wurde in reinem Methanol gelöst und für die Reaktion eingesetzt.

Die Reaktion wurde dünnschichtchromatographisch ausgewertet. Durch die Wiederholung 
des Tests wurde die Bildung des Vitamin E-Analogon sowohl qualitativ als auch quantitativ analysiert. Dazu diente die HPLC-Analyse.

Die Näpfe einer Maxi Sorp-Mikrotiterplatte wurden mit $100 \mu$ l Fang-Antikörper, 1 : 500 verdünnt in Coating-Puffer, beschichtet und anschließend dreimal mit jeweils $200 \mu \mathrm{l}$ Waschpuffer pro Napf gewaschen. Danach wurden ca. $200 \mu$ Kulturüberstand aus zu testenden Klonen in die Näpfe gegeben und für $2 \mathrm{~h}$ bei $37^{\circ} \mathrm{C}$ inkubiert. Nach dem Waschen (siehe oben) wurden $200 \mu \mathrm{l}$ in Methanol gelöstes Substrat (Abb. 10) mit einer Konzentration von 2 $\mathrm{mg} / \mathrm{ml}$ in jeden Napf pipettiert und die Platte bei $50^{\circ} \mathrm{C}$ für drei Tage inkubiert.<smiles>[R]CC(C)=C1Cc2c(C)c(O)c(C)c(C)c2OCC1[O+]</smiles>

1 monoklonaler Antikörper

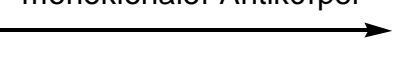<smiles>[R]C[C@]1(C)Oc2c(C)c(C)c(O)c(C)c2C[C@H]1[2H]</smiles>

2<smiles>[R]=CC[C@@H](C)CCC[C@H](C)CCCC(C)C</smiles>

Abbildung 10: Synthetisiertes Substrat, das von cat-mAk durch eine enantiofacial differenzierende Addition der freien phenolischen Hydroxylgruppe an ein Alken oder an ein intermediär gebildetes Carbokation katalysiert werden sollte.

\subsection{8 $\underline{\text { Reklonierung der Hybridome }}$}

\section{$\underline{\text { Material }}$}

- Mikrotiterplatte (96 Näpfe)

TC Qualität; Nunc GmbH,

Wiesbaden 
Nach der Analyse der enzymatischen Aktivität wurden Klone gewünschter Eigenschaften mittels der Grenzverdünnung rekloniert. Durch Grenzverdünnung wurde die Konzentration der Zellen im Kulturmedium so gesenkt, daß in je zwei Näpfen statistisch gesehen eine Zelle vorkommt (Coller und Coller, 1983). Auf diese Weise erhält man nach zweimaliger Reklonierung mit höher Wahrscheinlichkeit einen aus einer Zelle hervorgegangenen Zellklon, der einen monoklonalen Antikörper produziert. Die Produktion der Klone wird mittels ELISA kontrolliert.

\subsubsection{Etablierung und Kultivierung der Hybridome}

\section{$\underline{\text { Material }}$}

- 24-Napfplatte

TC-Qualität; Corning Costar, Bodenheim

- Maus IL-6

rm IL-6, R\&D-System, Kat1.Nr. 406-ML

- Zellkulturflasche

Sarstedt AG \& Co., Nümbrecht

Da die frisch fusionierten Hybridome sehr labil sind und besonders während der Selektion und Reklonierung unter unphysiologischen Bedingungen kultiviert werden, stellen sie besonders hohe, zum Teil zeit- und kostenintensive Anforderungen an die Kulturbedin-gungen. Dazu gehören die Zugabe von 20\% FCS (v/v), Einsatz von Peritoneal-Makrophagen und sogar Zugabe von IL-6 zum Kulturmedium.

Die gewünschten positiven Klone wurden daher nach der 2. Reklonierung stufenweise an "normale" Kulturbedingungen adaptiert: 
1- Adaption der Klone von einer 96-Napf Mikrotiterplatte mit Feederzellen auf eine 24Napfplatte mit Feederzellen.

2- Adaptation der Klone an 24-Napfplatten ohne Feederzellen. Da die Feederzellen die Zellreste phagozytieren und IL-6 produzieren, soll ggf. der Kultur IL-6 (20 U/ml) zugesetzt und schrittweise ausverdünnt werden.

3- Adaptation der Klone an kleine Kulturflaschen (50 ml).

4- Adaptation der Klone an Hybridommedium mit nur 10\% FCS (v/v).

\subsubsection{Bestimmung der Antikörperkonzentration mittels ELISA}

\section{$\underline{\text { Material }}$}

- ELISA-Platte

Maxi Sorp; Nunc GmbH, Wiesbaden

- Coating-Puffer (Lösungen A \& B in Aqua bidest.)

Stammlösung A: $10,6 \mathrm{~g} \mathrm{Na}_{2} \mathrm{CO}_{3} / 500 \mathrm{ml}$

Stammlösung B: 8,4 g NaHCO $3 / 500 \mathrm{ml}$

Gebrauchslösung: 8,5 ml Stammlösung A

4,0 ml Stammlösung B

37,5 ml Aqua bidest., $\mathrm{pH}$ 10,5

- Fang-Antikörper

Kaninchen anti-Maus-Antikörper,

Dako; Best. Nr.: Z259

- Waschpuffer

PBS mit 0,05\% Tween $20(\mathrm{v} / \mathrm{v})$

- Blockpuffer

PBS mit 5\% MMP (w/v) und 0,01\% $\mathrm{NaN}_{3}$ 
- Instant-Magermilchpulver (MMP)

- Nachweisantikörper

- Substrat

- Substratlösung

- Plattenphotometer
De-Vau-Ge Gesundkostwerke GmbH, Lüneburg

Kaninchen anti-Maus Antikörper

2,2-Azino-di-[3-ethylbenzthiazolinsulfonat]

(ABTS); Boehringer, Mannheim

$2 \mathrm{mM}$ ABTS, $100 \mathrm{mM} \mathrm{CH}{ }_{3} \mathrm{COONa} \times 3 \mathrm{H}_{2} \mathrm{O}$,

$50 \mathrm{mM} \mathrm{NaH}_{2} \mathrm{PO}_{4} \times \mathrm{H}_{2} \mathrm{O}, \mathrm{pH} 4,2$

Thermo-max microplate reader; Molecular

Devices, Menlo Park CA, USA

Die Ig-Konzentrationen der Hybridomkulturüberstände wurden durch einen Sandwich-ELISA (KENNY et al., 1983) bestimmt. Als Fangantikörper wurde ein Kaninchen- anti Maus-Antikörper eingesetzt. Der Nachweis erfolgte dann mit einem Enzym- konjugierten Antikörper, der ebenfalls gegen Mausimmunglobulin gerichtet ist.

Die Näpfe der ELISA-Platte wurden mit je $100 \mu$ l Kaninchen-anti-Maus Antikörper als FangAntikörper, der in Beschichtungspuffer auf $20 \mu \mathrm{l} / \mathrm{ml}$ verdünnt wurde, $2 \mathrm{~h}$ bei $37^{\circ} \mathrm{C}$ (oder über Nacht bei $4^{\circ} \mathrm{C}$ ) beschichtet. Nach der Inkubation wurde die Platte drei Mal mit jeweils $200 \mu \mathrm{l}$ Waschpuffer pro Napf gewaschen. Zur Blockierung unspezifischer Bindungsstellen wurden die Näpfe bei RT dreimal je 20 min mit $200 \mu$ l Blockpuffer inkubiert und anschließ-end gewaschen (siehe oben). Danach wurden die IgG-Standards (80-1,25 ng/ml eines Maus IgG bekannter Konzentration) und die Proben $(1: 500$ - $1: 16000)$ als Doppelansatz in die Näpfe pipettiert. Eine Medium- und eine Substrat-Kontrolle wurden mitgeführt. Nach zweistündiger Inkubation bei $37^{\circ} \mathrm{C}$ wurden die nicht gebundenen IgG durch Waschen (siehe oben) entfernt. 
Der Nachweisantikörper, ein mit Peroxidase konjugierter Kaninchen-anti-Maus Antikörper, wurde 1 : 2000 in PBS verdünnt. Davon wurden $100 \mu \mathrm{l} / \mathrm{Napf}$ in die Platte eingebracht und $1 \mathrm{~h}$ bei RT inkubiert. Nach dem Waschen (siehe oben) erfolgte dann die Substratinkubation, dazu wurden zu $10 \mathrm{ml}$ Substratlösung $50 \mu \mathrm{l} 3 \%$ iges $\mathrm{H}_{2} \mathrm{O}_{2}$ zugegeben. Davon wurden $100 \mu \mathrm{l}$ pro Napf pipettiert. Nach ca. 5 min wurden dann die optischen Dichten unter Verwendung eines $405 \mathrm{~nm}$ Meßfilters und eines $492 \mathrm{~nm}$ Referenzfilters im Plattenphotometer bestimmt. Die Antikörperkonzentration der Probe wurde mittels einer Standardkurve bestimmt.

\subsubsection{Antikörperproduktion der Hybridome}

Sind die Zellen an "normale" Kulturbedingungen adaptiert, werden Massenzellkulturen zur Antikörperproduktion eingesetzt. Dazu wurden die Zellen in großen Bakterienschalen in Hybridom-Medium mit 10\% FCS unter den üblichen Bedingungen (siehe 2.2.1) kultiviert. Wenn sich nach drei bis vier Tagen die Farbe des Mediums von lachsfarben auf gelblich änderte und die Vitalität der Kultur abnahm $(\leq 70 \%)$, wurde der Kulturüberstand zellfrei zentrifugiert (1200 x g, $15 \mathrm{~min}$ ) und steril abgenommen.

Ein Aliquot wurde auf Antikörpergehalt getestet und der gesamte Kulturüberstand bei $-20^{\circ} \mathrm{C}$ gelagert. 


\subsubsection{Antikörperproduktion in einem Minibioreaktor}

\section{$\underline{\text { Material }}$}

- Minibioreaktor

MiniPERM-Zellkulturgefäß

Heraeus Instruments, Osterode/Harz

- Kulturmedium

Medium 80/20 mit 10\% FCS und

4,5 g D(+) Glucose

- $\mathrm{D}(+)$ Glucose, wasserfrei

Sigma, Deisenhofen

Die Produktion größerer Mengen monoklonaler Antikörper erfolgte in einem MiniPERMMinibioreaktor, der zu diesem Zweck von FALKENBERG (FALKENBERG et al., 1993 \& 95) entwickelt wurde.

Dieser Minibioreaktor besteht aus zwei Modulen, einem wiederverwendbaren Versorgungsund einem einmal verwendbaren Produktionsmodul. Das Produktionsmodul mit einem Volumen von $40 \mathrm{ml}$ ist vom Versorgungsmodul durch eine Dialysemembran (Molekulargewicht "cat off", MWCo 12,5 kD) abgetrennt und wird nach außen durch eine gasdurchlässige Silikonmembran begrenzt. Der Minibioreaktor wird auf einer Rollstation im Brutschrank inkubiert. Über die Dialysemembran findet der Nährstoffaustausch mit dem Kulturmedium im Versorgungsmodul statt und über die Silikonmembran der Gasaustausch.

Nach eintägigem Vorlauf des Minireaktors ohne Zellen wurde die Antikörperproduktion durch Inkubation von $35 \mathrm{ml}$ Zellsuspension in dem Produktionsmodul gestartet.

Dazu wurden die Zellen gezählt und in vorgewärmtem $\left(37^{\circ} \mathrm{C}\right)$ Kulturmedium auf $2-3 \times 10^{6}$ Zellen/ml eingestellt. Täglich werden ca. $50 \mu \mathrm{l}$ Probe steril entnommen und daraus die 
Lebend- und Gesamtzellzahl bestimmt. Zu Beginn der Kultur wurde jeden zweiten Tag das Medium im Versorgungsmodul durch frisches Medium ersetzt. Ab einer Zellkonzentration von 1 x $10^{7}$ Zellen/ml war ein täglicher Mediumwechsel erforderlich. Die Kultur wurde beendet, wenn die Lebendzellzahl auf ca. $60 \%$ gesunken war. Dann wurde die Zellsuspension entnommen, die Zellen durch Zentrifugation pelletiert und der Überstand gewonnen. Die pelletierten Zellen wurden nach zweimaligem Waschen als MiniPerm-adaptierte Zellen kryokonserviert (siehe 2.2.12).

Die Antikörperkonzentration des Überstandes wurde bestimmt (siehe.2.2.10), aufgereinigt und bei $-20^{\circ} \mathrm{C}$ gelagert.

\subsubsection{Gefrierkonservierung von Zellen}

\section{Material}

- Kulturmedium

Medium 80/20

- Einfriermedium

90\% FCS +10\% Dimethylsulfoxid (DMSO) (v/v)

- Kryoröhrchen

Corning, New York, USA

- Einfrier-Styroporbox

Sarsted, Nürnbrecht

Die Gefrierkonservierung (PETERS \& BAUMGARTEN, 1992) ermöglicht eine Langzeitlagerung von Zellen in flüssigem Stickstoff unter weitgehender Beibehaltung der Vitalität. Die Zellen sollen beim Einfrieren in ihrer exponentiellen Wachstumsphase sein. Um während des Einfrierprozesses eine mechanische Zerstörung der Zellen durch entstehende Eiskristalle 
$\mathrm{zu}$ vermeiden, wird das membrangängige DMSO als Frostschutzmittel eingesetzt. Das DMSO-haltige Einfrierermedium wurde immer frisch eingesetzt.

Da DMSO bei einer Konzentration $\geq 4 \%(v / v)$ zytotoxisch wirkt, dürfen die Zellen beim Einfrieren und Auftauen nur möglichst kurz dem DMSO-haltigen Einfrierermedium ausgesetzt werden.

Nach der Zellzahlbestimmung wurden die Zellen abzentrifugiert (400 g, $10 \mathrm{~min}, 4^{\circ} \mathrm{C}$ ) und das Zellpellet mit ca. 1 x $10^{8}$ Zellen in $1 \mathrm{ml}$ gekühltem Einfrierermedium sanft resuspendiert. Anschließend wurde die Zellsuspension in 0,5 ml-Portionen auf beschriftete, vorgekühlten Kryoröhrchen verteilt. Der Einfriererprozeß (Abkühlung um $1^{\circ} \mathrm{C} / \mathrm{min}$ ) erfolgte in einer Styroporbox bei $-80^{\circ} \mathrm{C}$ über Nacht. Für eine längere Lagerung müssen die Kryoröhrchen am nächsten Tag in Gasphase über flüssigem Stickstoff gelagert werden.

\subsubsection{Auftauen}

Zum Auftauen der Zellen wurden $10 \mathrm{ml}$ kaltes Medium in einem Zentrifugenröhrchen vorgelegt. Die Kryoröhrchen wurden entweder in der Hand oder durch vorsichtiges Schwenken im Wasserbad $\left(37^{\circ} \mathrm{C}\right)$ solange erwärmt, bis nur noch ein kleiner Eisklumpen sichtbar war. Durch tropfenweise Zugabe von ca. $1 \mathrm{ml}$ kaltem Kulturmedium zur aufgetauten Zellsuspension erfolgte eine langsame und zellschonende Ausverdünnung des hyperosmo-laren DMSO. Die Zellsuspension wurde dann in den vorbereiteten Zentrifugröhrchen mit einer Pasteuer-Pipette unter das Medium geschichtet und langsam mit diesem gemischt. Anschließend wurden die Zellen durch Zentrifugation (400 x g, 5 min, $\left.4^{\circ} \mathrm{C}\right)$ zweimal mit Kulturmedium gewaschen und in Zellkulturflaschen überführt. In ca. 8 Stunden nach dem Auftauen wurden die Kulturen mikroskopisch kontrolliert und ggf. noch einmal gewaschen. 


\subsubsection{Mykoplasmentest}

\section{$\underline{\text { Material }}$}

- Indikatorzellen: Vero B4

Nierenzellkarzinom von Green Monkey

(DSM: ACC 33), Deutsche Sammlung für

Mikroorganismen, Braunschweig

- Kulturmedium

RPMI 1640 mit 10\% FCS (v/v)

Adhärenz-Objektträger

Star Frost; Camon, Wiesbaden

- Silikonaufsätze (für Objektträger)

Flexiperm-Slide (8 Napf); Heraeus, Hanau

- 4,6-Diamino-2-phenylindol di-

Boehringer, Mannheim hydrochlorid (DAPI)

- DAPI-Stammlösung

$100 \mu \mathrm{g} / \mathrm{ml}$ in PBS (ca. 1 Jahr haltbar, wenn lichtgeschützt und bei $4^{\circ} \mathrm{C}$ aufbewahrt)

- DAPI-Gebrauchlösung

DAPI-Stammlösung $1: 100(\mathrm{v} / \mathrm{v})$ in

Methanol Verdünnt

- Ciprobay 200

Wirkstoff Ciprofloxacin $(2 \mathrm{mg} / \mathrm{ml})$

Bayer, Leverkusen

- DAPI-Filterkombination

BP 365/11, FT 395 und LP 397

Zeiss, Oberkochen 
Mykoplasmen sind zellwandlose Prokaryonten, die als Parasiten auf der Oberfläche eukaryontischer Zellen wachsen. Aufgrund ihrer Flexibilität und geringen Größe (ca. 0,2 $\mu \mathrm{m})$ können Mykoplasmen durch bakteriendichte Filter treten. Wegen der zahlreichen potentiellen Kontaminationsquellen und ihrer störenden Wirkungen auf die Metabolismen der Wirtzellen (Mc GARRITY et al, 1984: WASSERMAN, 1993) ist der regelmäßige Mykoplasmentest erforderlich.

Mit Hilfe eines DNA-spezifischen Fluoreszenzfarbstoffes wird neben der zellulären DNA auch die DNA der Mykoplasmen sichtbar (RUSSEL et al., 1975). Sind die Zellen mit Mykoplasmen kontaminiert, können diese fluoreszenzmikroskopisch nachgewiesen werden. Da bei runden, zytoplasmaarmen Zellen, wie z. B. Hybridomen, eine sichere Auswertung nicht immer möglich ist, werden adhärent wachsende zytoplasmareiche Zellen als Indikatorzellen benutzt (PETERS, 1992 b). Dafür wurden die Objektträger drei Tage in einer Lösung aus Ethanol (26\%) und Essigsäure (2\%) in Aqua bidest. (v/v) gelegt und mindestens einen Tag in Aqua bidest. gewässert. Dadurch wurde die Glasoberfläche zellfreundlich gemacht. Die mit 70\%igen Ethanol gereinigte Flexipermkammer wurde gewässert, vor Gebrauch getrocknet und autoklaviert. Diese vorbehandelte Kammer wurde auf einen autoklavierten, getrockneten Objektträger aufgesetzt. Es wurden ca. $5 \times 10^{4}$ Indikatorzellen pro Kammer 1 bis 2 Tage vorkultiviert. Nach der Überprüfung der Zelldichte wurden 2/3 des Kulturmediums in der Kammer durch zellfreien Kulturüberstand aus der zu testenden Kultur ausgetauscht und für weitere 3 bis 5 Tage kultiviert. Anschließend wurde das Medium abgesaugt, die Kammer einmal mit PBS gewaschen und $200 \mu \mathrm{l}$ DAPI-Gebrauchlösung in jede Kammer pipettiert. Nach 15minütiger Inkubation bei RT wurde die Flexipermkammer entfernt und der Objektträger in einer mit PBS gefüllten Küvette gewaschen. In jedem Einsatz muß eine Kammer ohne Probekulturüberstand mitgetestet werden. Diese dient als Negativkontrolle. 
Die Auswertung der Indikatorzellen auf dem Objektträger erfolgte mittels eines Fluoreszenzmikroskopes.

\section{a) Behandlung mykoplasmeninfizierter Kulturen}

Bei einem positiven Testergebnis wurden die infizierten Zellen für mindestens 3 Wochen mit dem Antibiotikum „Ciprobay 200“ behandelt. Der darin enthaltene Wirkstoff Ciprofloxacin wurde dem Kulturmedium in einer Konzentration von $10 \mu \mathrm{g} / \mathrm{ml}$ (SCHMITT et al., 1988) zugefügt. Nach anschließender einwöchiger Kultur der Zellen ohne Antibiotikum wurde der Test wiederholt und ggf. die Behandlung fortgesetzt.

\subsubsection{Antikörper-Isotypisierung}

\section{Material}

- Isotypisierungskit

Mouse monoklonal antibody isotyping kit;

Amersham, Braunschweig

- $\quad$ PBS-Tween 20

PBS mit 0,1\% Tween $20(\mathrm{v} / \mathrm{v})$

Zur Typisierung der Antikörper wurde ein Isotyp-Bestimmungskit eingesetzt. Dieser ermöglichte eine schnelle und sensitive Bestimmung der Isotypen muriner monoklonaler Antikörper (IgA, IgM, IgG1, IgG2a, IgG2b und IgG3) sowie der leichten Ketten ( $\kappa$ und $\lambda$ ). Der Nachweis basiert auf Teststreifen, die mit dem entsprechenden anti-Isotyp Antikörper aus der Ziege beschichtet und dementsprechend gekennzeichnet sind. 
Je ein Teststreifen wurde mit 3 ml Kulturüberstand eines Hybridoms (1 : 10 in PBS-Tween 20 verdünnt) auf einer Drehvorrichtung 15 min bei RT inkubiert. Die Teststreifen wurden dann mit je $5 \mathrm{ml}$ PBS-Tween 20 zweimal je 5 min bei RT gewaschen. Es folgten die Inkubation mit $3 \mathrm{ml}$ Peroxidase-konjugiertem Kaninchen-anti-Maus Antikörper (1 : 600 in PBS-Tween 20 verdünnt) für 15 min bei RT und zwei weitere Waschschritte (siehe oben).

Zwischenzeitlich wurde als Substrat (a) eine 4-Chloro-1-Naphtol Tablette in $10 \mathrm{ml} 5^{\circ} \mathrm{C}$ kaltem Methanol gelöst und (b) $50 \mathrm{ml}$ PBS mit einem Tropfen $30 \%$ iger $\mathrm{H}_{2} \mathrm{O}_{2}$ versetzt. Die Lösungen (a) und (b) wurden kurz vor Gebrauch zusammen gemischt und $3 \mathrm{ml}$ dieser Substratlösung wurden für mindestens 15 min bei RT mit dem Teststreifen inkubiert. Nach Abschluß der Farbreaktion, sichtbar an dem schwarzen Niederschlag im Abschnitt der Positivkontrolle, wurden die Teststreifen dreimal mit je $5 \mathrm{ml}$ Aqua bidest. gewaschen und luftgetrocknet. Der Antikörper-Isotyp konnte dann anhand des Niederschlages in den gekennzeichneten Abschnitten abgelesen werden.

\subsubsection{Aufreinigung der mAk mittels Protein A-Affinitätschromatographie}

\section{$\underline{\text { Material }}$}

- Protein A-Säule

Protein A-Sepharose 4 Fast Flow,

Bindungskapazität: ca. 5 mg muriner

IgG pro ml Matrix; Pharmacia Biotech AB,

Uppsala, Schweden

- Waschpuffer (Säulenpuffer)

1,5 M Glycin (112,5 g/l),

3,0 M NaCl $(175,35 \mathrm{~g} / 1)$,

in Aqua bidest. $\mathrm{PH}$ 8,9 (mit $\mathrm{NaOH}$ ) 
- Elutionspuffer

- Regenerierungspuffer

- Neutralisationspuffer

- Spritzenvorsatzfilter

- PD10-Säule

- Lagerungspuffer
100 mM Citrat Monohydrat, pH 3,0

100 mM Citrat Monohydrat, $\mathrm{pH}$ 2,3

2 M Tris, $\mathrm{pH} 10$

$0,45 \mu$ mit Glasfaser-Vorfilter;

Sartorius AG, Göttingen

Sephadex G-25 M; Pharmacia,

Uppsala, Schweden

PBS mit $0,1 \% \mathrm{NaN}_{3}$, Lagerung bei $4^{\circ} \mathrm{C}$

Immunglobuline verschiedener Spezies (murin, Human) und unterschiedlicher Isotypen binden mit ihrem Fc-Teil spezifisch an Protein A, einem von Staphilococcus Aureus expremierten Oberflächenprotein. Daher ist die Protein A-Affinitätschromatographie eine geeignete Methode zur säulenchromatographischen Isolierung der Immunglobuline des Isotyps G (FORCGREEN \& SJÖQUIST, 1966). Die Protein A-Säulenchromatographie ermöglicht nach Herstellerangabe die Aufreinigung aller muriner IgG Subklassen als auch von murinem IgA. Vorbereitet wurde die Protein A-Säule mit 20fachen $(20 \mathrm{ml})$ Equilibrierungspuffer. Der Kulturüberstand (200-300 ml) wurde auf eine Endkonzentration von 1,5 M Glycin und 3,0 M $\mathrm{NaCl}$ gebracht, ein $\mathrm{pH}$ von 8,9 eingestellt und mit Aqua bidest. auf $500 \mathrm{ml}$ aufgefüllt. Damit die Säule nicht verstopfte, wurde der Kulturüberstand durch einen 0,45 $\mu$ m Spritzenvorsatzfilter mit Glasfaser-Vorfilter filtriert und in einem Ultraschallbad entgast.

Mit einer Flußgeschwindigkeit von $0,5 \mathrm{ml} / \mathrm{min}$ wurde der Kulturüberstand dann auf die Protein A-Säule aufgetragen. Anschließend wurde die Säule mit 20fachem Säulenvolumen Waschpuffer gewaschen. 
Zur Elution der Antikörper wurde die Säule luftblasenfrei an einem UV-Detektor angeschlossen, mit dessen Hilfe das Elutionsprofil (Extinktion des Eluates bei $280 \mathrm{~nm}$ ) aufgezeichnet wurde. Nach einem Vorlauf mit Waschpuffer zum Einstellen des Detektors wurden die Antikörper mit Elutionspuffer ausgespült. Das Eluat wurde fraktioniert. Die proteinhaltige Fraktion wurde durch Zugabe von ca. $500 \mu$ kaltgesättigtem Tris-Puffer neutralisiert. Die Umpufferung des Eluates erfolgte mittels Gelfilteration. Dazu wurde eine PD 10-Säule benutzt. Nach der Equilibrierung der PD 10-Säule mit 25 ml PBS wurden 2,5 ml Eluat auf die Säule aufgetragen. Nachdem das Eluat in die Matrix eingeschichtet war, wurden die Antikörper mit $3 \mathrm{ml}$ PBS eluiert. Die Antikörperkonzentration des Eluates wurde durch Extinktionsmessung bei $280 \mathrm{~nm}$ Wellenlänge bestimmt $\left(\mathrm{OD}_{280 \mathrm{~nm}}=0,12\right)$.

Die Regeneration der Protein A-Säule erfolgte durch Waschen mit (A) 10fachem Säulenvolumen Elutionspuffer, (B) 20fachem Säulenvolumen Regenerationspuffer und (C) 20fachem Säulenvolumen Equilibrierungspuffer.

Für die Lagerung wurde die Protein A-Säule abschließend mit 10fachem Säulenvolumen PBS $+0,1 \% \mathrm{NaN}_{3}$ gespült und bei $4^{\circ} \mathrm{C}$ aufbewahrt.

\subsubsection{Aufreinigung muriner Antikörper mittels Protein G-}

\section{Affinitätschromatographie}

\section{$\underline{\text { Material }}$}

- Protein G-Säule

Protein G-Sepharose High Performance;

Bindungskapazität: ca 20 mg muriner IgG

pro ml Matrix, 
Amersham Pharmacia Biotech, Freiburg

- Waschpuffer

- Elutionspuffer

- Regenerierungspuffer

- Neutralisationspuffer

- Spritzenvorsatzfilter

- PD10-Säule

- Lagerungspuffer
20 mM Na-Phosphat, $\mathrm{pH} 7,0$

0,1 M Glycin-HCl, pH 2,7

0,1 M Glycin-HCl, pH 2,0

1 M Tris, $\mathrm{pH} 10$

$0,45 \mu$ mit Glasfaser-Vorfilter;

Sartorius AG, Göttingen

Sephadex G-25 M; Pharmacia,

Uppsala, Schweden

PBS mit $0,1 \% \mathrm{NaN}_{3}$, Lagerung bei $4^{\circ} \mathrm{C}$

Das Prinzip dieser Aufreinigungsmethode entspricht der Protein A-Affinitätschromatographie, ebenfalls das Vorgehen. Es existieren allerdings einige Unterschiede bezüglich der Wasch-, Elutions- und Regenerierungspuffer (ACKERSTRÖM et al., 1985 \& 1986).

\subsubsection{Aufreinigung muriner Antikörper mittels Sephacryl 300HR-}

\section{Säulenchromatographie}

\section{$\underline{\text { Material }}$}

- Säulenmaterial

Sephacryl 300HR 
- Laufpuffer

$200 \mathrm{mM}$ Tris- $\mathrm{HCl}, \mathrm{pH} 7,0$

Die Gelfilteration dient zur Auftrennung von Proteinen. Im Gegenteil zur Affinitätschromatographie werden die physikalischen Eigenschaften von Proteinen benutzt, die aus einer Mischung zu isolieren sind. Die Ausschlußchromatographie setzt die Proteingröße als Kriterium der Trennung zu Grunde. Dafür werden verschiedene Säulenmaterialien benutzt, die im gequollenen Zustand eine poröse Matrix mit einer einheitlichen Porengröße bilden. Diese Säulenmaterialien bestehen aus unterschiedlich langkettigen Polymeren wie z. B. Polyacrylaten, Silikaten oder Sephadex, das aus Dextranen, einem Polysaccharid, besteht. Alle diese Moleküle sind stark hydratisierte Polymere. Proteine entsprechend ihrer Größe in ihrer Laufgeschwindigkeit verzögert. Die Proteine werden mit abnehmender Molekülgröße im Ausschlußvolumen von der Säule eluiert.

Zur Auftrennung des cat-mAk Doro-1, einem murinen IgA, wurde eine $100 \mathrm{~cm}$ lange Sephacryl 300HR-Säule mit einem Durchmesser von $2 \mathrm{~cm}$ verwendet. Diese Matrix kann Proteingemische $>100$ und $<300 \mathrm{kD}$ auftrennen. Die verwendete Säule mit einem Ausschlußvolumen von $36 \mathrm{ml}$ wurde bei $4^{\circ} \mathrm{C}$ mit ca. $200 \mathrm{ml}$ Gelfiltrationspuffer equilibriert. Ca. $3 \mathrm{ml}$ konzentrierter Kulturüberstand von Klon Doro-1 wurde auf die Säule aufgetragen. Die Elution erfolgte mit einer Flußrate von $12 \mathrm{ml}$ Elutionspuffer pro Stunde. Der Proteingehalt der Fraktionen wurde photometrisch bei einer Wellenlänge von $280 \mathrm{~nm}$ gemessen. Durch SDSPAGE und anschließendes Immunoblotting wurde die Reinheit der aufgetrennten Antikörper überprüft. 


\subsubsection{Herstellung von antigenbindenden Fragmenten $F_{(a b) 2}$}

\section{$\underline{\text { Material }}$}

- $\mathrm{F}_{\mathrm{ab}}$-Herstellungskit

Papain-Agarose-Beads. Pierce

Um das Bindungverhalten des mAks Ing-1 durch die röntgen-kristallographische Analyse charakterisieren zu können, sollte das antigenbindende Fragment $\left(\mathrm{F}(\mathrm{ab})^{2}\right)$ enzymatisch gespaltet, aufgereinigt und kristallisiert werden.

Pepsin und Papain sind zwei Enzyme, die zur proteolytischen Spaltung des Aks (IgG) eingesetzt werden könnnen. Pepsin spaltet einen IgG unter sauerem pH-Wert zu einem divalenten Fragment, das $\mathrm{F}\left(\mathrm{ab}^{\prime}\right)^{2}$ und $\mathrm{zu}$ unterschiedlich langen Fragmenten aus dem Fc-Bereich. Durch proteolytische Spaltung und unter thiolfreien Bedingungen überführt das Enzym Papain IgG in einen Fc-Abschnitt und zwei monovalente antigenbindende Fragmenten.

Zur Herstellung von Fab des mAks Ing-1 wurde das auf Agarose immobilisierte Enzym Papain verwendet. Dafür wurden 6,8 mg aufgereinigter Ak Ing-1 und 0,5 ml 6\%iges PapainAgarose-Beads in $600 \mu \mathrm{l}$ Spaltungspuffer zusammen gemischt und für $6 \mathrm{~h}$ bei $37^{\circ} \mathrm{C}$ auf einem Schüttler inkubiert, wobei nach 3 h Inkubation $10 \mu \mathrm{l}$ aus dem Ansatz entnommen und mittels SDS-PAGE getestet wurden. Da diese Probe noch vollständigen Ak beinhaltete, wurde die Re-aktion auf 6 h verlängert. Nach der Inkubation wurde das immobilisierte Enzym bei 1000 x g zentrifugiert und der Überstand abgenommen. Aus dem Überstand, der neben des gewünschten Fab noch Fc und eine sehr geringe Menge vollständige Immun-globuline sowie niedermolekulare Fragmente beinhaltete, wurden die gewünschten antigen-bindenden Fragmente über Protein A-Affinitätssäulenchromatographie isoliert. 


\section{$\underline{\text { Aufreinigung vom Fab }}$}

Dafür wurde die Affinität von Fc zu Protein A benutzt, um die Fab von den Fc-Fragmenten und intakten Ak zu trennen. Deshalb erschien das Fab im Durchfluß, während die Fc und komplete Ak am Protein A binden. Nach der Fab-Aufreinigung wurden die gebundenen AkFragmente durch Zugabe von $10 \mathrm{ml}$ Elutionspuffer (siehe Protein A) aus der Säule eluiert. Die Säule wurde dann mit 10fachen Volumen Regenerierungs- und anschließend Wasch-puffer gewaschen und in PBS $+0,1 \% \mathrm{Na} \mathrm{N}_{3}$ bei $4^{\circ} \mathrm{C}$ gelagert.

Es wurden $10 \mu \mathrm{l}$ aus dem aufgereinigten Fab-Probe zur Kontrolle durch SDS-PAGE entnommen und der Rest gegen Aqua bidest. dialysiert und anschließend lyophlisiert. Das Lyophilisat wurde bei $-20^{\circ} \mathrm{C}$ inkubiert.

\subsubsection{Dialyse und Anreicherung von Proteinlösungen}

\section{$\underline{\text { Material }}$}

- Dialyse-Schlauch

Servapor; $\varnothing 16$ mm, MW cut-off: $10 \mathrm{kD}$,

Serva Electrophoresis GmbH, Heidelberg

- Dialyse-Kassette

Slide-A-Lyzer 10k; 3-15 ml, MW cut-off: 10 kD,

Pierce; Rockford; IL, USA

- Konzentrator-Röhrchen

Centriplus; MW cut-off: 100 kD (blau)

Centriplus; MW cut-off: 50 kD (rot)

Millipore $\mathrm{GmbH}$, Eschborn 
Bei der Lagerung der Proteine für längere Zeit spielt der pH-Wert des Lösungsmittels eine entscheidende Rolle. Da die Elution unter sauren Bedingungen (pH-Wert um 2,5) erfolgt, sind dann die mittels Affinitätschromatographie aufgereinigten Immunglobuline besonders empfindlich. Die Seitenketten der Aminosäuren können unter saurem pH-Wert der Elutionspuffer dehydrolysiert werden und infolgedessen ändern sie ihre Eigenschaften. Um dies zu verhindern, wird der pH-Wert des Eluates schon während der Elution durch Zugabe von TrisPuffer neutralisiert. Die Umpufferung des Eluates erfolgte durch die unmittelbar anschließende Säulenchromatographie (siehe Protein A) oder Dialyse. Da die mAk Ing-1 und cat-mAk Doro-1 zur kristallographischen Analyse vorbereitet werden sollten, wurden die Eluate nach der Aufreinigung gegen Aqua bidest. dialysiert. Dafür wurden Dialysekassetten, -schläuche und spezielle Konzentratoren verwendet.

\section{a) Dialyseschläuche}

Ein ca. $15 \mathrm{~cm}$ langer Dialyseschlauch mit einem Ausschlußvolum (cut off) von $10 \mathrm{kD}$ wurde für eine Minute mit Aqua bidest. gewässert. Danach wurden $10 \mathrm{ml}$ Proteinlösung eingeführt und über Nacht gegen 51 Aqua bidest. (oder Dialysepuffer) unter ständigem Umrühren dialysiert.

\section{b) Dialyse mit Dialysekassetten}

Diese Kassetten wurden für $2 \mathrm{~min}$ in Aqua bidest. gewässert und anschließend mit $12 \mathrm{ml}$ Proteinlösung mit einer Spritze durch eine vorgesehene Stelle aufgefüllt. Die Dialysezeit betrug $6 \mathrm{~h}$ bei RT, wobei alle $2 \mathrm{~h}$ der Dialysepuffer (2 l) ausgetauscht wurde. Die Kassetten sind mehrfach verwendbar, allerdings nur mit gleichen Proteinlösungen. 


\section{c) Dialyse mit Konzentratoren}

Hierfür wurden spezielle Röhrchen verwendet, die mit Filter bestimmten Ausschlußvolumens vorgesehen sind. Da die Molekulargröße eines Antikörpers der Subklassen G und A ca. 150 kD entspricht, wurden die Konzentratoren mit einem Auschlußvolum von 100 kD benutzt. Die Konzentratoren wurden ebenfalls zum Ankonzentrieren und Dialysieren von $\mathrm{F}_{\mathrm{ab}}$-Fragmenten verwendet, allerdings mit einem Ausschlußvolumen von $50 \mathrm{kD}$. Es wurden $10 \mathrm{ml}$ Proben in "Centriplus"-Röhrchen gegeben und für $2 \mathrm{~h}$ bei $4^{\circ} \mathrm{C}$ und $2000 \mathrm{x}$ g zentrifugiert. Das Endvolumen von ca. $2 \mathrm{ml}$ wurde mit Dialysepuffer (oder Aqua bidest.) wieder auf $10 \mathrm{ml}$ aufgefüllt und in den selben Konzentratoren für weitere $2 \mathrm{~h}$ bei $4^{\circ} \mathrm{C}$ und $5000 \mathrm{x} \mathrm{g}$ zentrifugiert. Dieser Vorgang wurde zweimal wiederholt.

\subsubsection{Proteinfällung}

\section{$\underline{\text { Material }}$}

- Trichloressigsäure (TCA)

- Ammuniumsulfat

- $\mathrm{HCl}$

- Aceton
$30 \mathrm{mg}$ in $100 \mathrm{ml}$ Aqua bidest.

Fluka Chemie GmbH, Deisenhofen

Merck KgaA, Darmstadt

Merck KgaA, Darmstadt

Fluka Chemie GmbH, Deisenhofen 


\section{a) Fällung mit TCA}

Zur Fällung von Proteinen mit Hilfe von Trichloressigsäure (TCA) wurde wie folgt vorgegangen:

Die aufgereinigten und gegen Aqua bidest. dialysierten Proben wurden im Volumenverhältnis von 1:2 mit 30\%iger (w/v) TCA-Lösung gemischt. Nach 30minütiger Zentrifugation bei 14.000 x g wurde der Überstand quantitativ abgenommen und das Pellet einmal mit $1 \mathrm{ml}$ kaltem Aceton resuspendiert und nochmal zentrifugiert. Danach wurde Aceton dekantiert und der Rest bei RT verdunstet. Das gefällte Protein wurde bei $4^{\circ} \mathrm{C}$ gelagert.

\section{b) Fällung mit Ammuniumsulfat}

Dafür wurde zu $1 \mathrm{ml}$ Protein-Lösung 0,516 g Ammuniumsulfat bei $4^{\circ} \mathrm{C}$ zugegeben. Diese 80\%ige Ammuniumsulfatlösung wurde für $2 \mathrm{~h}$ bei $4^{\circ} \mathrm{C}$ auf einem Schüttler inkubiert und anschließend bei $14.000 \mathrm{x}$ g und $4^{\circ} \mathrm{C}$ für 30 min zentrifugiert. Der Überstand wurde dekantiert und das Pellet bei $4^{\circ} \mathrm{C}$ aufgehoben.

\section{c) Fällung mit Aceton-HCl}

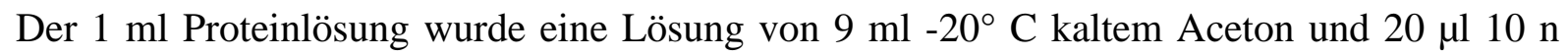
$\mathrm{HCl}$ eingereicht und bei $-20^{\circ} \mathrm{C}$ über Nacht inkubiert. Nach der Inkubation wurde der Ansatz für $30 \mathrm{~min}$ bei $14.000 \mathrm{x}$ g und $4^{\circ} \mathrm{C}$ zentrifugiert. Das Pellet wurde zweimal mit je $5 \mathrm{ml}$ kalten Aceton gewaschen und bei $4^{\circ} \mathrm{C}$ gelagert. 


\subsubsection{SDS-PAGE}

\section{$\underline{\text { Material }}$}

- Elektrophorese-Probenpuffer (nach Lämmli)

- 30\%iges Acrylamid-Mix

- SDS-Lösung

- Ammoniumpersulfat

- Trenngelpuffer (4 fach)

- Sammelgelpuffer (4 fach)

- Elektrodenpuffer (10 fach)
3,12 ml 1 M Tris-Puffer $\mathrm{pH}$ 6,8

$1,0 \mathrm{~g} \mathrm{SDS}$

5,8 g Glycerol (87\%)

50,0 mg Bromphenolblau

+/- 2,5 ml $\beta$-Mercaptoethanol

ad 12,5 ml Aqua bidest. (4x)

29,0 g Acrylamid (29\%)

1,0 g N,N-Bisacrylamid (1\%)

ad $100 \mathrm{ml}$ Aqua bidest.

10\%ige (w/v) Stammlösung

10\%ige (w/v) Stammlösung

1,5 M Tris-Puffer,

$\mathrm{pH}-$ Wert mit $\mathrm{HCl}$ auf 8,8 einstellen.

1,0 M Tris-Puffer,

$\mathrm{pH}-$ Wert mit $\mathrm{HCl}$ auf 6,8 einstellen.

0,25 M Tris-Lösung (61 g Tris)

1,9 M Glycin (288 g)

$1 \% \operatorname{SDS}(20 \mathrm{~g})$

ad 21 Aqua bidest.

$15 \mathrm{~g}$ Tris

72,5 g Glycin in 11 Methanol, ad 41 Aqua bidest., pH 8,5 
Proteine erhalten durch die Anlagerung des anionischen Detergens Sodiumdodecylsulfat (SDS) an die hydrophobe Seitenkette ihrer Aminosäuren negative Ladungen und trennen sich daher im elekterischen Feld fast ausschließlich nach ihrer relativen Molekülgröße auf. Durch Zugabe von reduzierenden Agentien wie $\beta$-Mercaptoethanol werden die Disulfidbrücken gespaltet, und durch Zugabe von SDS die Untereinheiten der Proteine aufgetrennt.

Die Gelmatrix besteht aus Acrylamid als aktivierter Monomeren und Bis-Acrylamid als Vernetzer. Die Konzentration der aktivierten Monomere bestimmt die Pörengröße des Gels. Durch Zugabe des Starters TEMED und des Radikalbilders Ammoniumpersulfat (AP) wird die Polymerisation gestartet. Die Polymerisation ist eine exotherme Reaktion, die unter Luftausschluß erfolgt.

Es wurden Mini- $(8,0 \mathrm{~cm}$ x 8,6 cm x 0,12 cm) und Midi-Gele $(16 \mathrm{~cm}$ x 14,5 cm x 0,15 cm) nach Lämmli und Midi-Gradientengele gegossen.

\section{a) Herstellung eines Gradientengels}

Gradientengele eignen sich besonders für die Auftrennung von nicht definierten Proteingemischen. In Abhängigkeit vom steigenden Vernetzungsgrad des Gels werden die Proteine über einen weiteren Molekulargewichtsbereich aufgetrennt, im Gegensatz zu den Gelen nach Lämmli mit konstanter Polyacrylamidkonzentration.

Durch Zugabe von $10 \mu \mathrm{l}$ TEMED und $3 \mathrm{mg}$ AP per $10 \mathrm{ml}$ entgaster Gellösung wurde die Polymerisation gestartet. Sofort wurden die Lösungen 1 und 2 in einen Gradientenmischer gefüllt und das Gel zwischen protein- und fettfreien eingespannten Glasplatten der Gelkassette gegossen. Dabei entstand ein linearer Gradient, beginnend mit höher konzentrierter 
Gellösung am unteren Gel. Nach dem Einsetzen der Teflonkammer zum Formen der Geltaschen polymerisierte das Gel innerhalb von $1 \mathrm{~h}$ bei RT.

\section{b) Herstellung der Gele nach LÄMMLI}

Zum Giessen der Gele nach LÄMMLI wurden von den Lösungen 1 und 2 je 5,0 ml für MiniGele und je $20 \mathrm{ml}$ für Midi-Gele vorbereitet. Die Proben wurden mit entsprechenden Volumen Probenpuffer gemischt und 5 min bei $95^{\circ} \mathrm{C}$ gekocht.

Zur Bestimmung der Molekulargewichte der Proben wurden farbstoffmarkierte Eichproteine mit definierten Molekulargewichten von 4 bis $250 \mathrm{kD}$ oder biotinylierte Markerproteine in einem Molekulargewichtsbereich von 14 bis 97 kD (ECL-Molekulargewichtsmarker) mit aufgetrent. Das gesammte Probenauftragungsvolumen betrug bei Minigelen $40 \mu \mathrm{l}$ und bei MidiGelen $80 \mu \mathrm{l}$.

\section{c) Elektrophorese}

Das luftblasenfrei polymerisierte Gel wurde mit der Gelkassette in die Elektrophoresekammer eingespannt und die Luftblasen an der Unterseite des Gels entfernt. Nach der Pipettierung der Proben in die mit Elektrophoresepuffer gespülten Geltaschen wurde die Elektrophorese mit einer konstanten Spannung von 250 V durchgeführt. Um eine gleichmäßige Auftrennung der Proteine bei den Gelen nach LÄMMLI zu gewährleisten, wanderten die Proben durch das Sammelgel bei schwächerer Stromstärke (12 mA/Mini-Gel und 18 mA/Midi-Gel) ein und wurden im Trenngel bei 20 bzw. $40 \mathrm{~mA}$ aufgetrennt (ca. $1 \mathrm{~mA} / \mathrm{cm}^{3}$ ). Die BromphenolblauBanden aus dem Probenpuffer dienten als Marker für die Lauffront. Wenn diese Banden ca. 1 cm vor dem Ende des Gel lagen, wurde die Elektrophorese beendet. 


\subsubsection{Proteintransfer mittels Elektroblotting}

\section{$\underline{\text { Material }}$}

- Polyvinyl-Membran (PVDF) Immobilon P $(45 \mu \mathrm{m}$ Porengröße $)$

Milipore GmbH, Eschborn

- Blot-Zubehör

Hoefer Scientific Instruments

San Francisco, USA

- Filterpapier

Whatman; Schleicher \& Schüll, Dassel

- Netzgerät

Pharmacia, Freiburg

- Blotpuffer

15,0 g Tris, 72,5 g Glycin, 11 Methanol

Ad 41 Aqua bidest., pH 8,5

Da die Proteine nach der Auftrennung durch SDS-PAGE immer noch stark negativ beladen sind, können sie in einem elektrischen Feld aus dem Gel auf ein proteinbindendes Trägermaterial transferiert werden, welches anodenwärts vom Gel liegen muß (modifiziert nach TOWBIN, et al, 1979). So immobilisiert können die Proteine in einer immunochemischen Reaktion sichtbar werden. Es gibt zusätzlich die Möglichkeit, die Proteine bereits im Gel anzufärben.

Dafür wurde das Gel für $5 \mathrm{~h}$ bei RT in Färbelösung und anschließend über Nacht in Entfärberlösung inkubiert.

Dazu wurde PVDF-Membran als Trägermaterial verwendet. Die Membran wurde der Gelgröße entsprechend zugeschnitten - in 100\%igem Methanol für eine Minute bei RT aktiviert und in Blotpuffer equilibriert. Zum Blotten wurde eine Blotkassette (Abb. 11) angefertigt. Alle Komponenten dieser Kassette wurden in einer Schale mit Blotpuffer luft- 
blasenfrei auf einander geschichtet. Der Proteintransfer erfolgte über Nacht bei $4^{\circ} \mathrm{C}$ und einer Stromstärke von $1 \mathrm{~mA} / \mathrm{cm}^{2}$ Membran.

\begin{tabular}{|l|} 
Kathode (-) \\
\hline Kassettengitter \\
\hline Schwamm \\
\hline Filterpapier \\
\hline \multicolumn{1}{|c|}{ Gel } \\
\hline PVDF-Membran \\
\hline Filterpapier \\
\hline Schwamm \\
\hline Kassettengitter \\
\hline Anode (+)
\end{tabular}

Abbildung 11: Schematischer Aufbau einer Blotkassette.

\subsubsection{Anfärbung der Proteine}

\section{$\underline{\text { Material }}$}

- Coomassie Blau Färbe-Lösung

0,2\% (w/v) Coomassie Blau R 250

$10 \%(\mathrm{v} / \mathrm{v})$ Essigsäure $+40 \%(\mathrm{v} / \mathrm{v})$ Methanol

- Entfärbelösung

$20 \%(v / v)$ Essigsäure $+70 \%(v / v)$ Methanol

- Aktivkohle

- Amidoschwarz Färbe-Lösung

0,1\% (w/v) Amidoschwarz

$45 \%(\mathrm{v} / \mathrm{v})$ Methanol

$9 \%(\mathrm{v} / \mathrm{v})$ Essigsäure

- Amidoschwarz-Entfärber

vollentsalztes Wasser 


\section{a) $\underline{\text { Im Gel }}$}

Dafür wurde das Gel für 5 h bei RT in Färbelösung und anschließend über Nacht in Entfärbelösung inkubiert.

\section{b) Auf der Membran}

Dafür wurde die Membran für ca. 30 min in Coomassie Blau-Färbelösung und danach für $2 \mathrm{~h}$ in Entfärbelösung inkubiert. Die Entfärbelösung wurde über Aktivkohle regeneriert.

Bei Amidoschwarz-Färbung wurde die Membran nur für 1 min in Färbelösung inkubiert. Die Entfärbung erfolgte mit vollentsalztem (ve) Wasser innerhalb von 2 min.

\subsubsection{Nachweis der Proteine mittels ECL "enhanced chemieluminiescence"}

\section{Material}

- Blockpuffer

$$
\begin{aligned}
& \text { PBS }+5 \% \text { Magermilchpulver }(\mathrm{w} / \mathrm{v})+ \\
& 0,1 \% \text { Tween } 20(\mathrm{v} / \mathrm{v})+ \\
& 0,02 \% \mathrm{Na}-\mathrm{N}_{3}(\mathrm{w} / \mathrm{v})
\end{aligned}
$$

- Waschpuffer

PBS mit 0,1\% Tween $20(\mathrm{v} / \mathrm{v})$

- Enzym-Lösung

Streptavidin-Peroxidase-Komplex

Fa. Amersham, Braunschweig

Best. Nr.: RPN 1231

- ECL-Detektionlösungen 1\&2

ECL-Detektionskit

Fa. Amersham, Braunschweig

Best. Nr.: RPN 2106 
- Röntgenfilm

Hyperfilm-ECL

Fa. Amersham, Braunschweig

Best. Nr.: RPN 2103

- Frischhaltefolie

Das ECL-Westernblotting-Verfahren kann entweder direkt über einen Peroxidase-konjugierten Antikörper oder mit dem Biotin-Streptavidin System über ein Streptavidin-Meerretich-Peroxidase-Konjugat erfolgen. Des weiteren kann auch ein indirekter Nachweis über Peroxidase-konjugierten sek. Antikörper erfolgen. Wegen mehrerer Amplifikationsschritte ermöglicht das ECL-Verfahren, die Proteine in äußerst geringer Menge nachzuweisen, was sonst nur durch radioaktive Detektion möglich ist. Die Detektion basiert auf der MeerretichPeroxidase $/ \mathrm{H}_{2} \mathrm{O}_{2}$-katalysierten Oxidation von Luminol unter alkalischen Bedingungen. Die oxidierte Substanz emittiert Licht, das auf einem Röntgenfilm aufgezeichnet wird. Die Chemielumineszenzereaktion wird durch Agenzien wie Phenol um das 100fache verstärkt. Nach der Immobilisierung der aufgetrennten Proteine wurden folgende Inkubationsschritte bei RT unter ständiger Bewegung auf einem Schüttler durchgeführt.

Die Membran wurde zuerst für $2 \mathrm{~h}$ in $100 \mathrm{ml}$ Blockpuffer inkubiert und anschließend in Waschpuffer geschwenkt, um die überschüssigen Blockpuffer zu entfernen.

Der Peroxidase-konjugierte Kaninchen anti-Maus Antikörper wurde in einer Verdünnung von 1 : 500 in $40 \mathrm{ml}$ Waschpuffer eingesetzt und die Membran damit für weitere $2 \mathrm{~h}$ bei $37^{\circ} \mathrm{C}$ inkubiert. Um unspezifische Signale zu minimieren, wurde die Membran anschließend besonders gründlich gewaschen (dreimal für $10 \mathrm{~min}$ mit $100 \mathrm{ml}$ Waschpuffer und viermal je 2 min mit PBS).

Für die Detektion wurden die ECL-Detektionslösungen 1 und 2 zu gleichen Teilen in einer separaten Schale gemischt $\left(0,125 \mathrm{ml} / \mathrm{cm}^{2}\right.$ Membranfläche). Die gut abgetropfte Membran 
wurde nun exakt für 1 min darin inkubiert. Die überschüssige Detektionslösung wurde abgetupft, die Membran luftblasenfrei in Frischhaltefolie verpackt und in die Filmkassette gelegt. In einer Dunkelkammer wurde ein Film auf die proteintragende Seite der Membran aufgelegt und für 1 min belichtet. Nach der Entwicklung des Filmes wurden weitere Filme mit kürzerer bzw. längerer Belichtungszeit exponiert. Der Film wurde nach der Entwicklung fixiert, gewässert und getrocknet. Die Molekulargewichte der Probe wurden in Relation zum Molekulargewichtsmarker ermittelt.

\subsubsection{Untersuchung zur Kreuzreaktion von mAk Ing-1 und cat-mAk Doro-1}

Zur Untersuchung der Kreuzreaktion der beiden Antikörper Ing-1 und Doro-1 wurde die Reaktivität der beiden Antikörper mit den folgenden Zellinien getestet: HL-60, THP-1, und darüber hinaus mit frisch isolierten humanen Monozyten, humanen monozytären dendritischen Zellen sowie humanen Makrophagen.

\subsubsection{Präparation der Monozyten}

\section{$\underline{\text { Material }}$}

- PBS

1 Tablette / $100 \mathrm{ml}$ bidest. Wasser, (ohne Magnesium und Calcium); Fa. Flow Lab., Meckenheim, (D); Katal. Nr.: 28-103-05

- Ficoll-Lösung

Lymphoprep; Fa. Nycomed, Oslo, (Nor) Ch. Nr.: 510441 


\section{a) Isolierung mononukleärer Leukozyten des periphären menschlichen Blutes} $\underline{\text { (PBMNL) }}$

Die Trennung der mononukleären Leukozyten des peripheren humanen Blutes (PBMNL) erfolgt durch Dichtegradienten-Zentrifugation (BØYUM, 1964). Als Trennmedium dient Lymphoprep, ein Gemisch aus hochpolymerer Methylzellulose (Ficoll) und Natrium-Metrizoat mit einer Dichte von $1,077 \mathrm{~g} / \mathrm{ml}$ bei $20^{\circ} \mathrm{C}$. Die Methylzellulose führt zur Agglutination der Erythrozyten und unterstützt dadurch die Sedimentation der aggregierten Erythrozyten. Die PBMNL wurden aus Buffy-Coat isoliert. Dieses wurde 1:2 (v/v) mit PBS (RT) verdünnt. Je $30 \mathrm{ml}$ wurden pro $50 \mathrm{ml}$-Zentrifugenröhrchen auf $15 \mathrm{ml}$ Trennmedium (RT) überschichtet und für 20 min mit $800 \mathrm{x}$ g bei RT (ohne Bremse) zentrifugiert. Nach der Zentrifugation befanden sich die Granulozyten und die aggregierten Erythrozyten im Pellet, während die MNL eine diffuse, weiße Bande bildeten, die aus den Röhrchen aufgehoben und in zwei 50 mlZentrifugenröhrchen zusammengepoolt wurden. Die MNL wurden mit eis-kaltem PBS/EDTA auf $50 \mathrm{ml}$ aufgefüllt und $10 \mathrm{~min}$ bei $500 \mathrm{x}$ g und $4^{\circ} \mathrm{C}$ zentrifugiert. Dadurch wurden die isolierten Zellen im Pellet aus dem Trennmedium, welches für längerer Exposition ist, getrennt. Danach wurden die MNL durch folgende Waschschritte von konta-miniernden Thrombozyten frei gewaschen. Dazu wurden die Zellen in $50 \mathrm{ml}$ eiskalter PBS/EDTA resuspendiert und für $8 \mathrm{~min}$ bei $250 \mathrm{x} \mathrm{g}$ und $4^{\circ} \mathrm{C}$ zentrifugiert. Der Überstand wurde abgesaugt und das Pellet nochmal gewaschen. Dieser Waschschritt wurde 4 bis 5 mal wiederholt. Die Depletion der Thrombozyten wurde mikroskopisch kontrolliert. War die Zellsuspension thrombozytenfrei, wurde die Zellzahl mittels einer Neubauer-Zählkammer bestimmt. 


\section{b) Isolierung der Monozyten von MNL durch Adhärenz}

\section{$\underline{\text { Material }}$}

- RPMI-1640

Fa. Biochrom KG, Berlin, (D):

Best. Nr.: T-121

- Waschpuffer:

1:2 (v/v) RPMI-1640-Medium mit PBS

- Petriperm-Schalen

Hydrophob-Qualität,

Fa. In Vitro Systems, Osterode(D)

Die aktive Adhäsionsfähigkeit der Monozyten an der Plastikoberfläche wird benutzt, um sie aus T- und B-Lymphozyten zu isolieren. Dieser aktive Prozeß findet bei Anwesenheit von Serum im Zellkulturmedium statt.

Dafür wurden $5 \times 10^{8}$ MNL mit einer Konzentration von $1 \times 10^{7}$ Zellen/ml AdhärenzKulturmedium in Petrischalen $(10 \mathrm{~cm})$ pipettiert und $45 \mathrm{~min}$ im Brutschrank inkubiert. Nach der mikroskopischen Kontrolle wurden die nicht adhärenten T- und B-Lymphozyten durch sanftes Waschen mit ca. $50 \mathrm{ml}$ Waschmedium aus der Kultur entfernt. Die Kulturen wurden nochmal mikroskopisch mittels eines Phasenkontrast-Mikroskopes kontrolliert. Waren noch viele suspendierte Zellen in Kultur, wurde der Waschschritt wiederholt. Nach dem letzten Waschvorgang wurden 2 Petrischalen (Monozytenkultur) mit 10 ml kalten PBS/EDTA für ca. 1h auf Eis inkubiert. Dadurch lösten sich die adhärenten Monozyten von der Oberfläche ab. Diese wurden aufgesammelt, in ein Zentrifugenröhrchen überführt und für 10 min bei $4^{\circ} \mathrm{C}$ und 400 x g zentrifugiert. Das Pellet wurde für die FACS-Färbung (siehe 2.2.26) aufgehoben. 


\section{c) Differenzierung der Monozyten zur dendritischen Zellen invitro}

\section{$\underline{\text { Material }}$}

- CG-Medium

ohne Antibiotika, mit BSA,

Transferrin und Lipiden

Fa.Vitromex, Vilshofen, (D); Ch.-B.: 4090145

- Zytokine:

rh INF- $\gamma ;$ Fa. PBH, Hannover, (D);

Best. Nr.: IFN- $\gamma-50$,

rh IL-4; Fa. Genzyme, Rüselsheim, (D);

Best. Nr.: B 4996

rh GM-CSF; Fa. Genzyme, Rüselsheim, (D);

Best. Nr.: B 50408

- RPMI-1640-Medium + 20\% humanes Serum (inakt.)

$\mathrm{Zu}$ den nach Methode (2.2.25.1 b) gewonnenen adhärenten Monozyten wurden je $10 \mathrm{ml} \mathrm{CG-}$ Medium/Schale und folgende Zytokine gegeben: IFN- $\gamma 50 \mathrm{U} / \mathrm{ml}$; IL-4 100 U/ml und GM-CSF 100 U/ml. Die Zytokinenmixtur ("Triple-Mix") induziert bei Monozyten die Differen-zierung zu monozytären dendritischen Zellen (PETERS, et al., 1992; KRÄMER et al., 1993).

Die Zellen wurden für 4 bzw. 5 Tage im Brutschrank inkubiert und morphologische Änderungen täglich mikroskopisch beobachtet (Abb.4).

\section{d) Differenzierung der Monozyten zu Makrophagen}

Zur Differenzierung der Monozyten zu Makrophagen wurden die adhärenten Monozyten mit 10 ml RPMI-1640 + $20 \%$ HuS (inaktiv.) für 10 Tage im Brutschrank inkubiert. In diesen Kulturen entwickelten sich die Monozyten zu Makrophagen. 


\section{d) Kultivierung der humanen Permanentlinien}

Die Zellen wurden in RPMI-1640 mit 10\% FCS unter normalen Bedingungen inkubiert.

\subsubsection{Färbung membranständiger Antigene für die durchflußzytometrische Analyse}

\section{$\underline{\text { Material }}$}

- Kaninchenserum

$10 \%$ in PBS mit $0,1 \% \mathrm{Na}-\mathrm{N}_{3}(\mathrm{w} / \mathrm{v})$

- Verdünnungs- und Waschpuffer

$1 \%$ BSA in PBS mit $0,01 \%$

$\mathrm{Na}-\mathrm{N}_{3}(\mathrm{w} / \mathrm{v})$

- Fluorochrom (FITC)- markierter

Fa. DAKO; Best.Nr.: F313

Kaninchen-anti-Maus Antikörper

- Fixierungspuffer

$1 \%$ Formalin in PBS (v/v)

- Isotyp-Kontrolle-Antikörper

TIB 8: (ATCC: TIB-8), Klon Nr. P3.6.2.8.1

- anti HLA-DR

mAk (ATCC), Klon Nr. B 8.12.2.

- HL-60

ATCC CRL-1964 Klon 15-HL-60

(humane promyelocytische Leukämie)

- THP-1

ATCC TIB-202 (THP-1)

(humane monozytäre Leukämie)

Um die Bindungsverhalten der mAk Ing-1 und Doro-1 mit anderen Antigenen und dadurch ihre Kreuzreaktion zu untersuchen, wurde eine indirekte Markierung der Oberflächen- 
Antigene der Monozyten, monozytären dendritische Zellen, Makrophagen, HL-60, THP-1 und mit jeweils einem der mAk vorgenommen (ZOLA et al., 1984).

Dafür wurden $2-5 \times 10^{6} \mathrm{Z} / \mathrm{Ak}$ isoliert. Es wurde eine indirekte Isotyp-Kontrolle (nur für Ing1) und eine positiv-Kontrolle mitgeführt. Die Isolierung von monozytären dendritischen Zellen und Makrophagen erfolgte durch $1 \mathrm{~h}$ Inkubation der Schale mit $10 \mathrm{ml}$ kaltem PBS/EDTA auf Eis. Die isolierten Zellen wurden in Näpfen einer 96-Napf Rundboden-Platte verteilt und mit $100 \mu$ l 10\%igen Kaninchenserum $+1 \% \mathrm{NaN}_{3}$ für 20 min auf Eis inkubiert. Das Kaninchenserum blockiert Fc-Rezeptoren und dadurch die Bindung der Ak mit ihren FcTeil an Fc-Rezeptoren, während das $\mathrm{NaN}_{3}$ Cytochromoxidasen in den Mitochondrien inhibiert und so die Atmungskette blockiert. Dadurch sind die Zellen nicht mehr fähig, die Ak zu internalisieren oder ihre Antigene abzustoßen. Desweiteren bleibt die Membranstruktur während der Färbung erhalten. Nach der Inkubation wurde die Platte bei 320 x g und RT für 2 min in einer Plattenzentrifuge zentrifugiert. Der Überstand wurde verworfen und das Zellpellet im Restvolumen resuspendiert. Anschließend wurden die Zellen mit $200 \mu \mathrm{l}$ Waschpuffer/Napf gewaschen. Einem Ansatz, als indirekte Isotypkontrolle nur für Ing-1, wurde Tib8 zugesetzt. Den weiteren Näpfen wurden jeweils $100 \mu$ Ing-1 oder Doro-1-Kulturüberstand zugegeben und für 45 min auf Eis inkubiert. Nach zweimaligem Waschen (siehe oben) wurden $50 \mu \mathrm{l} 1: 50$ verdünnter, FITC-konjugierter Kaninchen-anti-Maus Ak zugesetzt und 30 min lichtgeschützt auf Eis inkubiert. Die Zellen wurden danach zweimal gewaschen (siehe oben) und mit $200 \mu \mathrm{l} / \mathrm{Napf}$ einer 1\%igen Formalin/PBS-Lösung fixiert. Trotz der Lagerung bei $4^{\circ} \mathrm{C}$ sollen fixierte Zellen innerhalb einer Woche in Durchflußzytometer gemessen werden. 


\subsubsection{Epitop-Charakterisierung und Kreuzreaktion des mAk Ing-1}

\section{$\underline{\text { Material }}$}

- Dünnschichtchromatographische Platte

- Nachweisantikörper

Peroxidase konjugierter Kaninchen anti-Maus Ak Dako; Best. Nr.: P161

- Substrat 4-Chloro-1-naphtol und $50 \mu \mathrm{l} 30 \%$ ige $\mathrm{H}_{2} \mathrm{O}_{2}$

Zur näheren Charakterisierung des Epitops des $\alpha$-Tocopherol-Moleküls und der Bestimmung der Kreuzreaktion des mAks Ing-1 mit Molekülen unterschiedlicher Polarität sollte ein Testund Nachweisverfahren entwickelt werden. Dafür sollten zunächst zu testende unterschiedlich konfigurierte Moleküle auf eine optimale Oberfläche immobilisiert werden.

Bei diesem Epitop-Bestimmungstest wurden folgende Substanzen auf einer Dünnschicht chromatographischen Platte aufgetragen:

- Substrate 1-3: Derivate des Chromangerüstes von Vit. E,

- Substanz 4: Phytol, die Seitenkette des Vit. E,

- Substanz 5: das Vit. E,

- und schließlich Substanz 6 - Biotin, welches ein Doppelring-System darstellt und gleichzeitig in anderen Experimenten mit Vit. E verestert worden ist.

Die Substanzen wurden in gleichen Volumina und Konzentrationen auf die Platte aufgebracht. Danach wurde in einem Sandwich-Verfahren der Vit. E-spezifische mAk Ing-1 für $1 \mathrm{~h}$ bei $37^{\circ} \mathrm{C}$ inkubiert. Der Nachweis der gebundenen Ak erfolgte durch die Bindung des 
Peroxidase-konjugierten Kaninchen anti-Maus Antikörpers und durch die dunkle Ausfällung des Substrates 4-Chloro-1-naphtol und $\mathrm{H}_{2} \mathrm{O}_{2}$.

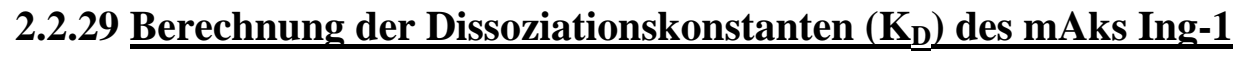

Die Dissoziationskonstante $\left(\mathrm{K}_{\mathrm{D}}\right)$ wird nach der Gleichung 1 gerechnet:

Gleichung 1) $\frac{1}{K D}=K a=\frac{[A g A k]}{[A g][A k]}=\frac{[A g A k]}{[A g]([A g] 0-[A g A k])}$

Wobei

$[A k]=$ frei Antikörperkonzentration,

$[A g]=$ frei Antigenkonzentration,

$[A k]_{0}=$ gesamte Antikörperkonzentration,

$[A g]_{0}=$ gesamte Antigenkonzentration

$K_{D}=$ die Dissoziationskonstante und

$K_{a}=$ die Assoziationskonstante

darstellen.

Wenn:

$A=$ Absorbanz des Antigen-Antikörper-Komplexes durch Peroxidase gekoppelten Sekundärantikörper,

$A_{0}=$ Absorbanz des inkubierten Antikörpers Ing-1 durch Peroxidase-gekoppelten Sekundärantikörper, 
$b=[A g A k]$ gebundene Antikörperkonzentration von Ing-1,

$f=[A k]$ freie Antikörperkonzentration (Konzentration der nicht gebundenen und wieder resuspendierten Ak) von Ing-1, und

$[A g]=$ frei Antigenkonzentration

darstellen, dann gilt die Gleichung 2:

$$
\frac{b}{[A k]_{0}}=\frac{A}{A_{0}} \Leftrightarrow b=\frac{A}{A_{0}}[A k]_{0} \quad \text { Gleichung } 2
$$

Diese Gleichung 2 zeigt, daß die Konzentration von gebundenen Antikörper Ing-1 (b) so wie die Gesamtmenge des Antikörpers Ing-1 ([Ab] $\left.]_{0}\right)$ mit ihren gemessenen Absorbazwerten $\left(A_{0}\right)$ proportional korrespondieren.

Wird die $[A g A k]$ durch den Ausdruck $b$ substituiert, dann wird die Assoziationskonstante nach der Gleichung 3 errechnet:

Gleichung 3 zur Berechnung der Assoziationskonstante:

$$
K a=\frac{b}{f([A g] 0-b)} \Leftrightarrow \frac{b}{f}=K a[A g] 0-K a b \quad \text { Gleichung } 3
$$

Wenn die Werte in der Gleichung 3 durch die in der Gleichung 1 substituiert werden, dann gilt die Gleichung 4 bzw., nach der Vereinfachung, die Gleichung 5

$$
\Rightarrow K a=\frac{\frac{A}{A 0}[A k]_{0}}{\left\{[A k]_{0}-\frac{A}{A 0}[A k]_{0}\right\}\left\{[A g]_{0}-\frac{A}{A 0}[A k]_{0}\right\}} \Leftrightarrow \frac{\frac{A}{A 0}[A k]_{0}}{[A k]_{0}-\frac{A}{A 0}[A k]_{0}} \quad \text { Gleichung } 4
$$

$\Leftrightarrow K a[A g] 0-K a\left(\frac{A}{A 0}[A k] 0\right) \quad$ Gleichung 5 
Wird die Gleichung 5 kalkuliert, dann

$$
\begin{aligned}
K a & =\frac{[A k] 0}{\frac{A 0}{A}[A k] 0[A g] 0-[A k] 0[A g] 0+[A k] 0^{2}+\frac{A}{A 0}[A k] 0[A g] 0} \\
K a & =\left(\frac{A 0}{A}[A g] 0-[A g] 0+[A k] 0+\frac{A}{A 0}[A g] 0\right)^{-1}
\end{aligned}
$$

Trägt man $b / f$ aus der Gleichung 3, so erhält man die Steigung $-K_{a}$. Da $K_{D}$ dem reziproken Wert von $K_{a}$ entspricht, erhält man so den Wert der Dissoziationskonstanten.

Die Lineare Regresion wird wie folgt berechnet:

$$
\begin{aligned}
& y_{i}=A+m x_{i} \\
& A=\bar{y}-m \bar{x} \\
& m=\frac{\sum_{i}^{N}\left(x_{i}-\bar{x}\right)\left(y_{i}-\bar{y}\right)}{\sum_{i}^{N}\left(x_{i}-\bar{x}\right)^{2}} \Rightarrow s t=\sqrt{\frac{\sum_{i-1}^{N}\left(y_{i}-\left(A+B x_{i}\right)\right)^{2}}{N-2}}
\end{aligned}
$$

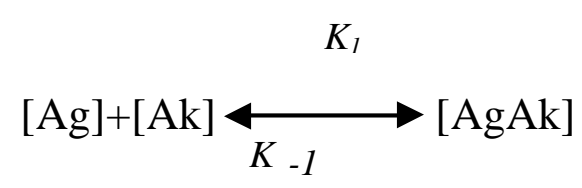

Die Dissoziationskonstante $\mathrm{K}_{\mathrm{D}}$ wurde aus der Steigung des Scatchard-Plots (Abb. 31b) errechnet. 


\section{Ergebnisse}

Im Rahmen dieser Arbeit sollten monoklonaler Ak mit katalytischen Aktivitäten zur enantioselektiven Synthesen von Vit. E und monoklonaler Ak, die gegen natürliches Vit. E gerichtet sind, hergestellt und charakterisiert werden.

Die in dieser Arbeit verwendeten chemischen Verbindungen sind von Herren Dr. J. GÖRLITZER und Dr. J. SEIBEL am Institut für Organische Chemie der Universität Göttingen synthetisiert, aufgereinigt und charakterisiert worden (SEIBEL, 2000).

\subsection{Immunisierung, Fusion und Screening}

Die Immunisierung wurde wie in 2.2.1. beschrieben, sowohl mit KLH-Hapten-Komplex und TiterMax, als auch mit Hapten allein unter Zusatz von P3CSK4 als Adjuvans, durchgeführt. Die Milzzellen der erfolgreich immunisierten Mäuse wurden mit Mylomzellen zur Fusion gebracht.

Es wurden 9/10 der Fusionate kryokonserviert und 1/10 mit einer plating efficiency von $\geq 10$ $\%$ ausplattiert. Zur Selektion der relevanten Hybridome wurden 1074 vereinzelte Klone einem Spezifitätstest unterzogen. Um Ak gegen das in der Immunisierung als Carrier benutzte KLH auszuschließen, wurde im Test Hapten-BSA-Konjugat eingesetzt (Abb. 12). Im Spezifitätstest (siehe Screening), basierend auf ELISA (Abb.13), zeigten 235 Klone Affinität zum Hapten (Tab. 5). 
<smiles></smiles>

Hapten
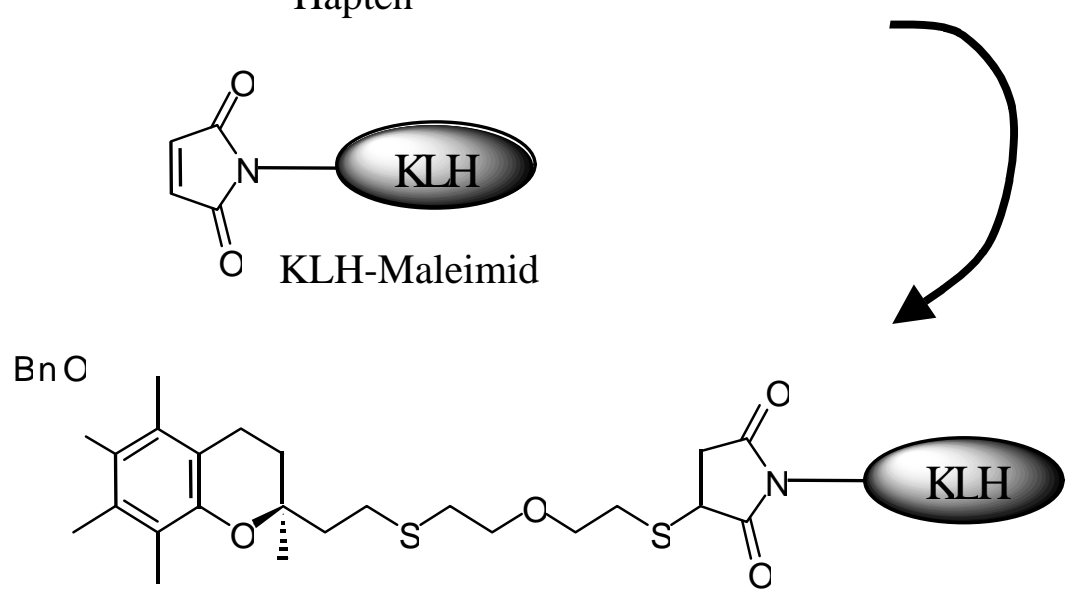

Hapten-KLH-Komplex

Abbildung 12: Die Konjugation des Haptens mit voraktiviertem KLH-Maleimid.

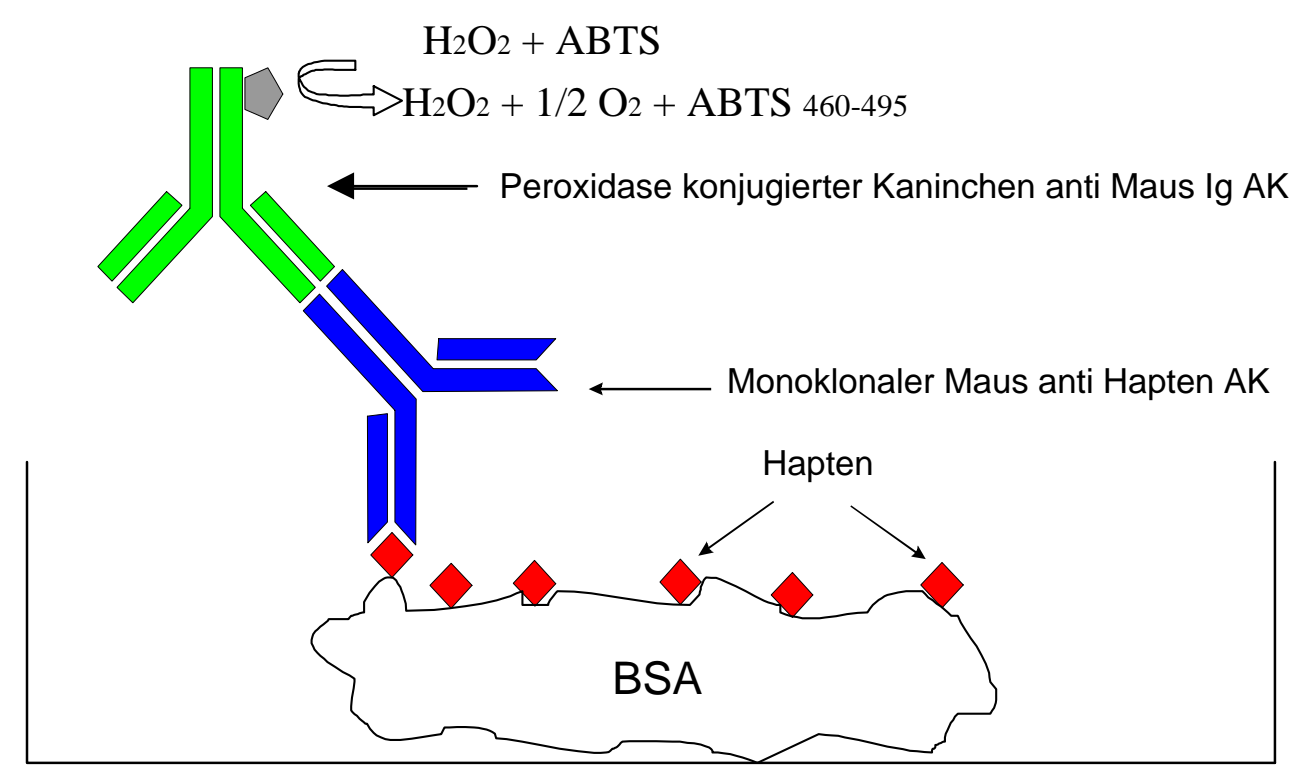

Abbildung 13: ELISA-Spezifitätstest. Selektiert wurden die Ak, die gegen das Hapten gerichtet waren. 
Tabelle 5: $\quad$ Die Ausbeute von Klonen nach der Immunisierung

\begin{tabular}{|c|c|c|c|c|}
\hline \multirow[b]{2}{*}{ Tierstamm } & \multicolumn{2}{|c|}{$\begin{array}{c}\text { Immunisierung mit } \\
\text { Hapten-KLH-Komplex und } \\
\text { TiterMax-Adjuvans }\end{array}$} & \multicolumn{2}{|c|}{\begin{tabular}{|c|} 
Immunisierung mit \\
Hapten (ohne Träger-Protein) \\
und Lipopeptid-Adjuvans \\
P3CSK4 \\
\end{tabular}} \\
\hline & $\mathrm{MRL}_{\mathrm{lpr} / \mathrm{lpr}}$ & $\mathrm{SJL} / \mathrm{Hsp}$ & $\mathrm{MRL}_{\mathrm{lpr} / \mathrm{lpr}}$ & $\mathrm{SJL} / \mathrm{Hsp}$ \\
\hline Zahl der Tiere & $4^{*}$ & 4 & 2 & $2^{* *}$ \\
\hline $\begin{array}{c}\text { \% des Materials } \\
\text { weiterverarbeitet }\end{array}$ & 25 & 10 & 5 & 5 \\
\hline $\begin{array}{c}\text { Zahl der isolierten } \\
\text { Klone }\end{array}$ & 642 & 300 & 90 & 32 \\
\hline $\begin{array}{l}\text { Zahl der Hapten- } \\
\text { spezifischen Klone }\end{array}$ & 123 & 87 & 27 & 8 \\
\hline $\begin{array}{c}\text { \% Hapten } \\
\text { spezifischer Klone }\end{array}$ & 19 & 29 & 30 & 25 \\
\hline $\begin{array}{c}\text { Zahl der Klone mit } \\
\text { katalytischen Ak }\end{array}$ & 7 & $\mathrm{nb}$ & $\mathrm{nb}$ & $\mathrm{nb}$ \\
\hline
\end{tabular}

*) Zwei Tieren starben während der Immunisierung. **) Die Fusionierung erfolgte kurz vor dem Tod. nb) Nicht bearbeitet.

\subsection{CAT-ELISA}

Um die katalytische Aktivität der Ak, die affin zum Hapten sind, testen zu können, wurde ein neuer Test auf katalytische Aktivität in Anlehnung an das Verfahren des ELISA, ein sog. catELISA, entwickelt (Abb. 14).

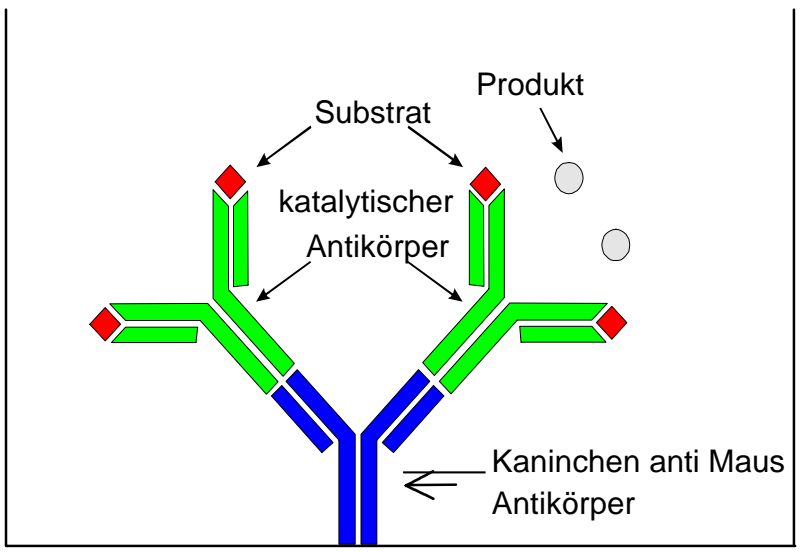

Abbildung 14: Aufbau eines cat-ELISA. 
Es wurden 118 Klone (M2 \& M8) auf katalytische Aktivität getestet. Davon zeigten 7 Ak starke Signale, die auf eine eindeutige katalytische Aktivität zurückzuführen sind, während 19 weitere Klone ein sehr schwaches Signal vermittelten. Mittels Dünnschichtchromato-graphie (Abb. 15) und HPLC (Abb. 16 a \& b) wurde die Transformation der Verbindung 1 zur Verbindung 2 (Abb. 10 \& 17) zuerst getestet und dann analysiert (Tab. 6).

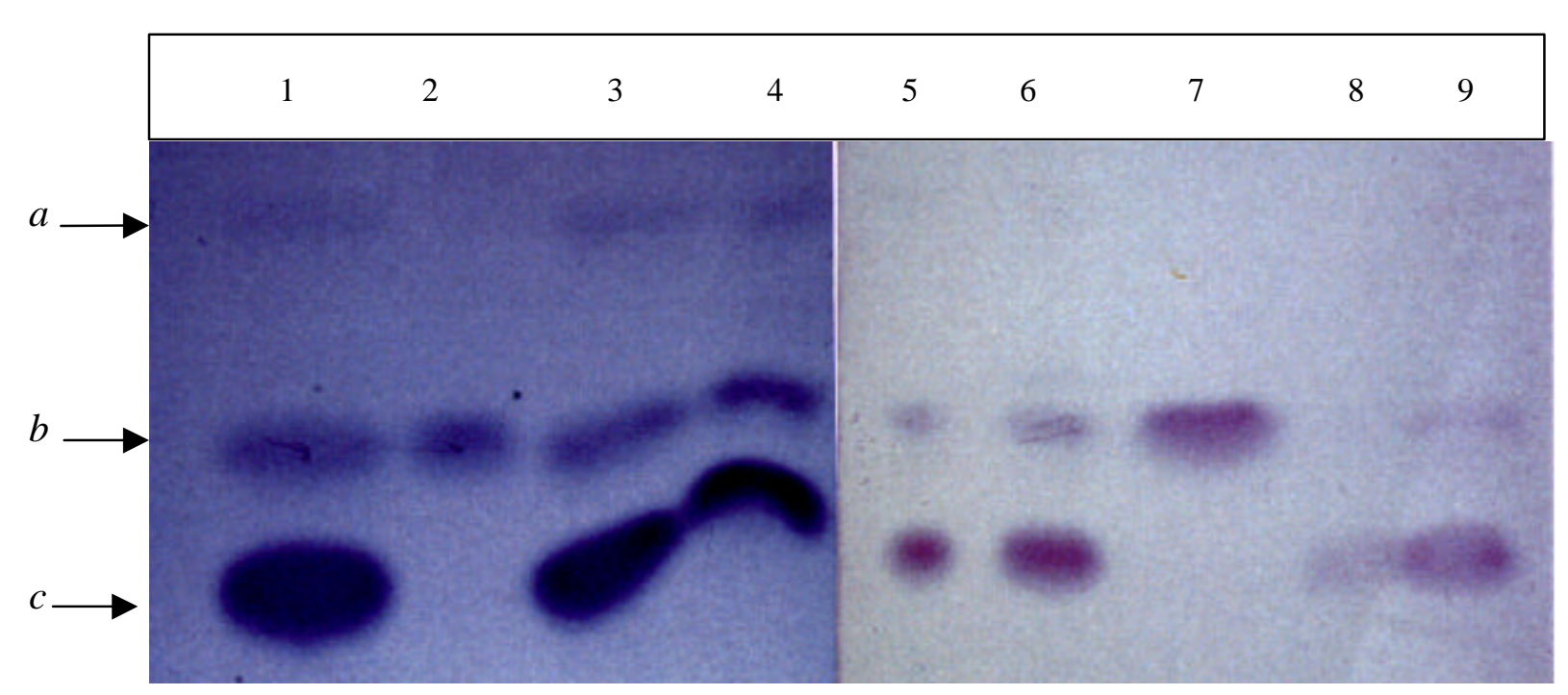

Abbildung 15: Die dünschichtchromatographische Auftragung nach der Katalyse.

1) \& 4) Die Probe aus der katalytischen Reaktion mit dem mAk M2-47 (Doro-1),

2) \& 7) Das enantiomerenreine Zyklisierungsprodukt,

3) Die Probe aus der Reaktion mit dem mAk M2-46,

5) Die Probe aus der Reaktion mit dem mAk M2-90,

6) Die Probe aus der Reaktion mit dem mAk M2-47 (Doro-1),

8) Die Probe aus der Reaktion mit dem mAk M8-153 (Ing-1),

9) Die Probe aus der Reaktion mit dem mAk M2-92.

Die Bande $\boldsymbol{a}$ ist das Oxidationsprodukt, $\boldsymbol{b}$ das zyklisierte Produkt und $\boldsymbol{c}$ das nicht transformierte Edukt.

Aus 6 getesteten Ak führte Ak (M2-47) zu einer Umsatzrate von 5\% und einer Enantiomerenreinheit von $42 \%$ ee. Dieser Ak und das Hybridom, das ihn produziert, wurden als Doro-1 bezeichnet. 
a)

$\% \mathrm{~B}$

b)

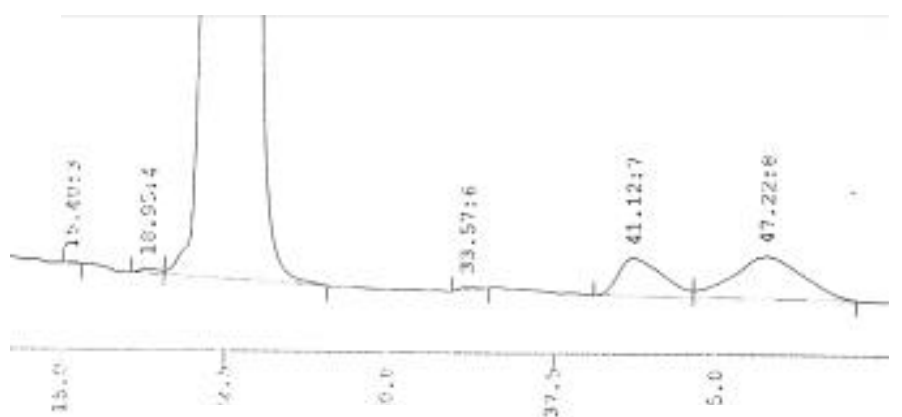

$\begin{array}{lll}\text { Substrat } 1 & (R) 2 & \text { (S) } 2\end{array}$

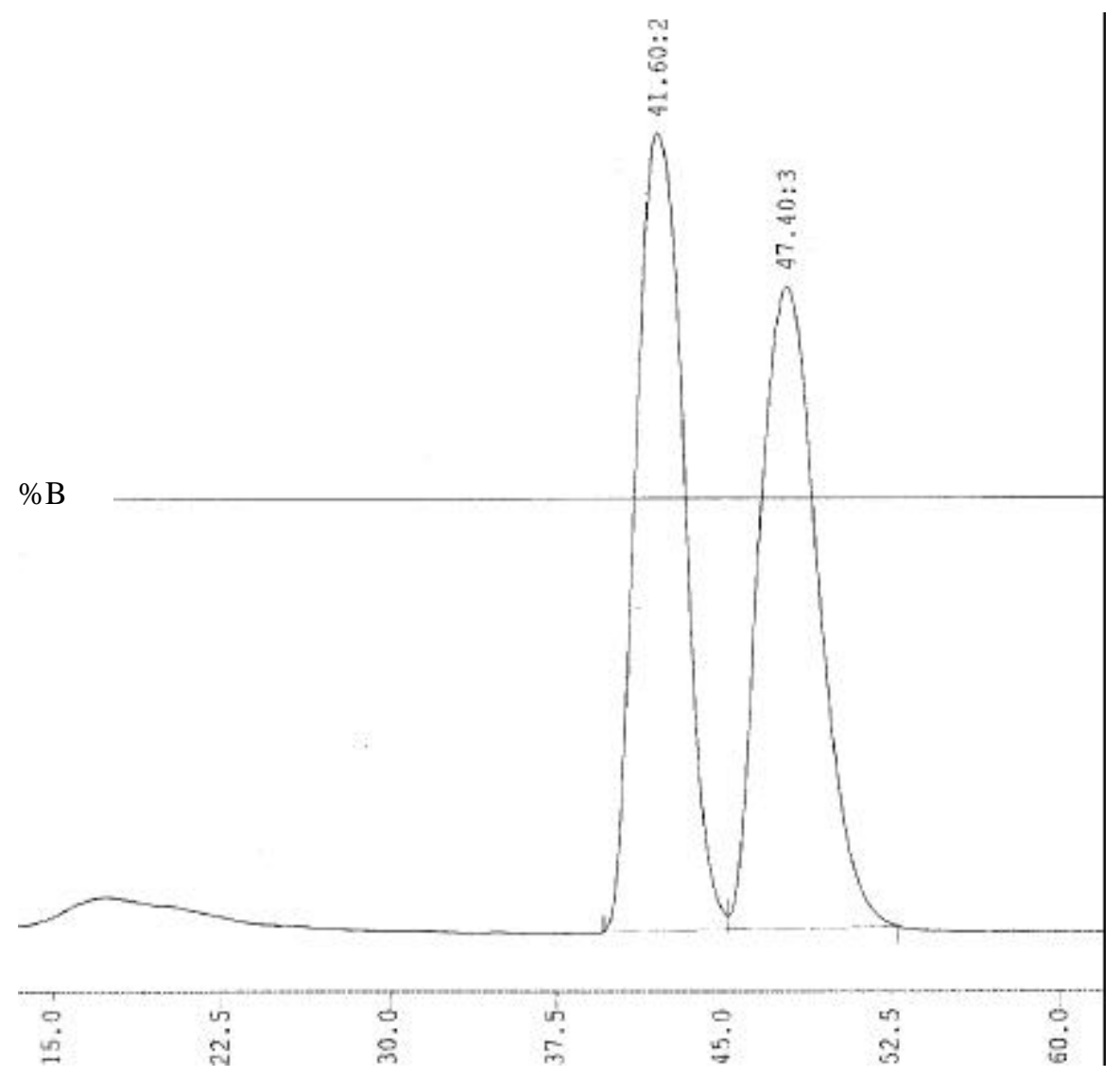

Abbildung 16: HPLC-Spektrum der Transformation von 1 zu 2 katalysiert durch cat mAk Doro-1.

a) Das Spektrum der Probereaktion mit catmAk Doro-1 und

b) die Referenz des racemischen Produktes.

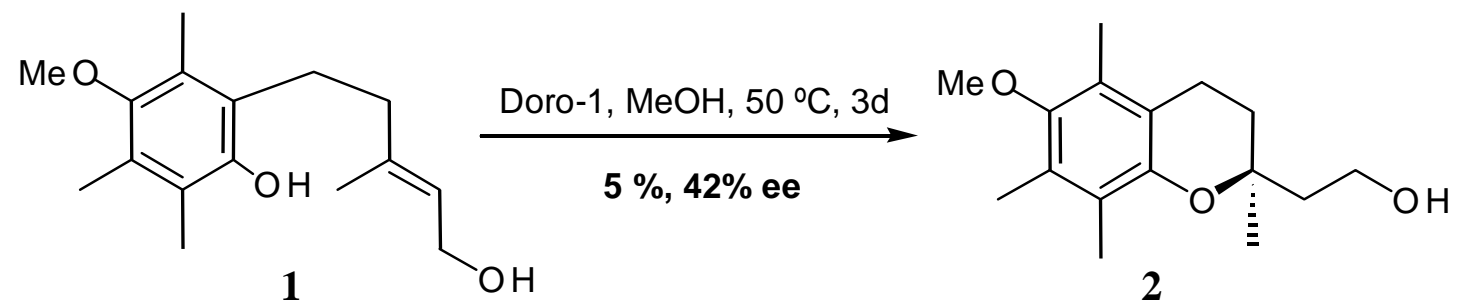

Abbildung 17: Das eingesetzte Substrat 1 im cat ELISA sowie das Produkt 2 nach der Transformation. 
Tabelle 6: HPLC-bezogene Profilanalyse der Transformation mit mAk Doro-1

\begin{tabular}{|c|c|c|c|c|c|}
\hline & & & Peak Nr*. & Ret. Zeit (min) & Rel. Ar. (\%) \\
\hline \multirow{3}{*}{ 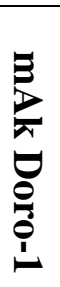 } & \multirow{3}{*}{ 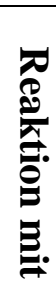 } & Substrat & 5 & $21.93: 5$ & 95 \\
\hline & & (R) 2 & 7 & $41.12: 7$ & 29 \\
\hline & & (S) 2 & 8 & $47.22: 8$ & 71 \\
\hline \multirow{2}{*}{\multicolumn{2}{|c|}{ 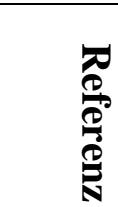 }} & (R) 2 & 2 & $41.60: 2$ & 50 \\
\hline & & (S) 2 & 3 & $47.40: 3$ & 50 \\
\hline
\end{tabular}

*) Die nicht relevanten Peaks, wie Nr. 6 in Reaktionsmessung mit einer Ret. Zeit um 33.57:6, nicht berücksichtigt.

\subsection{Vitamin E-bindender mAk Ing-1}

Nach der Überprüfung der katalytischen Aktivität wurden die Ak, die keine Aktivität aufwiesen, jedoch im Spezifitätstest gegen das Hapten gerichtet waren, wegen des gleichen Chromangerüsts (Abb. 18) auf Affinität zum natürlichen Vitamin E getestet (Abb. 19).

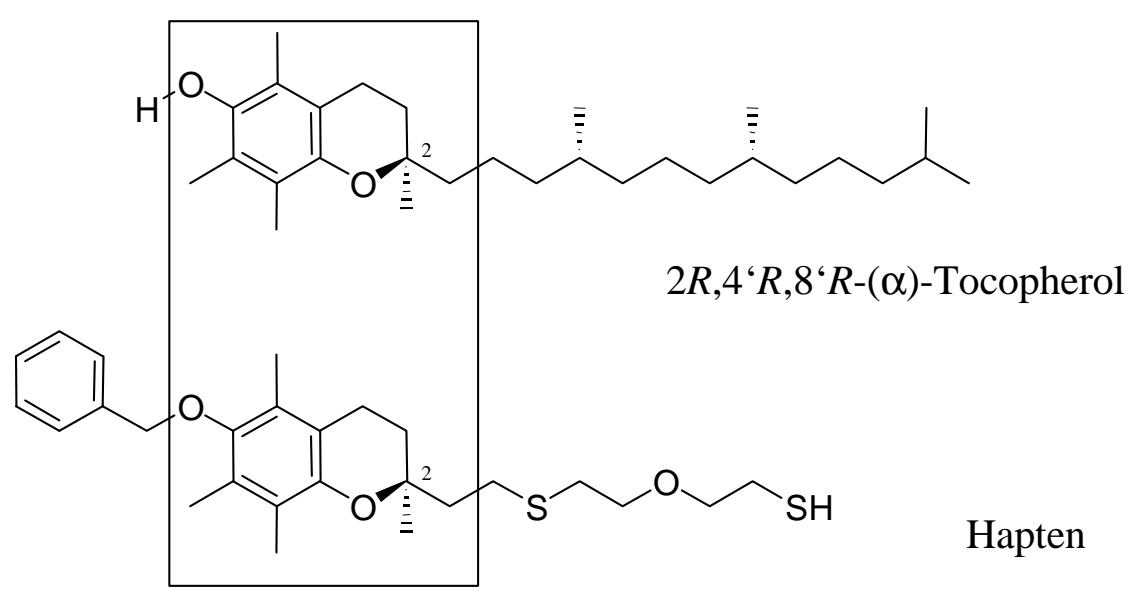

Abbildung 18: Das homologe Chromangerüst in Vit. E und Hapten. 
Hierfür wurde ein Verfahren entwickelt (Abb.19), das in der Lage ist, erstmals Vit. E mit immunologischer Methodik nachzuweisen (Abb. 24). Der anti Vit. E-Ak (M8-153) wurde zur Optimierung des qualitativen und quantitativen Nachweises vom Vitamin E eingesetzt; der M8-153 Ak und der Klon, aus dem er stammte, wurde als Ing-1 bezeichnet.

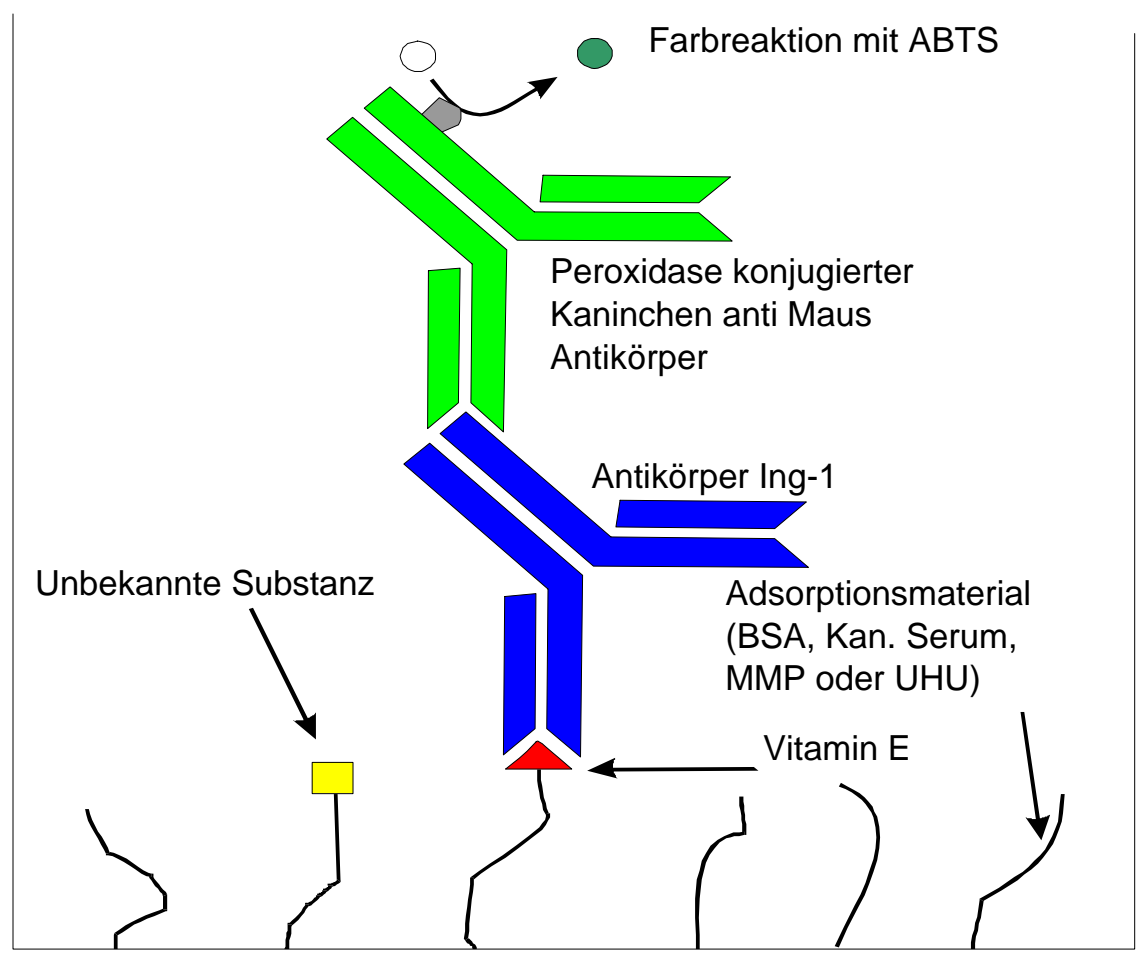

Abbildung 19: Schematische Darstellung zum Nachweis von immobilisiertem Vit.E.

\subsection{Antikörperproduktion der Hybridome}

Nach der zweimaligen Reklonierung und Adaption der Hybridome Doro-1 und Ing-1 auf „normale“ Kulturbedingungen (siehe 2.2.9) wurden von beiden Klonen Kulturüberstände gewonnen. Hybridome, die in Zellkulturflaschen oder Petrischalen kultiviert werden, produzieren 10 - $50 \mu \mathrm{g}$ Immunglobuline pro ml Kulturüberstand (PETERS \& BAUMGARTEN, 1990). Die auf Petrischalen ( hydrophob) adaptierten Doro-1 und Ing-1 Hybridome zeigten eine Produktivität zwischen 20 - $40 \mu \mathrm{g} / \mathrm{ml}$ (Tab.7). 
Tabelle 7: $\quad$ Die Antikörperkonzentration aus stationären Kulturen und Minibioreaktoren

\begin{tabular}{|c|c|c|c|c|}
\hline Klon & Doro-1 & Ing-1 & M2-46 & M2-92 \\
\hline $\begin{array}{c}\text { Antikörperkonzentration } \\
\text { in KÜ aus hydrophoben } \\
\text { Petrischalen }(\mu \mathrm{g} / \mathrm{ml})\end{array}$ & $30 * *$ & $50^{* *}$ & $10^{*}$ & $40^{*}$ \\
\hline $\begin{array}{c}\text { Antikörperkonzentration } \\
\text { in KÜ aus } \\
\text { Minibioreaktoren }(\mu \mathrm{g} / \mathrm{ml})\end{array}$ & 400 & 500 & ------ & ------ \\
\hline
\end{tabular}

*/**) Mittelwert von 4 / 9Messungen aus unterschiedlichen Kulturüberstanden.

KÜ = Kulturüberstand

Da die Hybridome in großen Petrischalen stationär kultiviert wurden, wurden ausreichende Mengen an Immunglobulinen gewonnen.

Unter Verwendung eines Minibioreaktors (siehe 2.2.11.1) wurde die Ak-Produktion bzw. AkKonzentration bis auf ca. $500 \mu \mathrm{g} / \mathrm{ml}$ erhöht (Tab.7).

\subsection{Mykoplasmentest}

Durch den Mykoplasmentest der Hybridome Doro-1 und Ing-1 wurde festgestellt, daß die Kulturen beider Hybridome mykoplasmenfrei waren. Dieses Testergebnis wurde von der „Deutschen Sammlung von Zellen und Mikroorganismen“ (DSZM) im Rahmen des Patentverfahrens bestätigt.

\subsection{Isotyp-Bestimmung}

Die Bestimmung der Klasse und Subklasse eines Antikörpers dient der Auswahl der Aufreinigungsmethode sowie der Optimierung des Testsverfahrens. Der Isotyp der Ak Doro-1 und Ing-1 wurde mit den Kulturüberständen beider Klone durchgeführt. Der kat-mAk Doro-1 
konnte dem Isotyp IgA und Ing-1 dem Isotyp IgG2a zugeordnet werden. Die leichten Ketten beider Ak wurden als $\kappa$ identifiziert.

\subsection{Antikörper-Aufreinigung}

Der mAk Ing-1 (IgG2a) wurde über Protein A- und Protein G-Affinitätschromatographie aufgereinigt (Abb.20 a \& b). Aus ca. $300 \mathrm{ml}$ serumhaltigem Kulturüberstand wurden über 9 mg Ak aufgereinigt. Dies entsprach 75\% der Gesamtimmunglobulinmenge.

a)

B

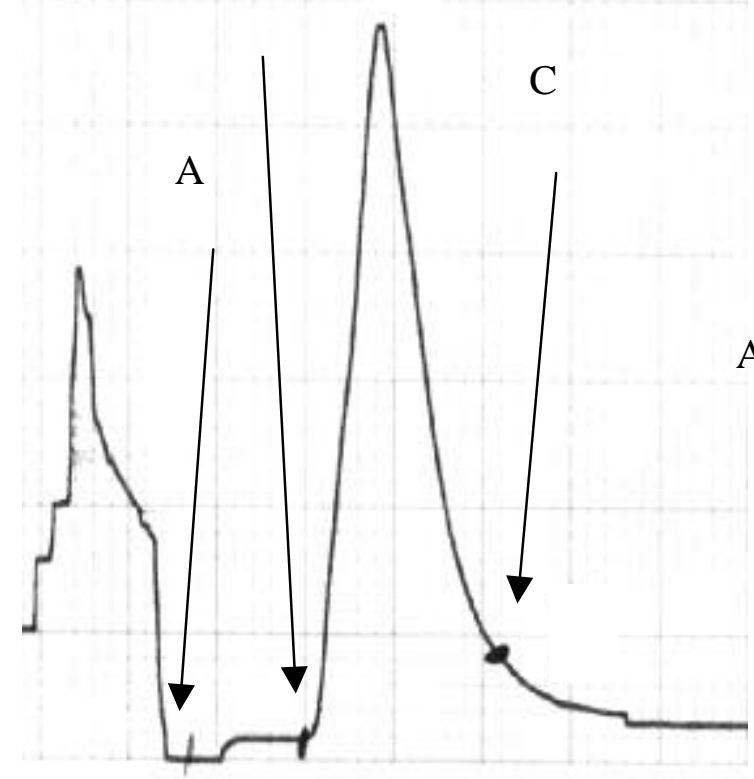

b)

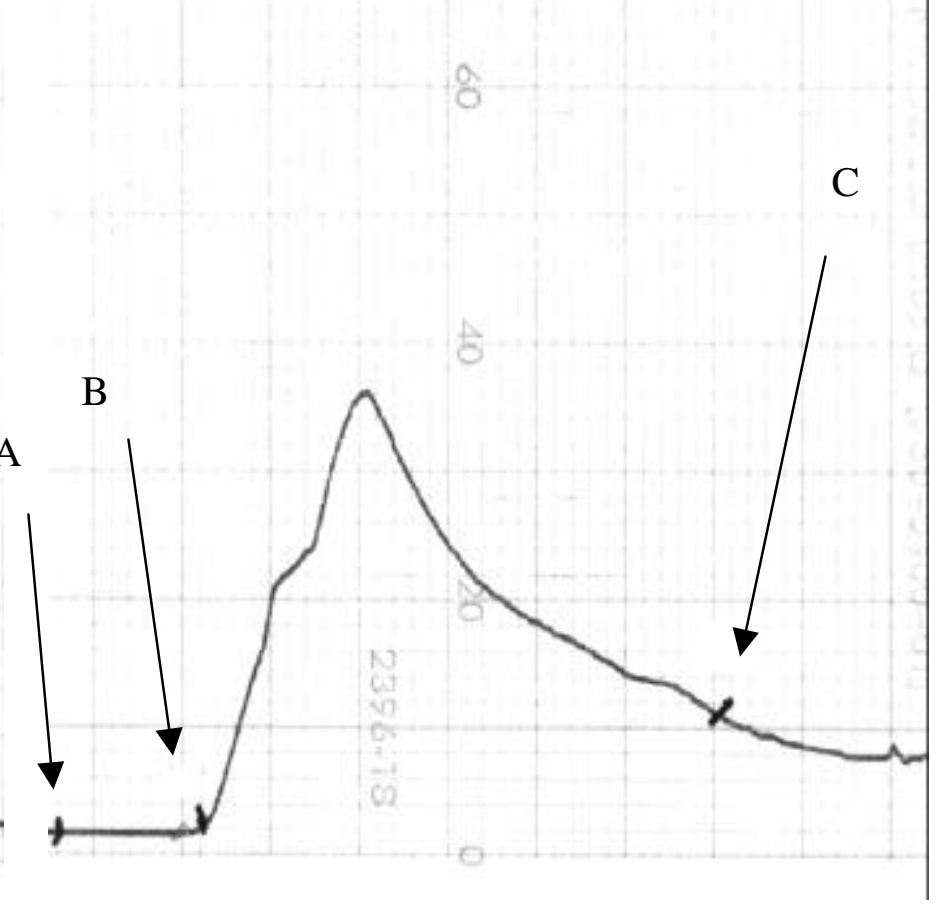

Abbildung 20: Das Spektrum bei der Elution der Ak über Affinitätschromatographie aus a) Protein A- und b) Protein G-Säule.

A) Zugabe von Waschpuffer; B) Zugabe von Elutionspuffer und C) Zugabe von Waschpuffer. Die BC-Fraktion wurde weiter bearbeitet.

Die Reinheit des mAks Ing-1 wurde nach der Umpufferung mittels SDS-PAGE bestimmt. Abbildung 21 zeigt die elektrophoretische Auftrennung des mAks Ing-1. Die Auftrennung erfolgte unter reduzierenden und nichtreduzierenden Bedingungen und zeigte, daß die Aufreinigung des mAks Ing-1 über Protein A- und Protein G-Affinitätschromatographie erfolgreich und ohne verunreinigende Proteine abgeschlossen werden konnte. 


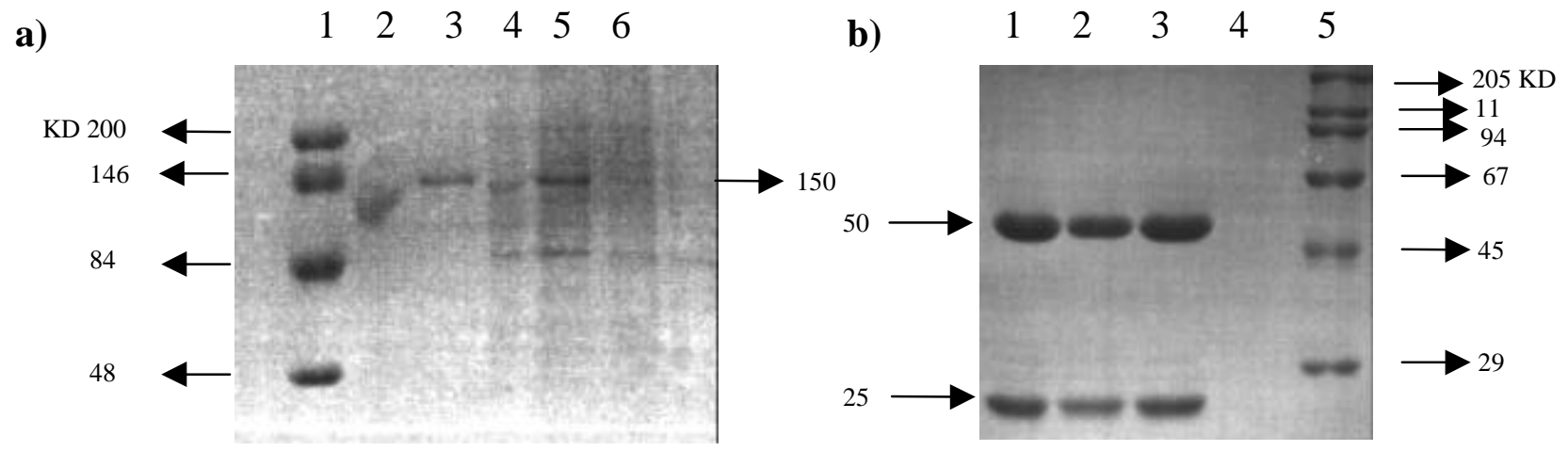

Abbildung 21: Auftrennung der gereinigten mAk durch SDS-PAGE

a) Nicht-reduzierende-Bedingung; $1=$ Protein Marker, 2, 3, 4, 5 und $6=\operatorname{IgG}$

b) Reduzierende Bedingung; 1, 2, 3 und 4 = IgG unterschiedlicher Konzentrationen, $5=$ Protein-Marker.

\subsubsection{Antikörperaufreinigung mittels Sephacryl $300 \mathrm{HR}$}

Der cat-mAk Doro-1 wurde mittels Säulenchromatographie mit Sephacryl-300 HR aufgereinigt. Aus $30 \mathrm{ml}$ serumhaltigem Kulturüberstand wurden nach der Ankonzentrierung ca. 5 ml zur Aufreinigung gewonnen. Die Antikörperkonzentration des Eluates wurde photometrisch bestimmt (Abb.22). Die IgA-haltigen Fraktionen wurden vereinigt und wieder ankonzentriert. Es wurden insgesamt 1,2 mg IgA gewonnen; dies entsprach einer Ausbeute von ca. $70 \%$.

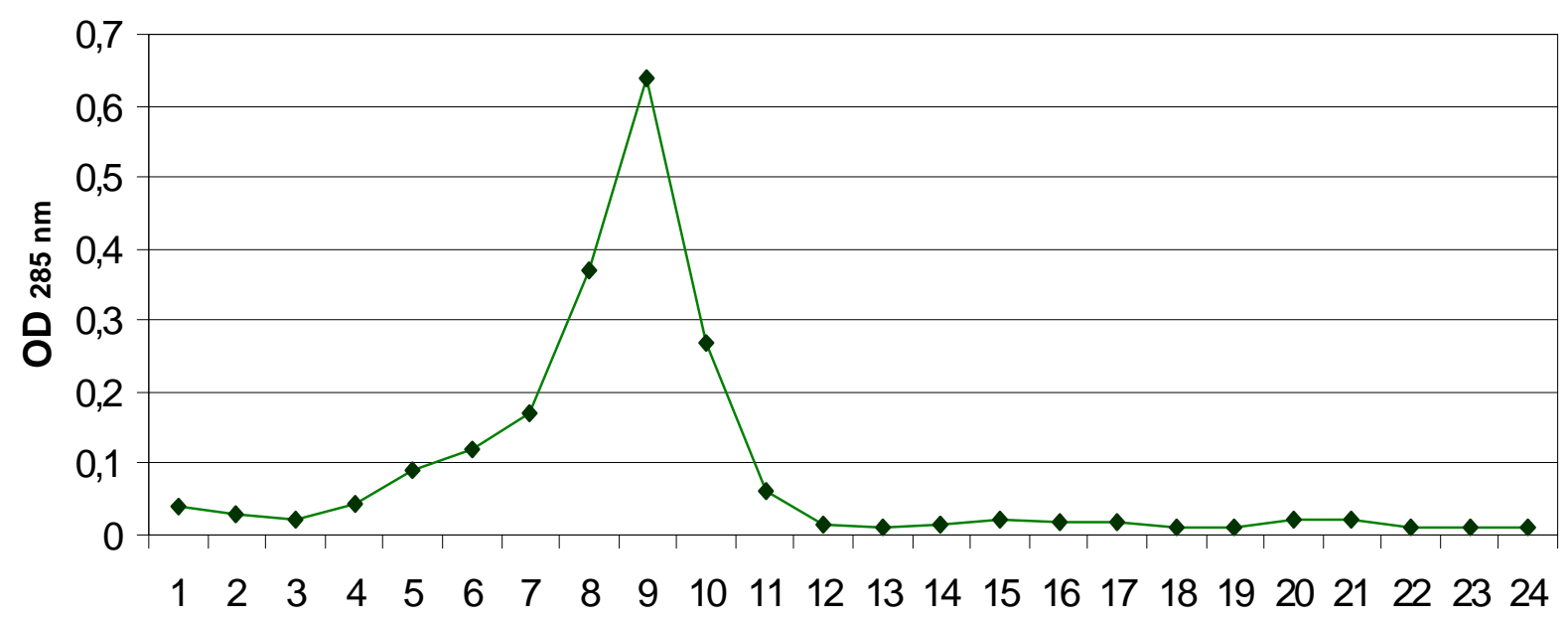

Fraktion

Abbildung 22: Der IgA-Gehalt der Fraktionen von der Sephacryl 300 HR-Säule. 


\subsection{Untersuchung der katalytischen Aktivität des monoklonalen Antikörpers Doro-1 zur}

\section{Bildung von Vit. E aus 3,5,6-Trimethyl-2-Phytylhydrochinon}

Nach der Entwicklung des cat-ELISA wurde die katalytische Aktivität des monoklonalen Antikörpers Doro-1 an 3,5,6-Trimethyl-2-Phytylhydrochinon untersucht (PhytylTMH) (Abb. 23). Diese Substanz gilt als unmittelbare Vorstufe von Vit. E. Da diese Substanz sehr leicht oxidiert wird, wurde die Reaktion unter Sauerstoff- bzw. Luftausschluß von Herrn Dr. J. SEIBEL am Institut für Organische Chemie der Universität Göttingen durchgeführt.

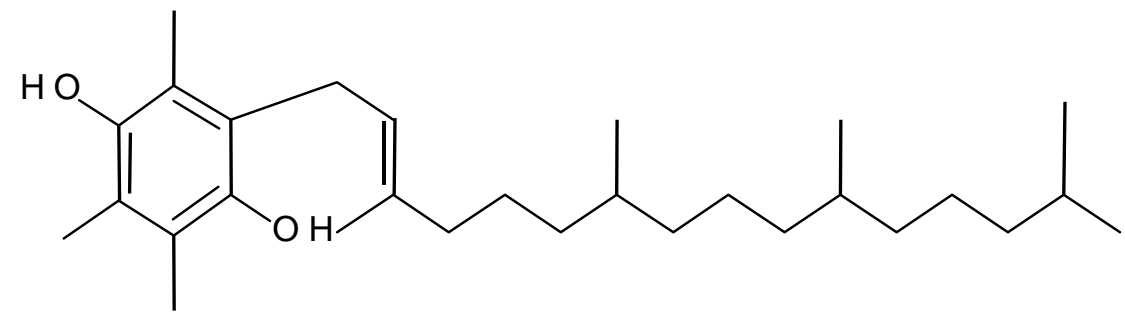

3,5,6-Trimethyl-2-Phytylhydrochinon

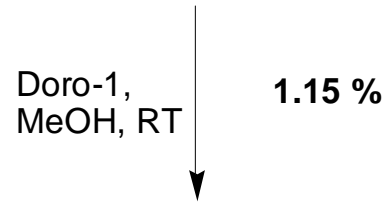<smiles>Cc1c(C)c2c(c(C)c1O)CCC(C)(CCCC(C)CCCC(C)CCCC(C)C)O2</smiles>

Abbildung 23: Die Synthese des Vit. E aus 3,5,6-Trimethyl-2-phytylhydrochinon, eine unmittelbare Vit. E-Vorstufe, durch katalytische Aktivität des cat mAks Doro-1.

Als Negativ-Kontrolle wurde in einem Parallelansatz der cat-mAk Doro-1 durch den Vit. Ebindenden Antikörper Ing-1 ersetzt, um die spontane Reaktion durch die Wirkung eines irrelevanten Maus-Antikörpers zu analysieren (Tab. 8). 


\section{Tabelle 8: $\quad$ Umsetzung von PhytylTMH mit den mAK Doro-1 und Ing-1}

\begin{tabular}{|l|c|c|}
\hline \multirow{2}{*}{\multicolumn{1}{|c|}{ T $\left[\mathrm{h}^{\prime}{ }^{\prime}\right]$}} & \multicolumn{2}{|c|}{ Umsatz [\%] } \\
\cline { 2 - 3 } & cat-mAk Doro-1 & mAk Ing-1 \\
\hline $27^{\prime}$ & 0,1 & 0 \\
\hline $2,4^{\prime}$ & 0,7 & 0 \\
\hline $4,25^{\prime}$ & 0,8 & 0 \\
\hline $18,52^{\prime}$ & 1,1 & 0 \\
\hline 23 & 1,2 & 0 \\
\hline
\end{tabular}

Die Reaktion erfolgte bei RT.

\subsection{Untersuchung des optimierten Vit. E-ELISA}

Dieser Antikörper wurde benutzt, um ein Testsystem zum qualitativen und quantitativen Nachweis von Vitamin E zu entwickeln. Zu diesem Zweck wurden BSA, Kaninchenserum und Magermilchpulver als blockierende Substanzen getestet, um dadurch die Messgenauigkeit zu erhöhen. Das Vit. E wurde in zwei verschiedenen Konzentrationen verwendet. Zum parallelen Einsatz wurde versucht, das Vit. E auf der festen Oberfläche physikalisch zu immobilisieren. Der Test basiert auf ELISA-Technik und konnte daher in einem PlattenELISA-Reader ausgewertet werden.

Unter den getesteten Substanzen, die gewöhnlich zur Blockierung verwendet werden, hat BSA eine optimale Wirkung gezeigt, wodurch die Empfindlichkeit der Messung wesentlich verbessert wurde (Abb. 24a). Das Verfahren wurde in weiteren Tests so verfeinert, daß das Vit. E schon in einer Konzentzration von $1 \mu \mathrm{g} / \mathrm{ml}$ (=250 p mol) nachgewiesen wurde (Abb. 24b). 
a)

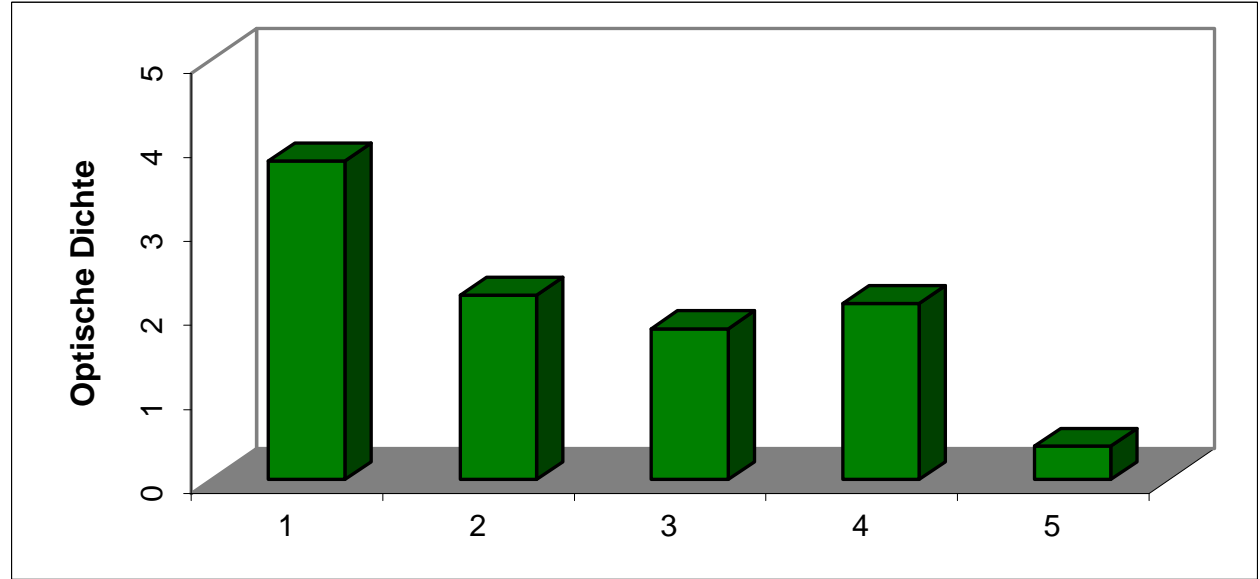

\begin{tabular}{|c|c|c|c|c|c|c|}
\hline \multirow{5}{*}{ 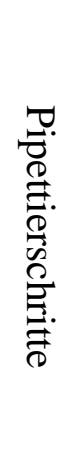 } & 5 & $\begin{array}{c}\text { ABTS } \\
+ \\
\mathrm{H}_{2} \mathrm{O}_{2}\end{array}$ & $\begin{array}{c}\text { ABTS } \\
+ \\
\mathrm{H}_{2} \mathrm{O}_{2}\end{array}$ & $\begin{array}{c}\mathrm{ABTS} \\
+ \\
\mathrm{H}_{2} \mathrm{O}_{2}\end{array}$ & $\begin{array}{c}\mathrm{ABTS} \\
+ \\
\mathrm{H}_{2} \mathrm{O}_{2}\end{array}$ & $\begin{array}{c}\mathrm{ABTS} \\
+ \\
\mathrm{H}_{2} \mathrm{O}_{2}\end{array}$ \\
\hline & $4 *$ & $\begin{array}{l}\text { Nachweis- } \\
\text { Ak }\end{array}$ & $\begin{array}{l}\text { Nachweis- } \\
\text { Ak }\end{array}$ & Nachweis-Ak & $\begin{array}{l}\text { Nachweis- } \\
\text { Ak }\end{array}$ & Nachweis-Ak \\
\hline & 3 & Ing-1 Ak & Ing-1 Ak & Ing-1 Ak & Ing-1 Ak & Ing-1 Ak \\
\hline & 2 & $\begin{array}{c}\text { Vit. E } \\
10 \mu \mathrm{g} / \mathrm{ml}\end{array}$ & $\begin{array}{c}\text { Vit. E } \\
10 \mu \mathrm{g} / \mathrm{ml}\end{array}$ & $\begin{array}{c}\text { Vit. E } \\
10 \mu \mathrm{g} / \mathrm{ml}\end{array}$ & $\begin{array}{c}\text { Vit. E } \\
10 \mu \mathrm{g} / \mathrm{ml}\end{array}$ & \\
\hline & 1 & BSA & MMP & Kan. Serum & UHU & BSA \\
\hline & & Probe 1 & Probe 2 & Probe 3 & Probe 4 & Neg. K. \\
\hline
\end{tabular}

b)

\begin{tabular}{|c|c|c|c|c|c|c|}
\hline & \\
\hline
\end{tabular}

Abbildung 24: Optimierung des Nachweissystems zur quantitativen Messung von

Vit. E (Abb. 19). 
Der Vergleich zwischen den Substanzen, die in bestimmten Konzentrationen

a) als Blockpuffer im ELISA verwendet werden.

b) Die Optimierung des Vit. E-ELISA durch unterschiedliche Beschichtungen.

*) Als Nachweis-Ak wurde ein Peroxidase-konjugierter Kaninchen anti MausAntikörper verwendet.

Neg. K. = Negativkontrolle

\subsection{Nachweis von Vitamin E im Biotin-Streptavidin-System}

Um die Bindung von mAk Ing-1 an Vitamin E analysieren zu können, wurde ein neues Nachweisverfahren entwickelt. Es wurde versucht, durch Biotinylierung von Vit. E das Biotin-Streptavidin-System zu verwenden. Dazu wurde der Vit. E-Biotin-Ester (Abb. 25) synthetisiert. Die Synthese dieses Makromoleküls, das aus den zwei Vitaminen E und H besteht, wurde von Herrn Dr. J. SEIBEL am Institut für Organische Chemie der Universität Göttingen durchgeführt.

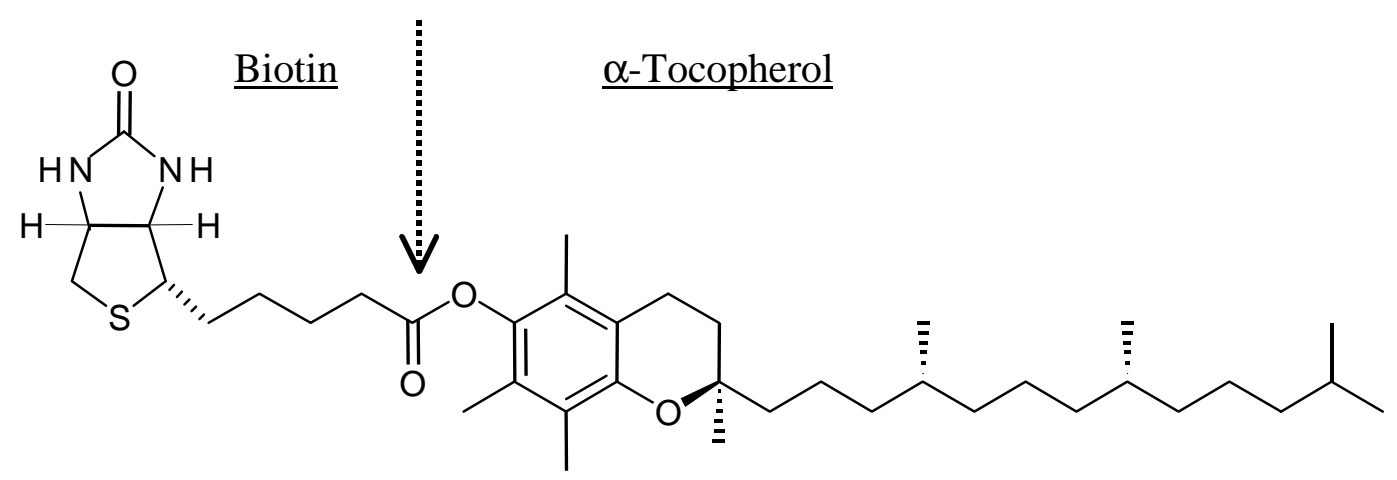

Abbildung 25: Biotin-Vit. E-Ester, ein neuartiges Molekül aus zwei Vitaminen.

Diese neu hergestellte Verbindung ermöglicht, den Vit. E-Biotin-Komplex auf einer mit Streptavidin beschichtete Oberfläche zu immobilisieren (Abb.26) und dadurch die Affinität des mAks Ing-1 zu untersuchen. 


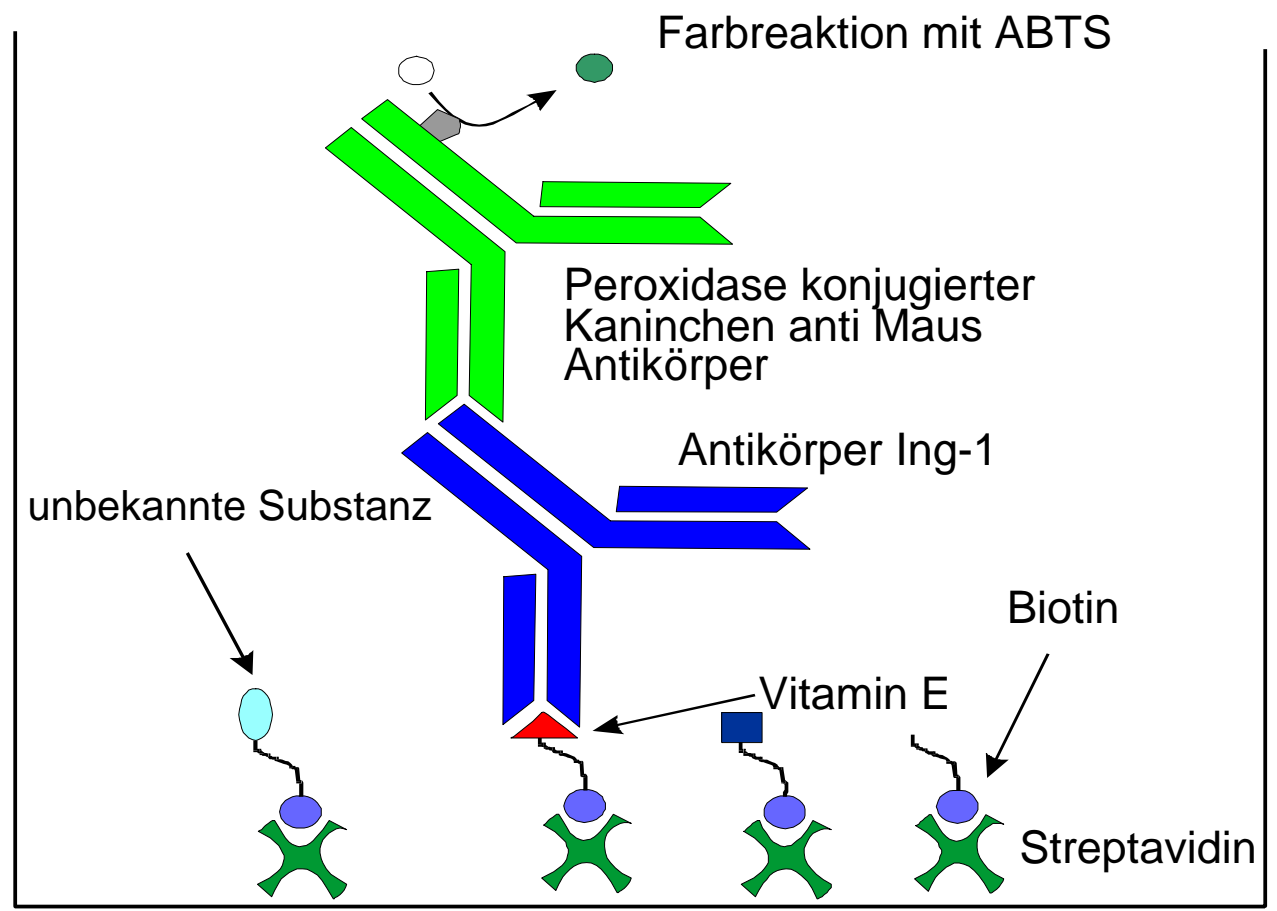

Abbildung 26: Durch biotinyliertes Vit. E wurde es möglich, das Biotin-StreptavidinSystem zu benutzen, um das Vit. E quantitativ zu erfassen. Außerdem wurde die Wasserlöslichkeit des Biotin-Vit. E Esters nach der Bindung an Streptavidin wesentlich erhöht.

Der Vit. E-Biotin-Ester wurde in diesem Nachweisverfahren, welches auf der ELISA-Technik basiert, bis zu einer Konzentration von 2 ng/ml (= 304 fmol) detektiert.

\subsection{Kristallographische Strukturanalyse des Substrates, des Biotin-Vit. E-Esters und des antigenbindnders Fragment (Fab) von Ing-1}

Die röntgenkristallographische Analyse des Vit. E-Biotin-Esters (Abb. 27a) und des Substrates (Abb. 27b) sollte die genaue Molekularstruktur dieser Verbindungen entschlüsseln.

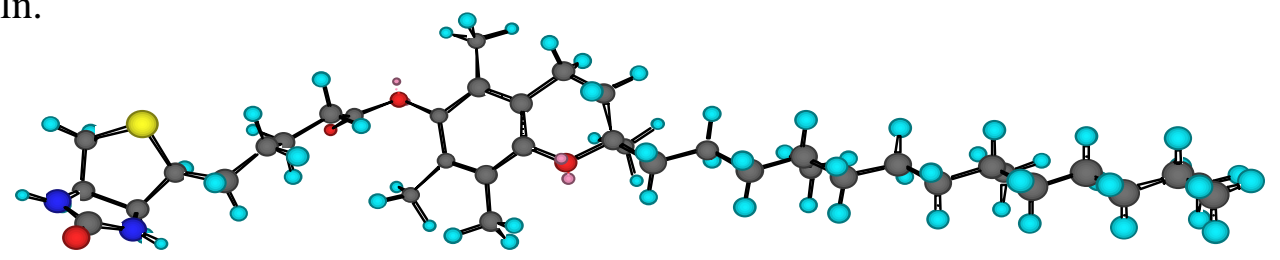

Abbildung 27: a) Berechnete Struktur des Biotin-Vit. E-Esters. 


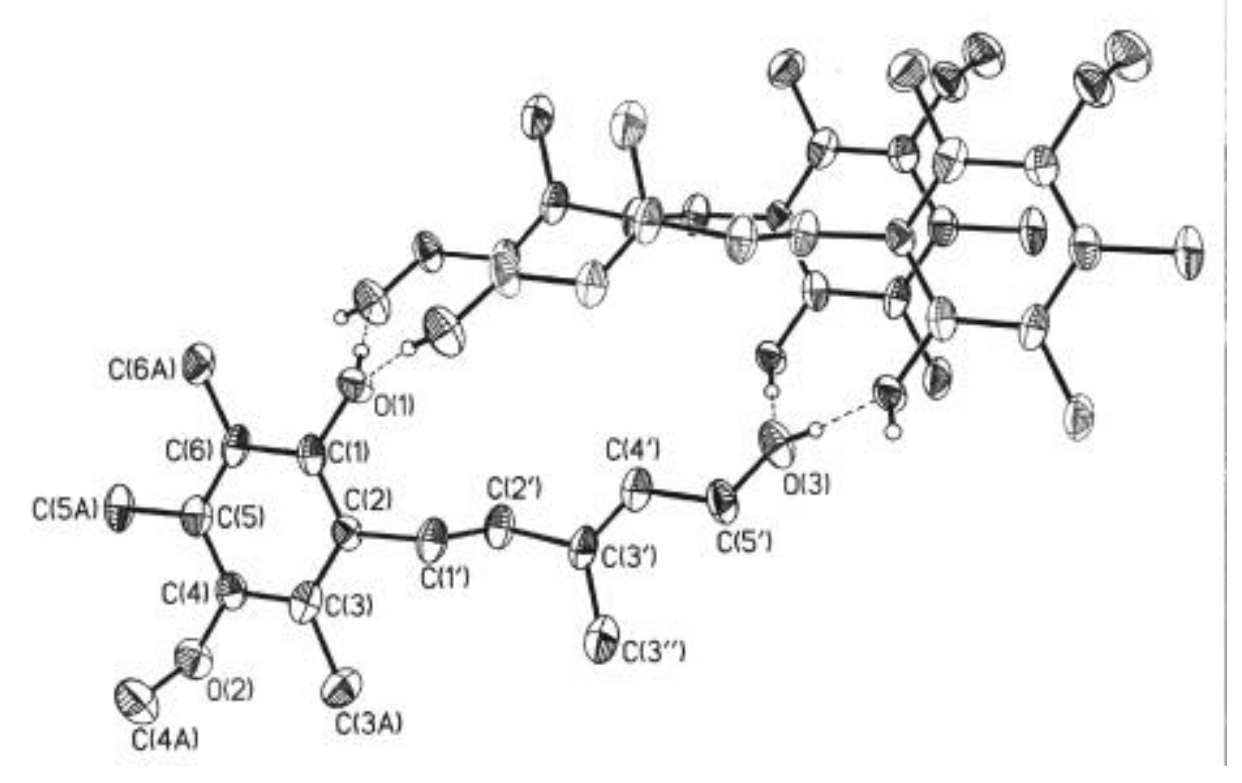

b) Die kristallographische Strukturanalyse des Substrates.

Diese Daten vervollständigen die ${ }^{13} \mathrm{C}$ - und ${ }^{1} \mathrm{H}-\mathrm{NMR}$-Analysen. Darüber hinaus sollen diese Daten in Kombinationen mit Ak und Ak-Fragmenten von Ing-1 und Doro-1 dazu beitragen, die funktionellen Aminosäuren hypervariabler Regionen der antigenbindenden Fragmente determinieren zu können.

Die Messung der Fab-Kristalle vom mAk Ing-1 (Abb.28 a, b \&c) und vom cat mAk Doro-1 sowie des Vit. E-Biotin-Esters sind noch nicht abgeschlossen. Die Messung und Röntgenanalyse erfolgt durch Herrn P. MÜLLER in der Arbeitsgruppe von Prof. Dr. G. M. SHELDRICK am Institut für Anorganische Chemie der Univ. Göttingen.

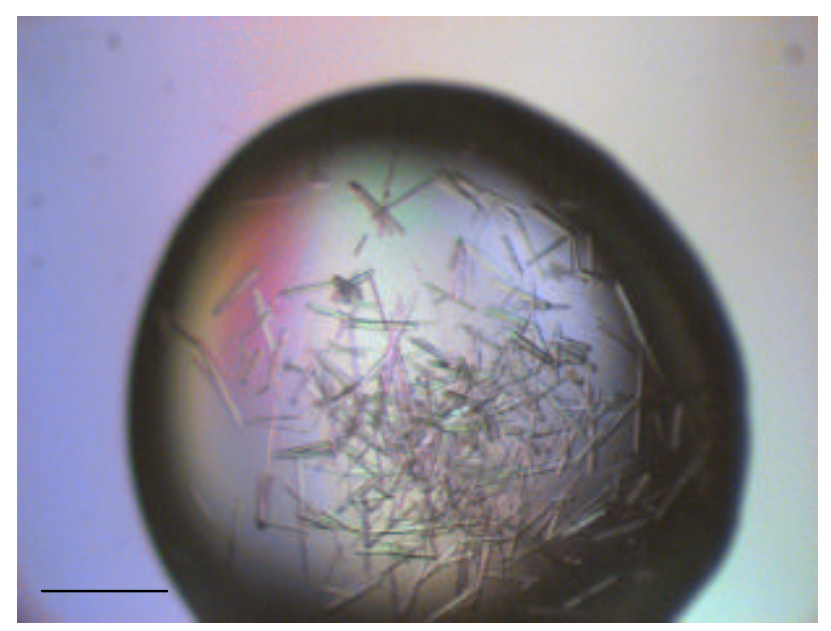

Abbildung 28: a) Die Fab-Kristalle bei polarisiertem Licht. Die einheitlich dunklen oder hellen Strukturen sind die Einzellkristalle $(-=1 \mathrm{~mm})$. 

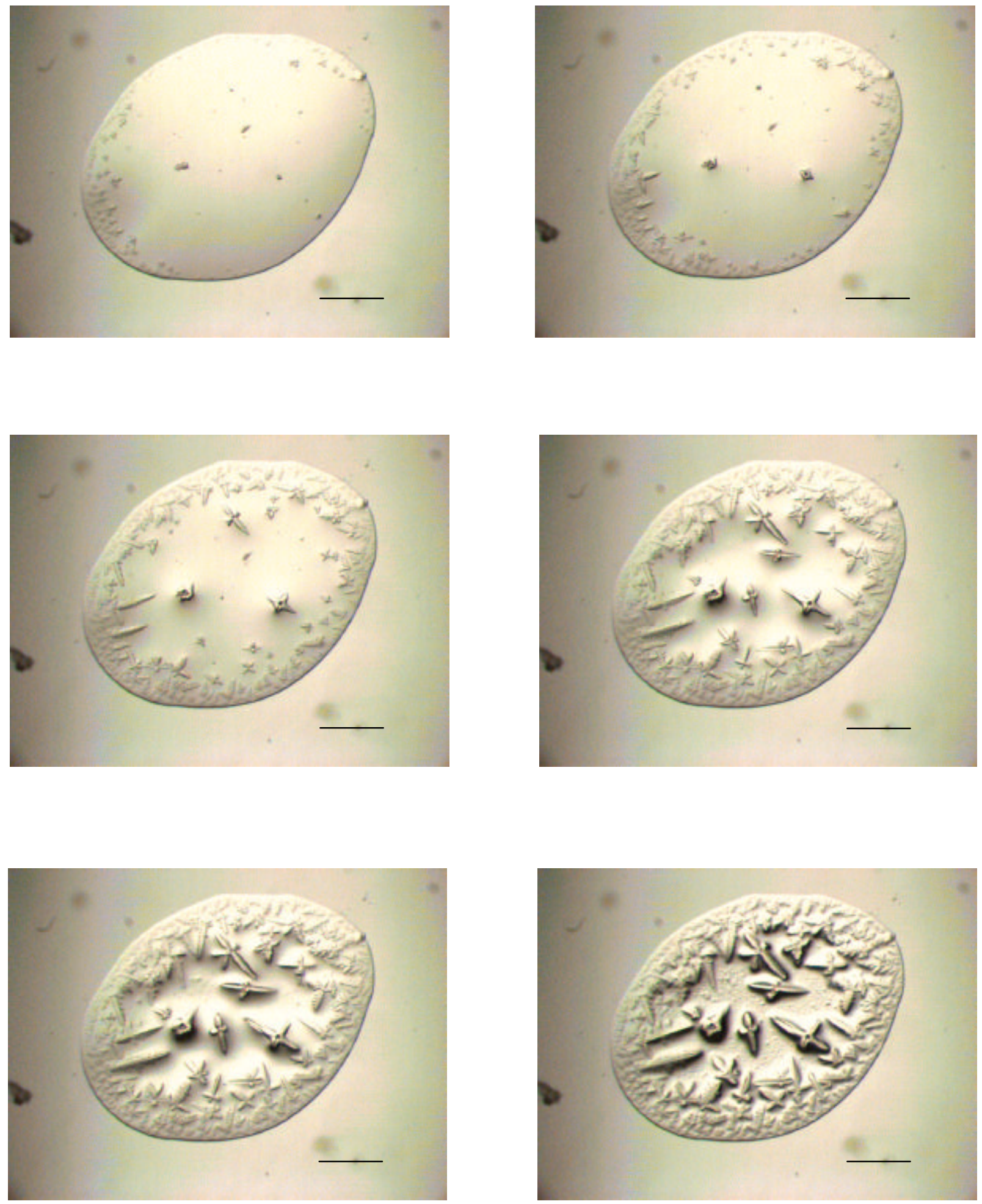

b) Die kristallisierenden Fab vom mAk Ing-1 innerhalb von 5 Minuten

( $-\mathbf{= 1} \mathbf{~ m m}$ ). (Digitale Zeitaufnahme mit $50 \mathrm{~s}$ Zeitinterval in PhasenkontrastMikroskop). 


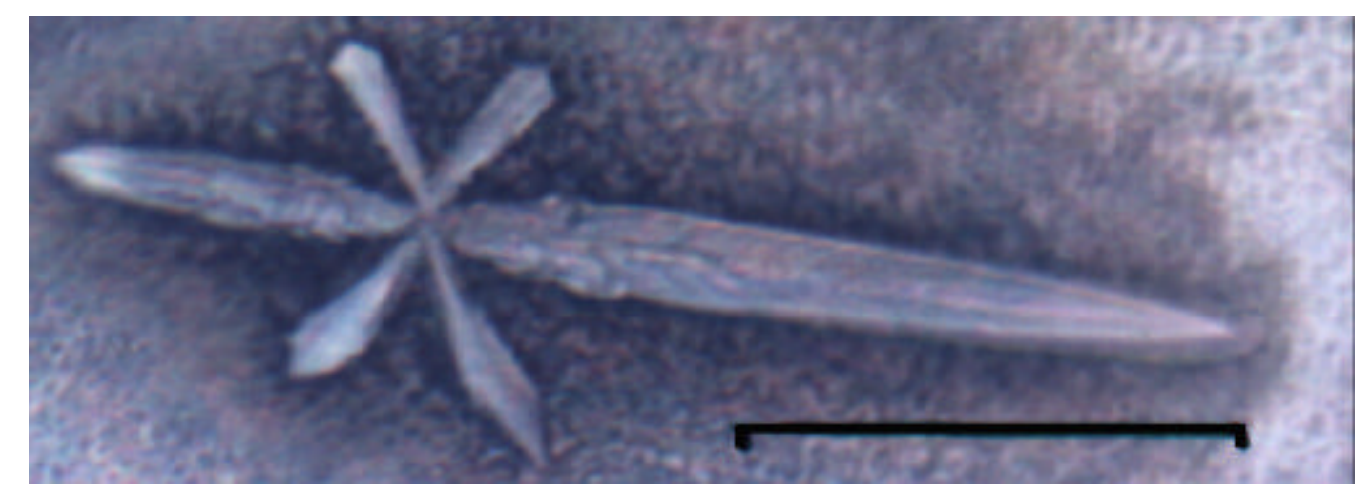

c) Die typischen Kristalle von aufgereinigtem Fab des mAks Ing-1 in Phasenkontrast- Mikroskop $(\square=0,25 \mathrm{~mm})$.

\subsection{Lokalisation des Epitops vom mAk Ing-1 innerhalb des Vit. E-Moleküls}

Zur Epitopbestimmung des mAks Ing-1 innerhalb des Vit. E-Moleküls wurden Derivate von Vit. E bzw. Vit. E-Analoga getestet (Abb. 29a). Der Test wurde durch Immunostaining auf einer dünnschichtchromatographischen Platte durchgeführt (Siehe 2.2.27). Die Verbindungen 1, 2 und 3 bestehen hauptsächlich aus Chromanringsystemen und unterscheiden sich ledig-lich durch ihre Seitenkette. Die Substanz 4 ist das enantiomerenreine Phytol (die Seitenkette von Vit. E), während die Substanz 5 das natürliche Vit. E darstellt. Als eine irrelevante Verbindung mit einem Doppelringsystem wurde das Biotin (Substanz 6) mitgetestet. Diese Verbindung ist gleichzeitig eine Negativkontrolle für das Vit. E-Biotin-Nach-weisverfahren.

Der Test zeigt, daß das Chromangerüst des Vit. E die Bindungsstelle des mAks Ing-1 ist und jede kleine Änderung der Schutzgruppe bzw. Seitenkette die Bindung des Antikörpers beeinträchtigt (Abb.29b). 
a)

1<smiles>COc1c(C)c(C)c2c(c1C)CC[C@](C)(CCO)O2</smiles>

2<smiles>Cc1c(C)c2c(c(C)c1OCc1ccccc1)CC[C@@](C)(CCO)O2</smiles>

3<smiles>Cc1c(C)c2c(c(C)c1O)CC[C@@](C)(CCO)O2</smiles>

4<smiles>CC(=CCO)CCC[C@@H](C)CCC[C@H](C)CCCC(C)C</smiles><smiles>Cc1c(C)c2c(c(C)c1O)CC[C@@H](CCCCCCCC(C)CCCC(C)C)O2</smiles>

6<smiles>O=C(O)CCCC[C@H]1SC[C@@H]2NC(=O)N[C@@H]21</smiles>

b)
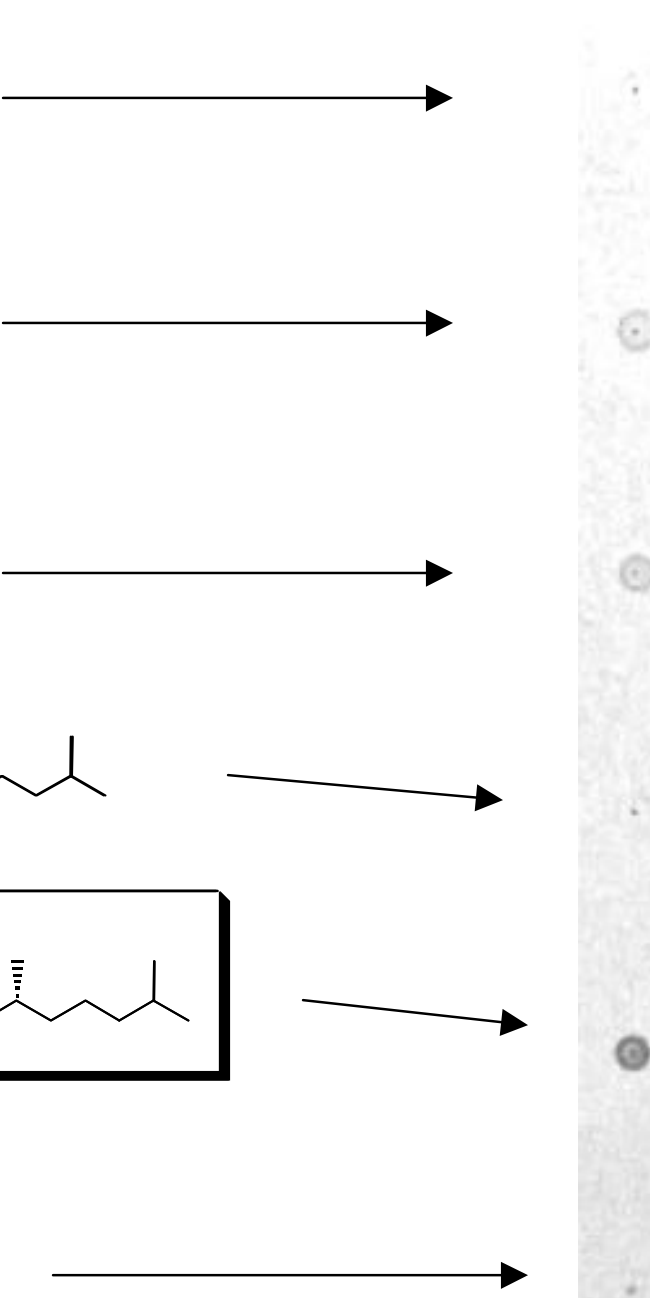

Abbildung 29: Epitop-Bestimmung zur Charakterisierung des mAks Ing-1.

a) Die Strukturformeln von Vit. E-Analoga (1 - 3), Phytol (4), natürlisches Vit. E (5) und Biotin (6).

b) Die Ausfällung des Substrates 4-Chloro-1-naphthol auf der Dünschicht-

Platte nach der Reaktion mit Peroxidase-konjugierten Kaninchen anti

Maus-Ak (Matherialien und Methoden).

\subsection{3 $\underline{\text { Nachweis von natürlichem } \alpha \text {-Tocopherol mittels einer hydrophoben Oberfläche }}$}

Zur Verbesserung des Vit. E-Nachweisverfahrens wurde ein neues Detektionssystem entwickelt, um das Vit. E auf einer hydrophoben Oberfläche so nachzuweisen, wie es in der 
Natur vorkommt. Zum Lokalisieren des Vit. E sollte daher einer Art Oberfläche konstruieren werden, die so ähnlich wie eine Membran aus hydrophoben Molekülen besteht. Hierfür wurde die Glasoberfläche eines Objektträgers zunächst mit Säure $\left(10 \% \mathrm{H}_{2} \mathrm{SO}_{4}\right.$ in Aqua bidest. (v/v) über Nacht) und danach mit Dodecyltrichlorsilan behandelt. Durch das Säurebad entstehen viele OH-Gruppen, an die das Silanderivat bindet (Abb.30a).

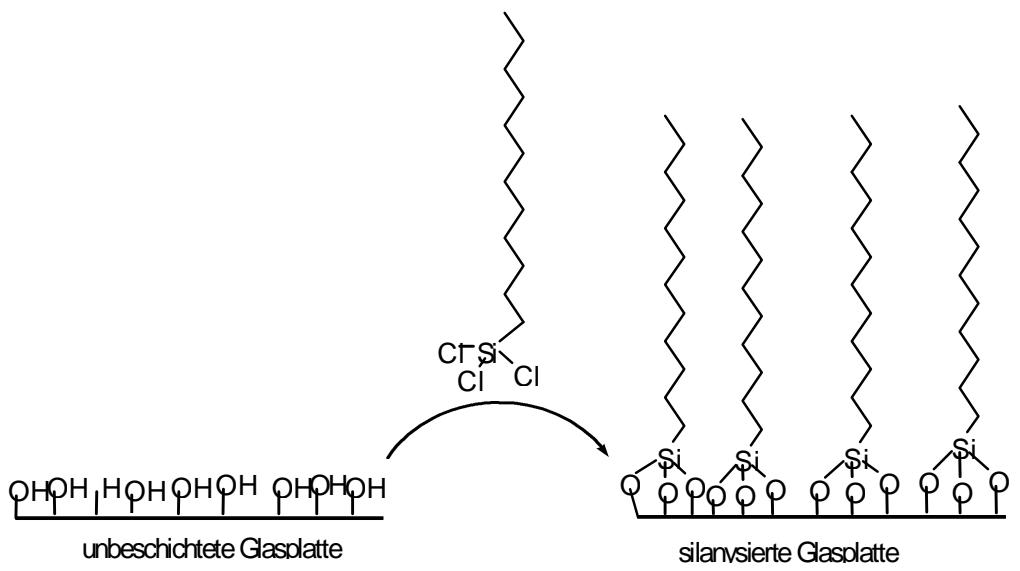

Abbildung 30: a) Die mit Säure behandelte Glasoberfläche präsentiert OH-Gruppen, die mit Dodecyltrichlorsilan reagieren und eine hydrophobe Oberfläche entwickeln.

Durch diese Reaktion entsteht eine hydrophobe Glasoberfläche und das Vit. E lokalisiert sich mit seiner langen ebenso hydrophoben Seitenkette so zwischen den Kohlenwasserstoffen, wie sie in einer biologischen Membran ausgerichtet sind (Abb.30b).
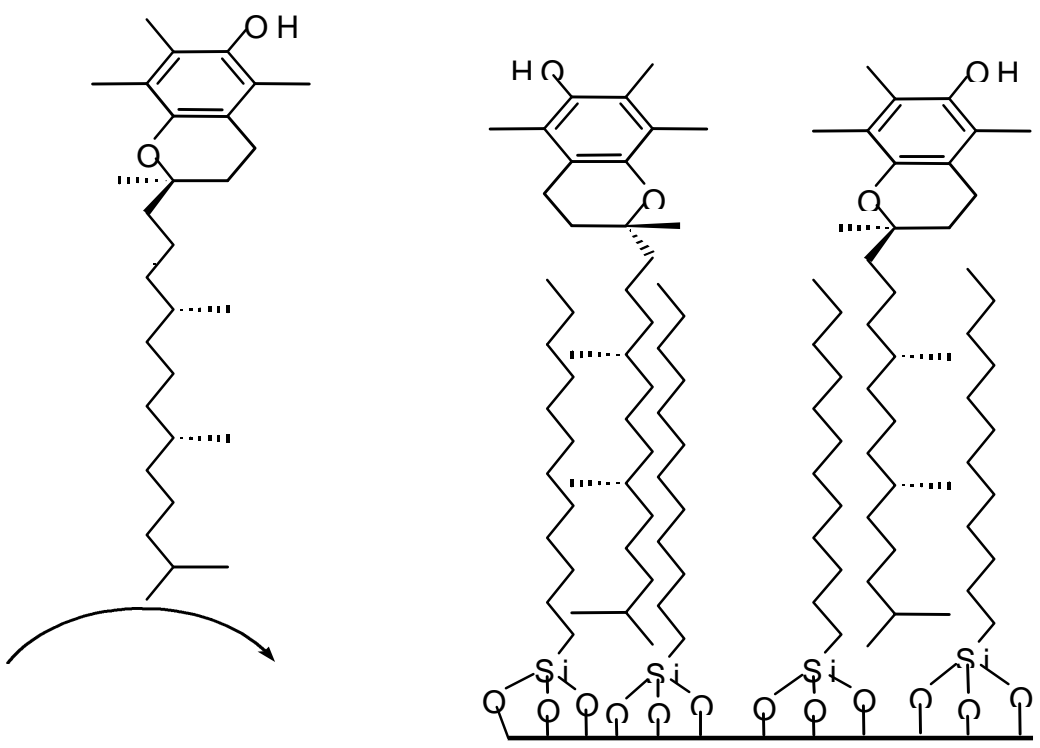

b) Die Lokalisation des Vit. E so, wie es in der Natur in der Membran vorkommt (Abb. 3a). 
Zur Optimierung dieser Technik wurde in Anlehnung an des ELISA das Glas durch eine ELISA-Platte ersetzt. Dadurch konnte die Bindung des mAks Ing-1 an Vit. E in einem Plattenphotometer quantitativ erfaßt werden. Das Vit. E wurde durch Inkubation von mAk Ing-1 bis zu einer Konzentration von $10 \mu \mathrm{g} / \mathrm{ml}(=23 \mu \mathrm{M})$ nachgewiesen. Nach dem Test wurde das Vit. E auf der Oberfläche der Mikrotiterplatte mittels massenspektrometrischer Untersuchungen nachgewiesen.

\subsection{Berechnung der Dissoziationskonstante des mAks Ing-1 mittel ELISA}

Durch die Silanisierung der ELISA-Platte wurde die Effizienz der Messungen so optimiert, daß diese Methode zur Bestimmung der Dissoziationskonstante $\left(K_{D}\right)$ der Bindung zwischen Ag (Vit. E) und dem Ak Ing-1 verwendet wurde. Die zur Bestimmung der $\mathrm{K}_{\mathrm{D}}$ benötigte Berechnung wurde von Herrn Dr. J. SEIBEL entwickelt (Siehe 2.2.27). Durch die 4malige Wiederholung der Doppel-Ansätze wurde eine Eichkurve zur $\mathrm{K}_{\mathrm{D}}$-Bestimmung errechnet (Abb. 31 a).

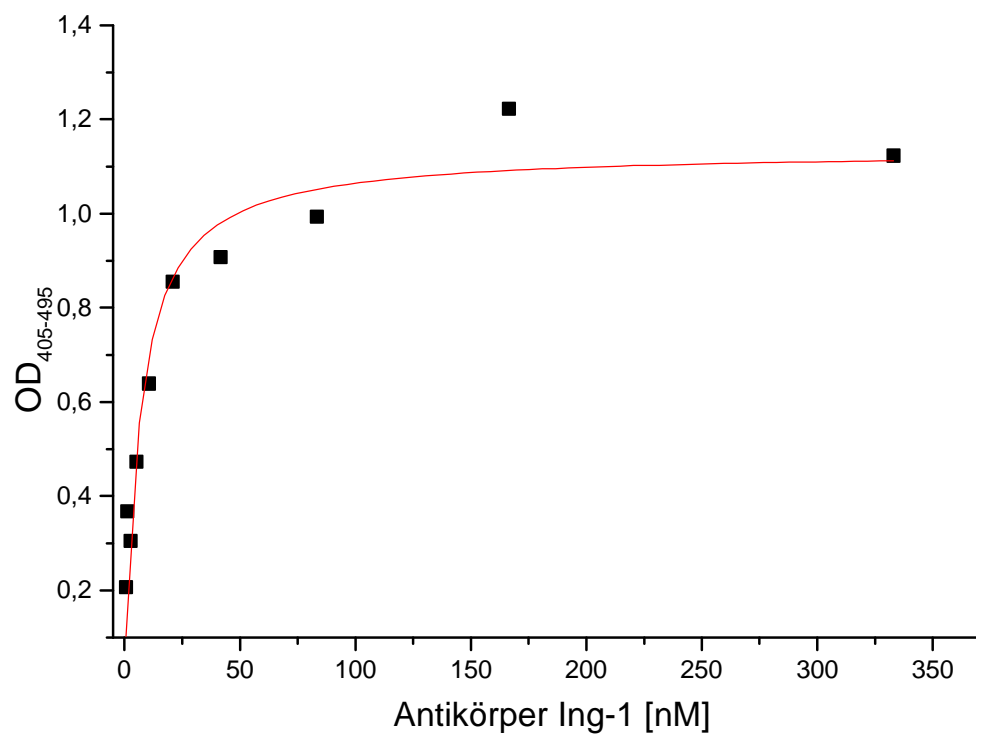

Abbildung 31: a) Titration der Antikörperkonzentration Ing-1 zur Bestimmung der Affinitätskonstante an Vit.E. Diese Meßwerten wurden aus den Meßungen abgeleitet, die in Abb. 32 dargestellt sind. Die Standardkurve wurde vom Programm „Soft Pro“ errechnet. Das Programm ist das Standardsoftwear des ELISA- Readers. 
Für die Berechnung der Dissoziationskonstante $\left(K_{D}\right)$ wurde eine Konzentration des aufgereinigten mAk Ing-1 von $10 \mu \mathrm{M}$ zugrunde gelegt (durchschnittlich $\mathrm{MW}$ eines IgG: $1 \mathrm{M}=1,5 \mathrm{x}$ $\left.10^{5} \mathrm{~g} / \mathrm{l}\right)$. Die Assoziationskonstante $\left(\mathrm{K}_{\mathrm{a}}\right)$ wird nach der Gleichung 1 errechnet:

$$
K_{A}=b / f=K_{A} x f=b
$$

Wobei: $b$ für die Konzentration der gebunden mAk Ing-1 und $f$ für die Konzentration der freien mAk Ing-1 stehen. Die Konzentration der freien mAk Ing-1 besteht aus $[\mathrm{Ak}]_{0}$ (die Konzentration der nicht gebunden mAk Ing-1) und der Konzentration der resuspendierten mAk Ing-1 (Materil und Methoden 2.2.28 die Gleichung 3).

Aus der Auftragung der Werte $b / f$ gegen die spezifische Bindung (Ak-Konzentration) im Scatchard Plot erhielten die Punkte durch lineare Regression (Abb. 31 b) folgende Gradenfunktion:

$$
\mathrm{F}_{(\mathrm{y})}=\mathrm{mx}+\mathrm{b}
$$

$(\mathrm{m}=$ Gradensteigung $; \mathrm{b}=$ Schnittszelle mit der Ordinate $)$.

Der absolute Steigungswert entspricht der Assoziationskonstanten $\left(K_{A}\right)$ :

$$
-\mathrm{m}=K_{A}
$$

Die Dissoziationskonstante $K_{D}$ leitet sich von der $K_{A}$ ab:

$$
K_{D}=1 / K_{A}
$$

Aus (3) und (4) wird (5) abgeleitet:

$$
\left\{-\mathrm{m}=1 / K_{D} \text { oder } \mathrm{m}=K_{D}^{-1}\right\}
$$

Aus den acht verschiedenen Messungen wurde als Mittelwert eine Dissoziationskonstante $\left(K_{D}\right)$ von $6,72 \pm 2,10 \times 10^{-9} \mathrm{M}$ berechnet. 


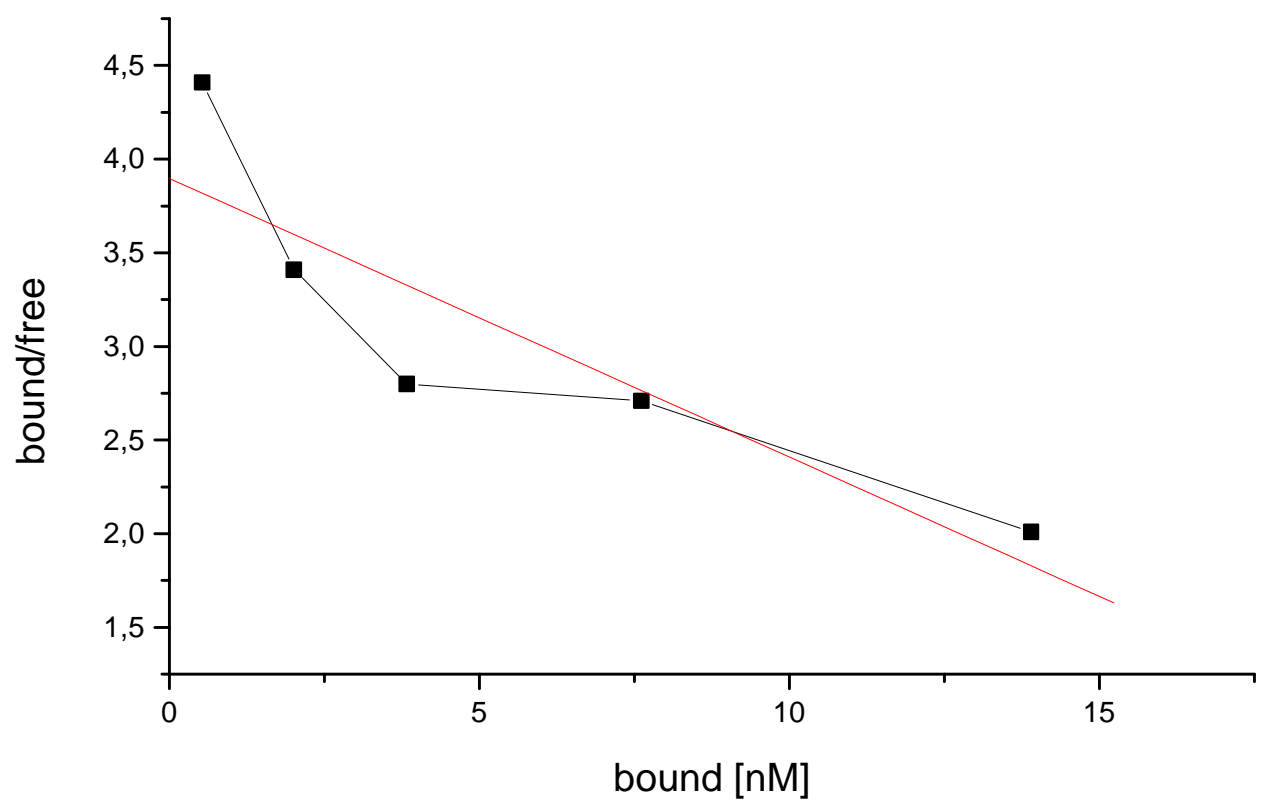

b) Die lineare Funktion (errechnet im Programm „Origin 5.0“) der gemessene Werte. Die Steigung wird nach der Gleichung (2) kalkuliert (Abb. 31c).

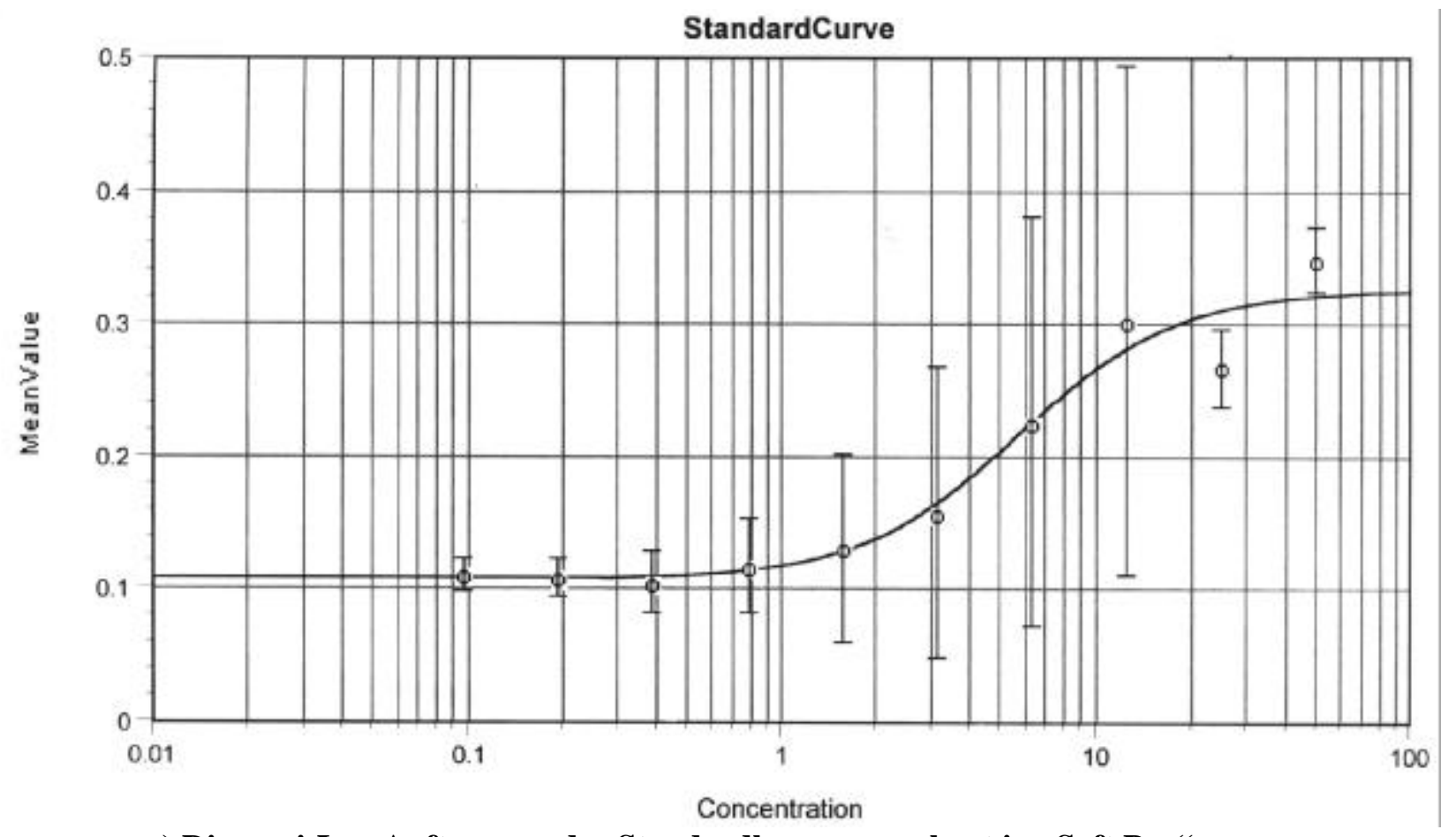

c) Die semi-Log Auftragung der Standardkurve, errechnet in „Soft Pro“

Programm. 


\subsection{Untersuchung zur Kreuzreaktion der mAk Doro-1 und Ing-1}

Um die mAk Doro-1 und Ing-1 weiter zu charakterisieren, wurden die Untersuchungen zur Bestimmung der Kreuzreaktion mit irrelevanten Strukturen mittels durchflußzytometrischer Analyse und zytochemischen Färbungen an humanen Zellen: Monozyten und monozytären Dendritischen Zellen sowie akute monozytären Leukämie-Zellen THP-1 und HL-60 durchgeführt. Sowohl die FACS-Messungen als auch die zytochemischen Färbungen zeigten keinerlei Aktivität von mAk Doro-1 und Ing-1 an untersuchten Zellen (nicht gezeigt). 


\section{Diskussion}

\subsection{Das Hapten und seine Eigenschaften}

Zur Generierung der monoklonalen Antikörper mit katalytischer Aktivität werden in der Regel die Verbindungen als Haptene zur Immunisierung verwendet, die dem Übergangszustand der gewünschten Transformation entsprechen(BLACKBORN et al., 1989; LERNER, BENKOVIC \& SCHULTZ, 1991; TINGYU et al., 1994). Diese Verbindungen bzw. ihre Analogen repräsentieren das energetische Niveau des Übergangzustandes TS (Abb. 32 a \&b), wodurch der Ablauf der Reaktion zur Herstellung des Produktes positiv beeinflußt wird.

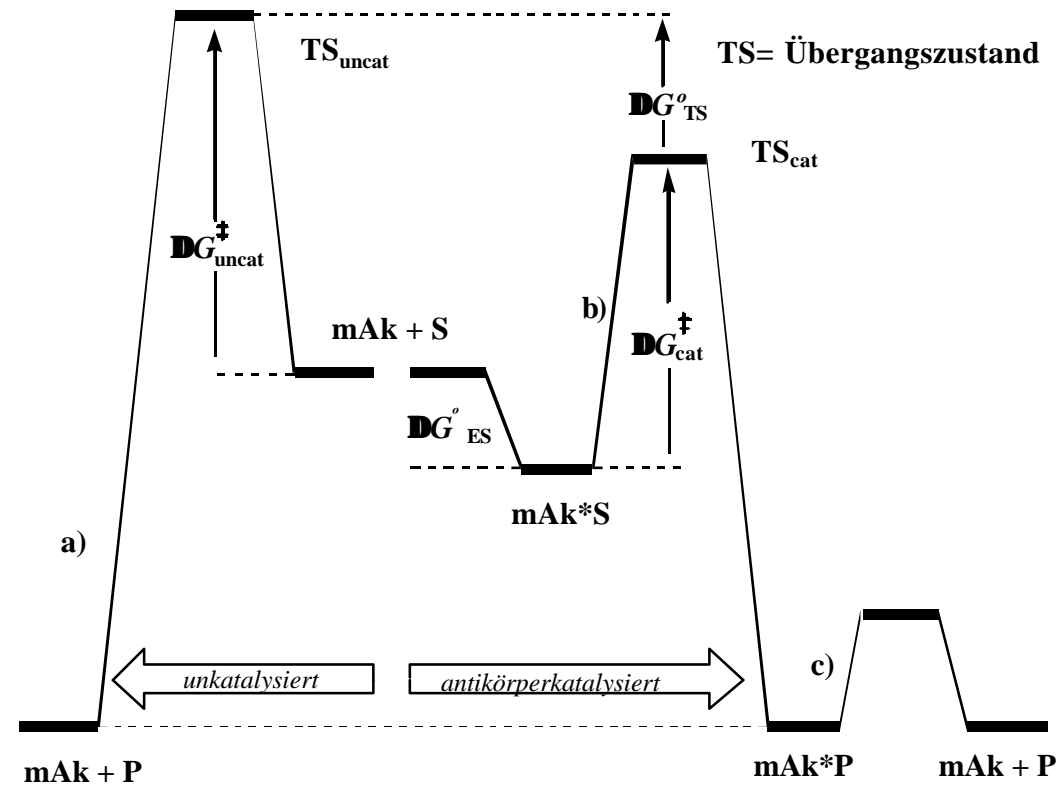

Abbildung 32: Die Energiezustände eines Substrates während einer

Reaktion mit und ohne katalytischen Ak. Auf der Ordinate ist mit G die

Gibbs-Energie und auf der Abszisse der Reaktionsverlauf aufgetragen.

(Modifiziert nach Burton, 1989) 
a) Die Energiezustände eines Substrates in einer nicht katalytischen Reakton; Die Aktivierungsenergie $\left(\Delta G^{\ddagger}{ }_{\text {uncat }}\right)$ zur Entstehung des Übergangzustandes eines Substrates im Verlauf einer Reaktion mit katalytische Ak und

b) der Verlauf des Energieniveaus des Enzym-Produkt-Komplexes und der Freilassung des gebildeten Produktes $\left(\Delta G^{\ddagger}{ }_{\text {cat }}\right)$.

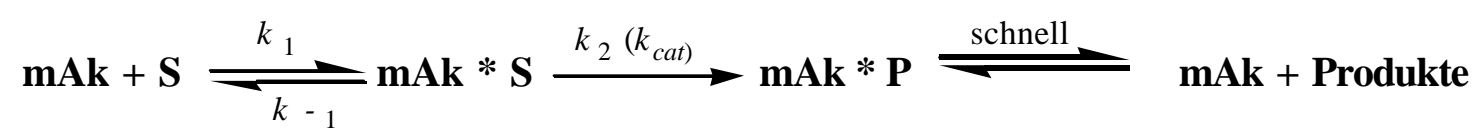

c) Der Ablauf einer enzymatischen Reaktion mit cat mAk. (modifiziert nach LERNER, 1991).

S) Substrat; P) Produkt; mAk) monoklonaler Antikörper; TS) Übergangzustand; cat) katalytisch; uncat) nicht katalytisch; ES) Enzym-Substrat; G) Gibbs-Energie

Da das Übergangszustandsanalogon des in dieser Arbeit verwendeten Substrates nicht stabil war (GÖRLITZER, 1997), wurden einige alternative Verbindungen zum Übergangszustandsanalogon synthetisiert (Abb.33). Damit könnte ein Enzym an der re- bzw. si-Seite (links oder rechts zum C2 positioniert) ein Doppelbindungssubstrat protonieren und so die Zyklisierung selektiv zu einem 2R bzw. 2S-Produkt durchführen (Abb.33).

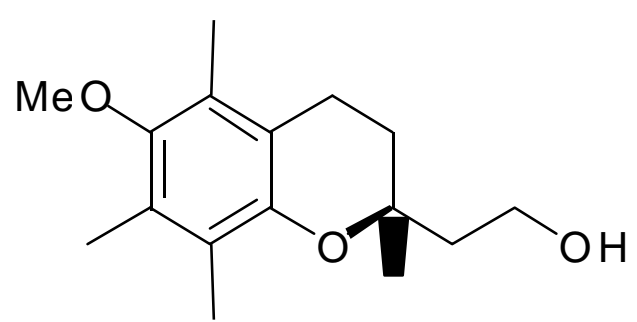<smiles>COc1c(C)c(C)c2c(c1C)CC[C@](C)(CCO)O2</smiles>

Abbildung 33: Zwei mögliche Isomere, die als 2R und 2S-Produkt entstehen können. 
1)

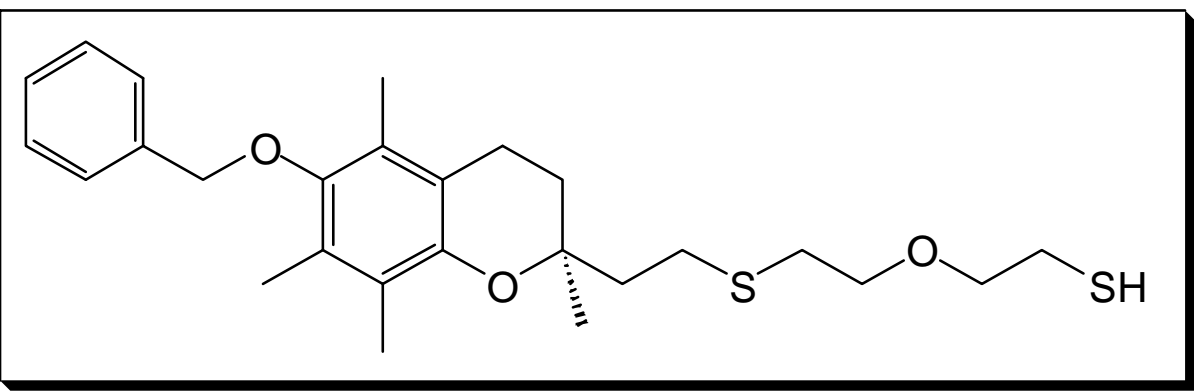

2)

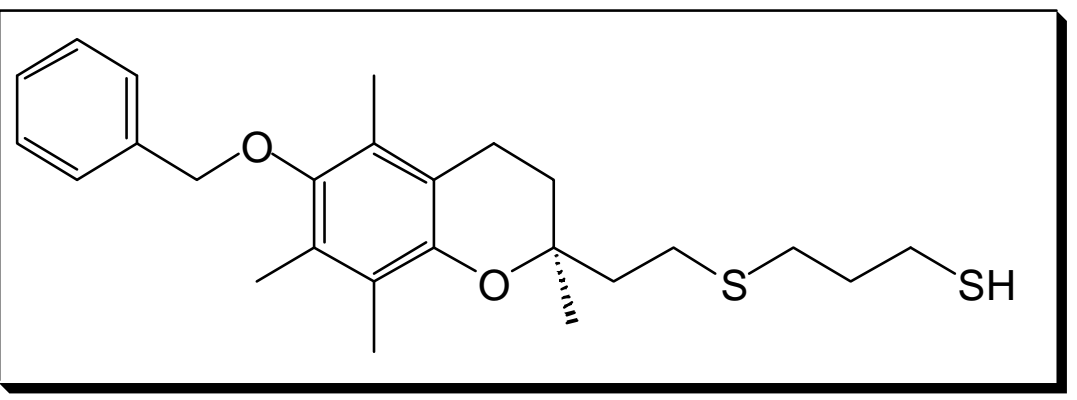

3)

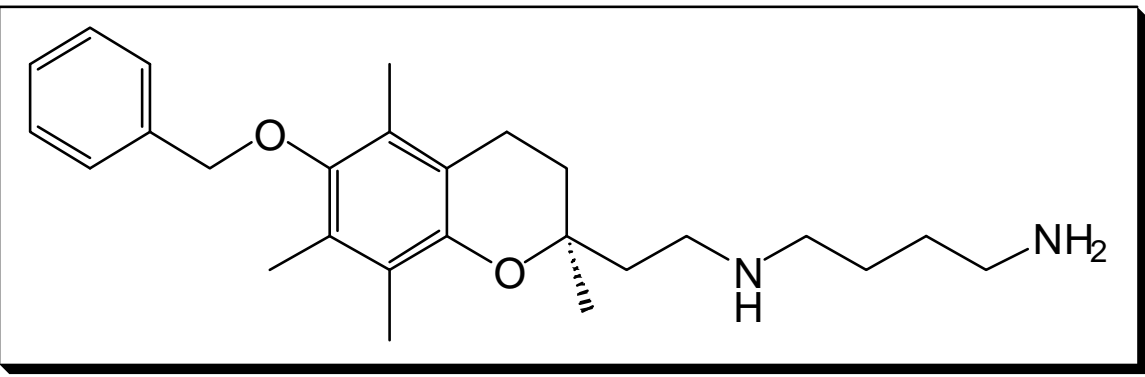

4)

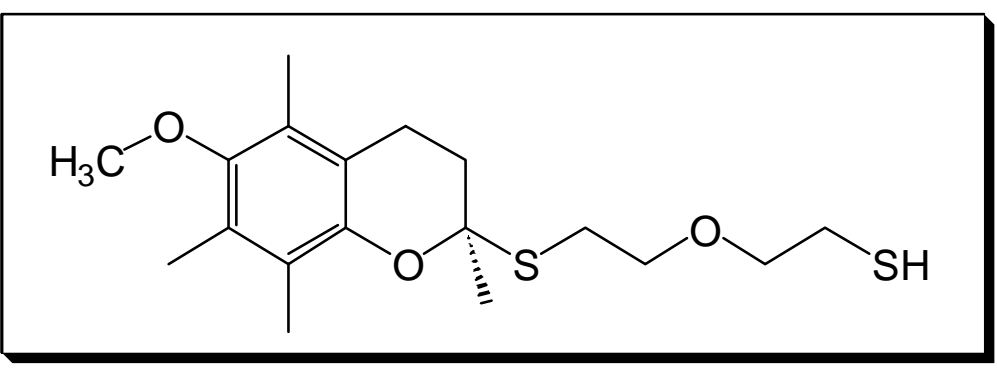

5)

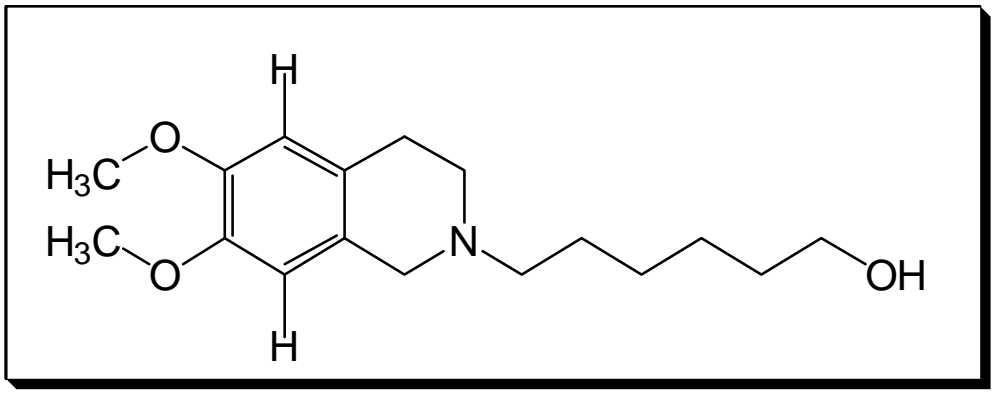


6)

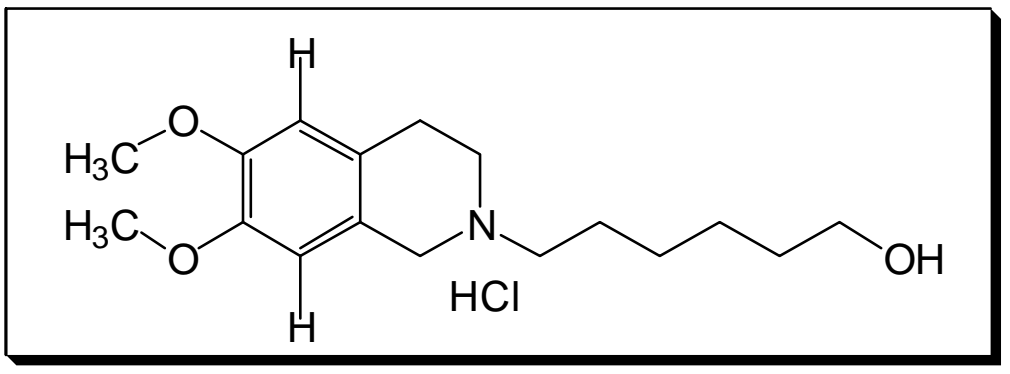

7)

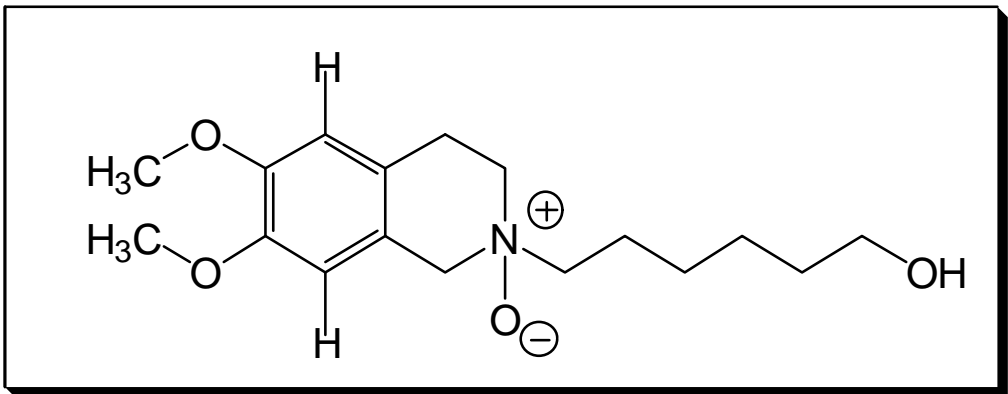

Abbildung 34: Die synthetisierten Haptene.

\subsubsection{Design des Haptens}

Sieben synthetisierte Haptene standen zur Auswahl. Alle diese Haptene haben drei gemeinsame Strukturmerkmale:

1. Ein Chromangerüst, ein Doppelringsystem, jedoch unterschiedlich derivatisiert,

2. einen Linker, der an der Seitenkette des Chromangerüstes kovalent gebunden ist, und

3. eine Bindungsstelle, durch die das Hapten an das Trägerprotein gebunden wird.

Da die Immunisierung nur mit einem Hapten erfolgen sollte, wurden die Kriterien zur Auswahl eines Haptens wie folgt angesetzt:

1. Die Menge des Haptens: Das Hapten sollte in ausreichender Menge zur Immunisierung von 12 Tieren und zum Screening der Klone vorhanden sein. 
2. Reinheit des Haptens: Da die Haptene synthetisch hergestellt waren und solche synthetisierten Moleküle selbst nach der Aufreinigung mit Nebenprodukten verunreinigt sind, war die Reinheit des Haptens von entscheidender Bedeutung.

3. Die Länge des Linkers sowie die Bindungsstelle: Da das Hapten an ein Trägerprotein gekoppelt werden sollte, wurde ein Hapten ausgesucht, welches einen relativ langen Linker (größer C6) besaß. Dadurch sollte verhindert werden, daß das Hapten in der Faltung des Trägerproteins für Antikörper unerreichbar bleibt. Die reaktive Bindungsstelle sollte eine optimale kovalente Bindung an aktiviertes Trägerprotein (Maleimid) ermöglichen.

Aus den oben angeführten Gründen wurde aus sieben Haptenen das Hapten Nr. 1 (Abb. 34) zur Immunisierung ausgewählt.

\subsection{Auswahl der Tiere}

Die zur Immunisierung ausgewählten autoimmunkranken Stämme sollten in der Lage sein, mehr katalytische Antikörper zu produzieren als übliche Versuchstiere (TAWFIK et al., 1995).

Die Ausbeute katalytisch aktiver Ak mit einem Anteil von cat mAk (ca. 5\%, (Tab.5)), ist vergleichbar mit den Ergebnissen von TOWFIK et al. (4\%), der dieses Ergebnis an mehreren Tierstämmen erzielte (TAWFIK et al., 1195). Der Immunisierungskalender in dieser Arbeit entspricht fast dem Langzeitprotokoll von TOWFIK et al., bis auf kleine Unterschiede wie z. B. Injektionsort beim Priming. Weder eine Kurzzeitimmunisierung noch die Immunisierung die Tiere anderer Stämme wurden im Rahmen dieser Arbeit durchgeführt, so daß keine 
Möglichkeit besteht, die Wichtigkeit der Immunisierungsdauer so wie die Bedeutung der Stämme im Zusammenhang mit der Produktion katalytischer Ak analysieren zu können.

\subsection{Auswahl der Adjuvantien}

Da Adjuvantien die Immunantwort unter anderem durch bessere Präsentation des Antigens von APC (PETERS und BAUMGARTEN, 1992) und die Aktivierung der CD4 ${ }^{+}$-T-Zellen (JANEWAY and TRAVERS, 1996) positiv beeinflussen, wurden sie auch in dieser Arbeit verwendet.

Obwohl die beiden benutzten Adjuvantien unter absolut identischen und mit einander vergleichbaren Bedingungen eingesetzt worden waren, konnten ihre Auswirkung nicht statistisch vollständig erfasst werden. Der Prozentsatz bearbeiteter Fusionate (ca. 10\%) ist zu niedrig, um über die Wirkung der Adjuvantien Aussagen treffen zu können. Jedoch ist der Rest (ca. 90\%) der Fusionate kryokonserviert und kann nach dem Auftauen in etablierten Testsystemen nachbearbeitet werden. Durch die große Zahl der immunisierten Tiere (12) liegt genug Material vor, interessanten Fragen wie z. B. die Auswirkung des Adjuvans P3CSK4 (Abb. 9a) auf den Ak-Isotyp im Vergleich zu konventionellem Adjuvans TiterMax beantworten zu können.

\subsection{Auswahl des Haptens}

Die Idee, Ak zu generieren, die die Eigenschaften eines Enzyms aufweisen, existiert seit Mitte der 80er Jahre. Von den ersten katalytischen Antikörpern berichteten 1986 zwei unabhängige Arbeitsgruppen (LERNER, et al. \& SCHULZ et al.; 1986). 
Trotz vieler optimierter Protokolle, wie z. B. die Strukturmerkmale des Haptens, stellt die Herstellung von cat mAk einen schwierigen Prozeß dar. Der limitierende Faktor in der Entwicklung von cat mAk ist das Testsytem, in dem die katalytische Aktivität der Ak untersucht wird. Daher wurden Systeme entwickelt, in denen viele Ak gegen viele Substanzen getestet werden können (SCHULZ et al., 1992).

Die Zahl der Derivatisierungsmöglichkeiten und die Variation der Seitenketten eines Substrates weist darauf hin, daß viele cat $\mathrm{mAk}$ nicht substratspezifisch, sondern reaktionstypspezifisch sind (LERNER \& BENKOVIC \& SCHULZ; 1992).

Das Ziel dieser Arbeit war die Herstellung eines cat mAk mit definierter Funktion, nämlich die stereoselektive Synthese von Vit. E. So sind die Substrate, die in dieser Arbeit verwendet werden können, durch das gewünschte Produkt definiert, d. h. solche Substrate wurden eingesetzt, die Vit. E als Produkt ermöglichen. Die Retrosynthese zeigte, daß analog der Biosynthese vornehmlich drei Verbindungen (Abb.35), als Substrate geeignet sind.

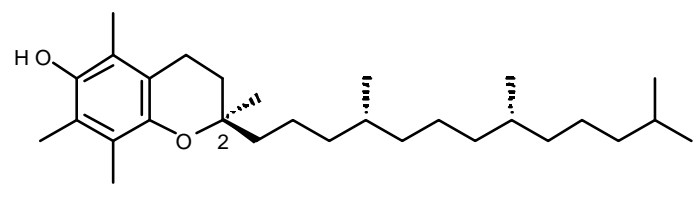

$\alpha$-Tocopherol 1

$$
\Downarrow \text { Retrosynthese }
$$<smiles>CC=CCCc1c(C)c(O)c(C)c(O)c1C</smiles>

A<smiles>CCc1c(C)c(O)c(C)c(O)c1C</smiles>

B<smiles>C=C(C)CCc1c(C)c(O)c(C)c(O)c1O</smiles>

C

\section{Abbildung 35: Schema der Retrosynthese, bei der aus $\alpha$-Tocopherol die Substrate A, B, C synthetisiert wurden.}


Das zweite wichtige Merkmal dieser Arbeit besteht darin, daß vergleichbare Enzyme noch kaum beschrieben worden sind. Das einzige Enzym, das aus Cyanobakteria Anabaena variablis (grün-blaue Alge) isoliert und als Tocopherol-Zyklase bezeichnet wurde, zeigte zwar eine streng substratspezifische Aktivität, war jedoch nicht stabil (Stocker et al., 1996).

1998 haben ARANGO und HEISE aus der Chromoplastmembran der gelben Paprika (Capsicum anuum L.) Homogenisate hergestellt, die die Synthese von $\gamma$-Tocopherol positiv beeinflussen, konnten aber das Enzym nicht isolieren (ARGANO \& HEISE, 1998).

Die cat mAk sollen in der Lage sein, die Umsetzung eines Substrates um Faktoren zwischen $10^{3}$ und $10^{6} \mathrm{zu}$ beschleunigen. Für viele Reaktionen, die durch cat mAk katalysiert worden sind, gibt es bekannte Katalysatoren sowohl chemischer als auch biologischer Herkunft, wie z. B. eine bestimmte Oxidationsreaktion, die allerdings durch Zugabe von $\mathrm{H}_{2} \mathrm{O}_{2}$ und Mesoporphyrin-Fe (III) ohne cat mAk auch stattfindet (LERNER, BENKOVIC \& SCHULZ; 1991).

Obwohl die Funktion (Abb.3a \& 4) und die biologische Synthese (Abb.36) von Vit. E weitgehend bekannt sind, gab es bisher dennoch kein Konzept, wonach das enantiomerenreine Vit. E produziert wird. 


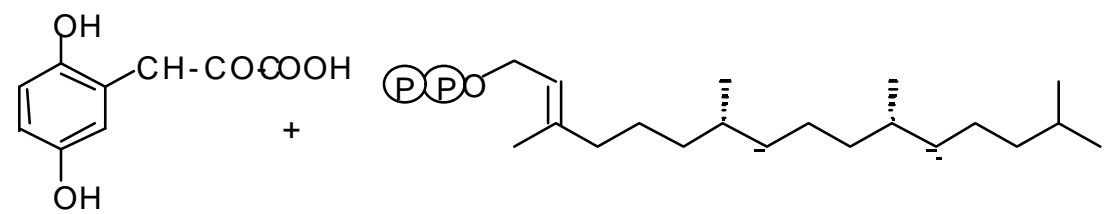

Homogentisinsäure

Phytyldiphosphat

$\downarrow$

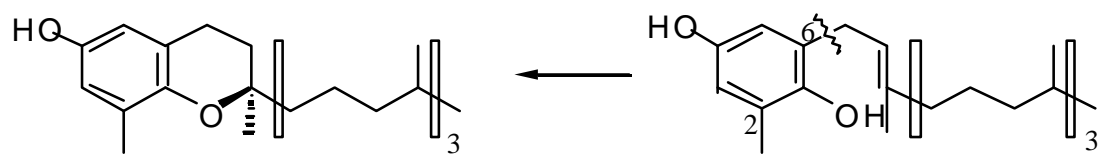

$\delta$-Tocopherol

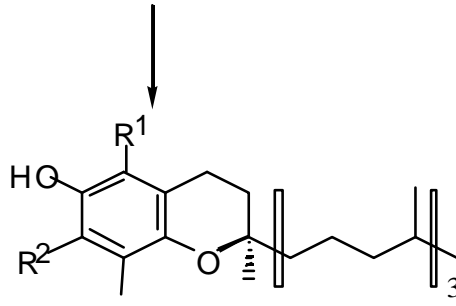

2-Methyl-6-phytylhydrochinon

$\mathrm{R}^{1}=\mathrm{Me}, \mathrm{R}^{2}=\mathrm{H}: \beta$-Tocopherol 2

$R^{1}=H, R^{2}=$ Me: $\gamma-$ Tocopherol 3

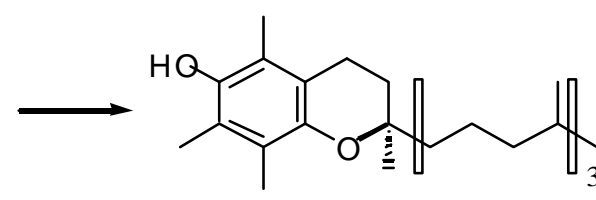

$\alpha$-Tocopherol 1 -

Abbildung 36: Die Biosynthese von Vit. E (nach THREFALL 1971).

Die in dieser Arbeit beschriebenen Reaktionen sind Beispiele für die Entwicklung der cat mAk mit definierten Funktionen in einer Reaktionen, für die kaum natürliche Enzyme verfügbar sind. Anders als beim Einsatz natürlicher Enzyme können cat mAk wegen des Variationsreichtums des immunologischen Repertoires in Varianten „maßgeschneidet“ werden (LERNER \& BEKOVIC \& SCHULTZ; 1991).

\subsection{Aufbau des cat-ELISA}

Bei der Entwicklung katalytischer monoklonaler Ak spielt das Selektionssystem die wichtigste Rolle, da in diesem System eine Unzahl von Ak auf ihrer katalytischer Aktivität untersucht werden sollen. Da die katalytischen Ak geringere Umsatzrate als chemische oder biolo- 
gische Enzyme aufweisen, ist die Effizienz des Selektionssystems sein wichtigstes Kriterium. Das bedeutet, dass ein Selektionssystem so aufgebaut werden muß, dass die Aktivität vieler Ak am Substraten möglichst präzis untersuchen lässt. Aus diesen Gründen sollte zum Nachweis die stereoselektive Synthese von Vit. E aus den Vorstufen dieser Verbindung ein neuer cat-ELISA konstruiert werden.

Das Selektionssysten, welches von TAWFIK et al. (TAWFIK et al., 1995) herausgearbeitet wurde, erfüllt die Ansprüchen der Selektion eines Antikörpers mit stereoselektive Synthese, die Zielreaktion dieser Arbeit, nicht. In dem System von TAWFIK et al., wird das Substrat, gekoppelt an einem Trägerprotein, auf der Oberfläche einer Platte immobilisiert. Auf das Substrat-Trägerprotein-Konjugat werden Probe Ak (cat mAk) gegeben, die aus Mäusen stammen. Nach der Inkubation der ersten Ak erfolgt die Inkubation einer zweiten Ak, ebenfalls muriner Herkunft, der spezifisch am Produkt bindet. Durch Zugabe von einem enzymkonjugierten anti Maus-Ak sollen nur die Antiprodukt-Ak nachgewiesen werden. Das Problem bei diesem System liegt darin, dass der anti Maus Nachweis-Ak nicht nur am Antiprodukt-Ak, sondern genauso gut auch am cat mAk binden kann, da die beiden Ak muriner Herkunft sind (Abb. 37 ).

Um das Problem zu lösen, müssen die cat-mAk und Antiprodukt-Ak Unterschiede aufweisen und erst dann durch diese Unterschiede kann die Bindung des Nachweisantikörpers nur an den produktbindenden Ak geklärt werden. 

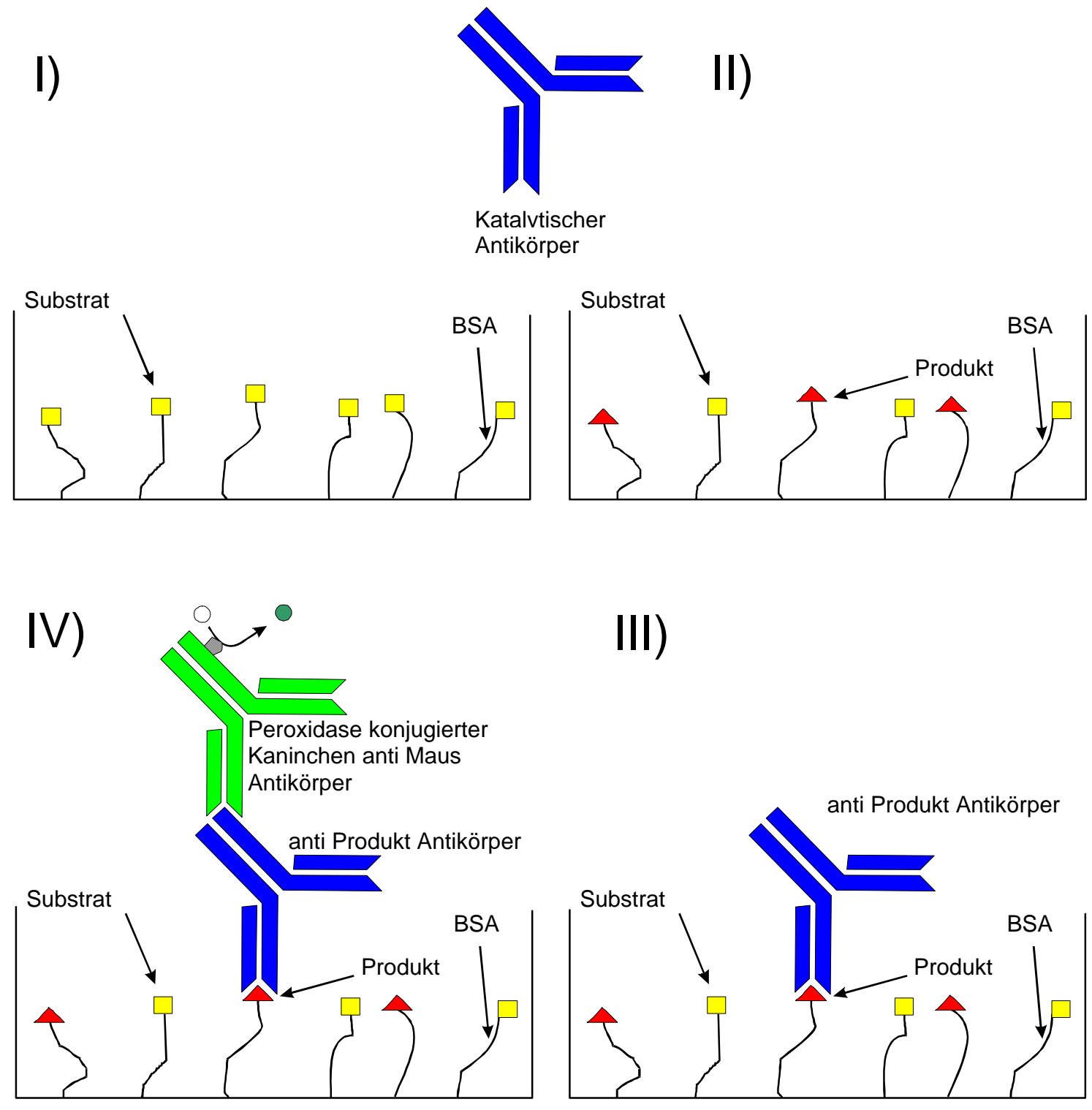

III)

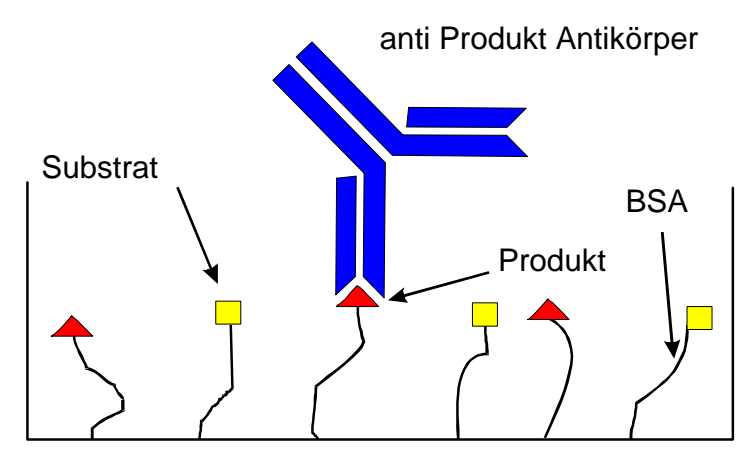

Abbildung 37: Schematische Darstellung des von TAWFIK et al. verwendeten cat-ELISA.

(modifiziert nach TAWFIK et al., 1995); I-IV: Die Inkubationsschritte.

Der Aufbau des in dieser Arbeit entwickelten cat-ELISA ist umgekehrter Reihenfolge zu dem von TAWFIK et al. Zuerst wird ein Kaninchen anti Maus-Ak auf der Oberfläche einer ELISA-Platte immobilisiert. Diese binden an den Probe-Ak (cat mAk). Durch mehrmaliges Waschen nach jedem Inkubationsschritt werden die nicht oder unspezifisch gebundenen Ak aus den Näpfen entfernt. Danach erfolgt die Substratzugabe und somit wird die Reaktion gestartet. Der Nachweis der Produktbildung erfolgt mit nicht immunologischen Nachweisver- 
fahren, wie dünnschichtchromatographische Auftrennung. Gibt es Hinweise auf synthetisiertes Produkt, wird die Reaktion mittels HPLC gemessen und analysiert.

Die Vorteile dieses ELISA wird wie folgt zusammengefasst:

1. Die Bindung von Proben-Ak (cat-mAk) an Kaninchen anti Maus-Ak ist eine hochspezifische Aufreinigung des Proben-Aks

2. Die Immobilisierung des Proben-Aks (cat-mAk) ermöglicht, dass das Substrat ohne Kopplung an anderen Molekülen der Reaktion gegeben wird.

3. Der Nachweis erfolgt durch präzise Messtechniken, nämlich HPLC, und unabhängig von Amplifikationen, die im TAWFIK et al.-System durch enzymatische Farbreaktion des Nachweis-Aks zustande kommt und dann cholorometrisch (OD) gemessen wird.

4. Da die Bindung des Nachweis-Aks am anti Produkt-Ak auf unterschiedliche Isotypen der beiden cat-mAk und anti Produkt-Ak erfolgt, werden die Proben-Ak, die das selbe Isotyp wie anti Produkt-Ak besitzen, aus dem Test ausgeschlossen, da der Nachweis nur eines Aks aus den selben Spezies mit den selben Isotyp unmöglich ist.

Von TAWFIK et al. vorgestellter ELISA kann wahrscheinlich unter bestimmten Umständen und Voraussetzungen eine ungenaue Angabe über die katalytische Aktivität eines Aks vermitteln, er ist jedoch keineswegs ein etabliertes Protokoll zum Nachweis von cat-mAk.

\subsection{Nachweis der katalytischen Aktivität des mAks Doro-1}

Zum Nachweis der katalytischen Aktivität der Ak wurde ein neuer ELISA entwickelt. Da sowohl das Substrat als auch das Produkt hydrophob waren, sollte die Reaktion in einem or- 
ganischen Lösungsmittel erfolgen. Zwischen den organischen Lösungsmitteln ist Methanol das kleinste Molekül und deshalb polarer als andere Alkohole. Das erleichtert die Protonierung des 2. C-Atoms und dadurch die Auflösung der Doppellbindung. Deshalb wurde das Substrat in reinem Methanol gelöst und zu immobilisierten Probe-Ak gegeben (Siehe 2.2.7). Die Reaktion wurde in Methanol bei $50^{\circ} \mathrm{C}$ gestartet und dauerte $72 \mathrm{~h}$ (Siehe 3.2).

Da die HPLC-Analyse und dünnschichchromatographische Auftrennung keine schweren Moleküle, wie Peptide, zeigten, kann davon ausgegangen werden, daß die Ak unter den Reaktionsbedingung nicht fragmentiert worden sind.

\subsubsection{Die niedrige Umsatzrate von Doro-1}

Die dünnschichtchromatographische Auftrennung sowie die HPLC-unterstützte Analyse zeigten, daß mAk Doro-1, ein muriner IgA, die gewünschte Reaktion (Abb.17) katalysiert und die Substrate zum Vitamin E-Vorläufer transformiert. Die HPLC-Analyse hat insgesamt eine Umsatzrate von $5 \%$ festgestellt sowie relativ hohe ee-Werte um $42 \%$. Die Gründe dafür können im verwendeten Selektionssystem (siehe 2.2.5) liegen. Da die Selektion der Klone zuerst über die Affinität ihrer Ak zum Hapten, dessen Konfiguration dem Produkt zu ähnlich war, erfolgte, wurden Antikörper mit Affinität zum Produkt ausgewählt. Deshalb kann davon ausgegangen werden, daß das Produkt an die Bindungsstellen des Aks bindet und dadurch sein aktives Zentrum blockiert. Die Versuche zur Optimierung des cat-ELISA wie z. B. die Verwendung anderer Lösungsmittel führte dazu, daß die Reaktion stark beeinträchtigt wurde (nicht gezeigt). Trotz dieser niedrigen Umsatzrate kann die Reaktion als erfolgreich betrachtet werden angesichts der Tatsache, daß eine enantiomerenreine chemische Synthese bis heute kaum möglich ist (ARANGO und HEISE, 1998; GÖRLITZER, 1997; SEIBEL, 1997). 


\subsection{Der Vit. E bindende Ak Ing-1}

Ausgehend vom Spezifitätstest wurden Ak gefunden, die an Vit. E binden (Tab.5). Einer dieser Ak, Ing-1, wurde zur Entwicklung und Optimierung qualitativer und quantitativer Testsysteme benutzt. Das Problem bei der Entwicklung dieser Systeme bestand in fehlenden Referenzen, da zum ersten Mal das Vit. E durch Anwendung immunologischer Methoden nachgewiesen werden sollte.

Es sollte ein System konstruiert werden, in dem das nicht wasserlösliche Vit. E mit immunologischen Methoden, die auf wässrigen Puffersystemen basieren, qualitativ und quantitativ erfaßt werden. Die Experimente zur Bestimmung unterschiedlicher Oberflächenbeschichtungen (Abb. 24) zeigten signifikante Unterschiede zwischen untersuchten Parametern (unterschiedliche Proteine und unterschiedliche Pipettierungsreihenfolge) innerhalb einer Messung, sie korrelierten jedoch nicht mit den Änderungen. Die Versuche, Vit. E zu modifizieren, um dadurch dessen Wasserlöslichkeit zu ändern, waren in Form des synthetisierten Biotin-Vit. EEsters (Abb. 25) erfolgreich, der an Streptavidin gekoppelt werden konnte.

Um die Konzentration von Vit. E bestimmen zu können, ohne es zu modifizieren, wurde ein neuer ELISA entwickelt. Da das Vit. E stark hydrophob ist, wurde zuerst durch Silanisierung mit Dodecyltrichlorsilan versucht, eine Oberfläche zu konstruieren, die eine optimale, hydrophobe Grundlage für Vit. E vorbereitet (Siehe 3. 13). Das Dodecyltrichlorsilan wurde auf der Glasoberfläche (Abb. 30 a \&b) durch seine hydrophobe Eigenschaft nachgewiesen (Abperlen von Wassertropfen), während die Ergebnisse der Silanbehandlung der Plastikoberfläche (ELISA-Platte) nicht kontrolliert werden konnte. Es wurde angenommen, daß das Silanderivat auf der Oberfläche der Mikrotiterplatte präsent war, da das Dodecyltrichlorsilan in Pentan gelost wurde und nach dem Abdampfen des Lösungsmittells sichtbar war. Gleichzeitig diente 
die Silan als Block, der unspezifische Bindungen der $\mathrm{Ak}$ an die Oberfläche verminderte. Diese Methode lieferte so konstante Ergebnisse, daß sie zur Bestimmung der Dissoziationskonstante des mAks Ing-1 an Vit. E diente.

\subsubsection{Epitopbestimmung durch Biotin-Vit. E-Ester}

Um das Epitop des mAks Ing-1 innerhalb der $\alpha$-Tocopherol-Verbindung zu bestimmen, wurde das Vit. E biotinyliert (Abb. 25) und an immobilisiertes Streptavidin gekoppelt. Dadurch blieb das Vit. E nur von einer Seite zugänglich für den mAk Ing-1 (Abb. 26). Die ersten Ergebnisse zeigten, daß das Epitop des mAks Ing-1 durch die Veresterung des Vit. E mit Biotin nicht blockiert wird. Durch weitere Versuche wurden die Einzelteile dieses Esters als potentielles Epitop für den mAk Ing-1 untersucht (Siehe 3.12 und Abb. 29). Es wurde festgestellt, daß das Chromangerüst des $\alpha$-Tocopherols den wichtigsten Teil des Epitops darstellt.

Der Biotin-Vit. E-Ester stellt eine neue Form von Vit. E-Derivaten dar. Da jedes Teilmolekül aus einem Vitamin besteht, kann davon ausgegangen werden, daß diese Verbindung biologische Aktivität besitzt. Dieser Aspekt konnte im Rahmen dieser Arbeit nicht weiter bearbeitet werden.

\subsubsection{Die Reaktion der mAk Ing-1 und Doro-1 mit verschiedenen humanen Zellen}

Zur Charakterisierung beider mAk Doro-1 und Ing-1 wurde die Affinität dieser Ak gegen Strukturen auf der Zelloberfläche untersucht. Die Experimente für jeden mAk wurden getrennt durchgeführt. Die durchflußzytometrische (FACS)-Analyse und zytochemische Fär- 
bungen ergaben jedoch entgegen der Erwartungen keine nachweisbare Bindung an die untersuchten Zelloberflächen (nicht gezeigt).

\subsubsection{Praxisbezogene Anwendung von Ing-1}

Da der mAk Ing-1 natürliches Vit.E erkennt, ist davon auszugehen, daß dieser Ak eine praxisbezogene Anwendung zur Bestimmung des Vit. E-Gehaltes natürlicher und synthetischer Produkte findet. Das in dieser Arbeit vorgestellte Nachweissystem könnte bei der Gestaltung praxisbezogener Anwendungen eine entscheidende Rolle spielen. 


\section{Zusammenfassung}

Im Rahmen dieser Arbeit sollten ein monoklonaler Antikörper mit katalytischer Aktivität zur enantioselektiven Synthese von Vit. E und ein monoklonaler Antikörper, der gegen Vit. E gerichtet ist, generiert werden.

Aus der direkten Vorstufe des Vit. E wird industriell durch chemische Synthese ein Gemisch aus acht Isomeren produziert. Deshalb wurde versucht, mit Hilfe des genetischen Repertoires des Immunsystems ein biologisches Enzym zu entwickeln, welches die Synthese des Vit. E katalysiert.

Dazu wurden zwei autoimmun erkrankte Mausstämme, MRL $L_{\text {lpr/lpr }}$ und SJL/Hsp, ausgewählt, und mit einem an das Trägerprotein KLH gekoppelten, enantiomerenreinen Hapten immunisiert. Nach der Fusionierung wurde die Spezifität der Klone an Hapten-BSA-Komplex getestet und die Klone, die affin zum Hapten waren, positiv selektiert. Die Selektion der katalytisch aktiven Ak erfolgte in einem dafür entwickelten cat-ELISA. Aus 123 Hapten spezifischen Klonen wurden sieben katalytische Antikörper identifiziert, die die gewünschte Reaktion katalysieren, allerdings mit unterschiedlichen Umsatzraten. Durch HPLC-Analyse wurde festgestellt, daß unter sieben cat-mAk der Ak M2-47 (Doro-1), ein muriner IgA mit $\kappa$ leichter Kette, mit 5\% Umsatzrate und einem ee-Wert von 42\%, der aktivste ist.

Dem Ziel dieser Arbeit entsprechend wurde ein zweiter Ak generiert, der gegen Vit. E gerichtet ist. Um das Vit. E qualitativ und quantitativ nachzuweisen, wurden verschiedene Nach-weisverfahren in Anlehnung an die ELISA-Technik mit Hilfe dieses Aks entwickelt. 
Die Genauigkeit dieser Systeme wurde unter Anwendung einer hydrophoben Oberfläche soweit optimiert, daß bis zu $23 \mu \mathrm{M}$ Vit. E nachgewiesen werden konnte. Die Genauigkeit dieses Systems ermöglichte die Berechnung der Dissoziationskonstanten $\left(\mathrm{K}_{\mathrm{D}}\right)$ des Aks Ing-1 an seinem Antigen (Vit. E).

Das Epitop dieses Aks wurde durch die Synthese einer neuen Verbindung, die aus Vit. H und Vit. E (Biotin-Vit. E-Ester) besteht, am Chromangerüst lokalisiert. Durch die proteinbiochemischen Versuche sollten die cat-mAk Doro-1 (IgA), mAk Ing-1 (IgG2a) und FabFragment des mAks Ing-1 aufgereinigt und für die röntgenkristallographische Analyse vorbereitet werden. Diese Versuche sind zum größten Teil abgeschlossen.

Damit wurden die Ziele dieser Arbeit, die Generierung eines cat-mAks zur stereoselektiven Synthese von Vit. E und eines anti Vit. E-Aks, erreicht.

\section{Weitere Aspekte}

Da sich diese Arbeit mit der Generierung eines katalytisch aktiven und eines gegen Vit. E gerichteten Antikörpers befaßte, wurden dennoch viele beobachtete interessante Nebenbefunde nicht ausreichend bearbeitet. In vielen Abschnitten dieser Arbeit wurden die Experimente so gestaltet, daß für spätere Untersuchungen Materialien in umfangreicher Menge vorhanden sind. 


\section{Untersuchungen der Adjuvantien}

Die zwei in dieser Arbeit verwendeten Adjuvantien wurden unter absolut vergleichbaren Bedingungen zur Immunisierung von 12 Tieren angesetzt. Die Materialien aus den Fusionierungsversuchen wurden in vollem Umfang kryokonserviert. Es gibt deshalb genug Materialien, die zur statistischen Auswertung der Wirkung dieser Adjuvantien geeignet sind. Damit können folgende Fragen beantwortet werden:

1. Der Vergleich zweier Adjuvantien in bezug auf Fusionsausbeute.

2. Der Einfluß jedes Adjuvans auf Isotyp der Antikörper und Klassen-Switch.

3. Die Effektivität des Adjuvans P3CSK4 auf die Immunantwort in Abwesenheit des Trägerproteins.

\section{$\underline{\text { Selektion eines cat-mAks durch direkte Untersuchung mit dem cat-ELISA }}$}

Nach der Entwicklung des cat-ELISAs in dieser Arbeit ist es nun möglich, die Ak direkt auf ihre katalytische Aktivität hin zu testen, ohne den Spezifitätstest durchführen zu müssen. Dabei kann der cat-mAk Doro-1 als Referenz betrachtet werden.

\section{Praxis bezogene Anwendungen von Ing-1}

Da der mAk Ing-1 an natürliches Vit. E bindet, ist es möglich, das Vit. E-Nachweissystem so zu optimieren, daß die Vit. E-Konzentration noch einfacher bestimmt werden kann. Erstrebenswert ist es allerdings, ein System zu entwickeln, in dem das Vit. E quantitativ in pflanzlichem Gewebe nachgewiesen werden kann. 


\section{$\underline{\text { Literaturverzeichnis }}$}

Acuff, R.V., Dunworth, R.G., Webb, L.W., Lane, J.R. (1998): Transport of deuteriumlabeled tocopherols during pregnancy. Am. J. Clin. Nutr. 67: 459-464.

Ackerström, B., Brodin, T., Reis, K., Björck, L. (1985): Protein G: a powerful tool for binding and detection of monoclonal and polyclonal antidodies. J. Immunol. 135: 2589-2592.

Ackerström, B., Björck, L. (1985): A physicochemical study of protein G, a molecule with unique immunoglobulin G-binding properties. J. Biol. Chem. 261: 10240-10247.

Arango, Y., Heise, K.P. (1998): Tocopherol synthesis from homogenisate in Capsicum anиит L. (yellow pepper) chromoplast membranes: evidence for tocopherol cyclase.

Biochem. J. 336: 531-533.

Bartel, A., \& Campbell, D. (1959): Some immunochemical differences between associated and dissociated hemocyanin. Arch. Biochem. Biophys. ⒉ 2332.

Blackburn, G.M., Kang, A.S., Kingsbury, G.A., Burton, D.R. (1989): Catalytic antibodies. Biochem. J. 262: 381-390.

BØyum, А. (1964): Separation of white blood cells. Nature 204: 793-797.

Burton, G.W., Joyce, A., Ingold, K.U. (1982): First proof that vitamin E is major lipidsoluble, chain-breaking antioxidant in human blood plasma. Lancet 7 327.

Burton, G.W., Joyce, A., Ingold, K.U. (1983): Is vitamin E the only lipid-soluble, chainbreaking antioxidant in human blood plasma and erythrocyte membranes? Arch. Biochem. Biophys. 221: 281-290.

Carpenter, D. (1985): Vitamin E Deficiency. Sem. Neurol. 5: 283-287.

Cheng, S.G., Burton, G.W., Ingold, K.U., Foster, D.O. (1987): Chiral discrimination in the exchange of alpha-tocopherol stereoisomers between plasma and red blood cells. Lipids $\underline{22}$ : 469-473. 
Coller, H.A., Coller, B.S. (1983): Poisson statical analysis of repetive subcloning by the limiting dilution technique as a way of assessing hybridoma monoclonality. Meth. Enzymol. 121: 412-417.

Eisenberg, R.A., Tan, E.M., Dixon, F.J. (1978): Presence of anti-Sm reactivity in autoimmun mouse strain. J. Exp. Med. 147: 582-587.

Factor, V.M., Laskowska, D., Jensen, M.R., Woitach, J.T., Popescu, N.C., Toigarsson, S.S. (2000): Vitamin E reduces crosomal damage and inhibits hepatic tumor formation in transgenic mouse model. Proc. Natl. Acad. Sci. USA. 97: 2196-2201.

Falkenberg, F. W., Hengelage, T., Krane, M., Bartels, I., Albrecht, A., Holtmeier, N., Wüthrich, M. (1993): A simple and inexpensive high density dialysis tubing cell culture system for the in vitro production of monoclonal antibodies in high concentration. J. Immunol. Methods 165: 193-206.

Falkenberg, F.W., Weichert, H., Krane, M., Bartels, I., Palme, M., Nagels, H.O., Feibig, H. (1995): In vitro production of monoclonal antibodies in high concentration in a new and easy to handle modular minifermenter. J. Immunol. Methods 179: 13-29.

Forsgren, A., Sjöquist, J. (1966): "Protein A" from S. aureus I. pseudo-immune reaction with human gamma-globulin. J. Immunol. 97: 822-827.

Freund, J. (1956): The mode of action of immunologic adjuvants. Fortsch. Tuberk.-Forsch. 7: $130-148$.

Gonzales, M.J. (1990): Serum concentration and cellular uptake of vitamin E. Med. Hypotheses 32: 107-110.

Görlitzer, J., (1997): Dissertation, Göttingen.

Hoffmann, P., Loleit, M., Mittenbuhler, K., Beck, W., Wiesmuller, K.H., Jung, G., Bessler W.G. (1997): Induction of an epitope-specific humoral immune response by lipopeptide-hapten conjugates: enhancement of the anti-melittin response by a synthetic $\mathrm{T}$ helper (Th)-cell epitop. FEMS immunol. Med. Microbiol. 17(4): 225-234. 
Hersckovits, T. (1988): Recent aspects of the subunit organization and dissociation of hamocyanin. Comp. Biochem. Physiol. 91B: 597-611.

Hoffmann, P., Bessler W.G. (2000): Lipopeptides as immunoadjuvants and immunostimulants in mucosal immunization. Immunobiology 201: 391-405.

Horwitt, M.K., (1986): Interpretations of requirements for thiamin, riboflavin, niacintryptophan, and vitamin E plus comments on balance studies and vitamin B-6. Am. J. Nutr. 44: 937-985.

Ingold, K.U., Burton, G.W., Foster, D.O., Hughes, L., Lindsay, D.A., Webb, A. (1987): Biokinetics of and discrimination between dietry RRR-and SRR-alpha-tocopherols in the male rat. Lipids 22: 163-172.

Jacobsen, J.R., Prudent, J.R., Kochersperger, L., Yonkovich, S., Schultz, P.G. (1992): An Efficient Antibody-Catalyzed Aminoacylation Reaction. Sience 256: 365-367.

Janeway, C.A., \& Travers, P. (1995) :Immunologie. Spektrum Akademischer Verlag Heidelber, Berlin, Oxford.

Kearney J.F.,Radbruch, A., Liesegang, B., Rajewski, K. (1979): A mouse myeloma cell line that has lost immunoglobulin expression but permit the contruction of antibody-secreting hybridoma cell lines. J. Immunol. 123: 1548-1558.

Kenny, G.E., Dunsmoor, C.L. (1983): Principles, problems, and strategies in the use of antigenic mixtures for the enzyme-linked immuno-sorbent assay. J. Clin. Microbiol. 17: 655665.

Kiyose, C., Muramatsu, R., Kameyama, Y., Ueda, T., Igarashi, O. (1997):

Biodiscrimination of alpha-tocopherol stereoisomers in human after oral administration. Am. J. Clin. Nutr. 65: 785-789.

Lerner, R.A., Benkovic, S., Schultz, P.G. (1991): At the Crossroads of Chemistry and Immunologie: Catalytic Antibodies. Science 252: 659-667. 
Li, T., Janda, K.D., Ashley, J.A., Lerner, R.A. (1994): Antibody Catalyzed Cationic Cyclization. Science 264: 1289-1293.

Lubin, F., Farbstein, H., Chetrit, A., Farbstein, E., ALFANDARI, E. und MODAN, E (2000): The rolle of nutritional habits during gestation and child life in pediatric brain tumor etilogy. Int. J. Cancer 86: 139-143

Mahony, C.W., Azzi, A. (1988): Vitamin E inhibits protein kinase C activity. Biochem. Biophys. Res. Commun. 154: 694-697.

Mc Garrity, G.J., Vanaman, V., Sarama, J. (1984): Cytogenetic effects of mycoplasmal infection of cell cultur: a review. In vitro $\underline{20}$ : 1-18.

Murphy, E.D., \& Roths, J.B. (1977): A single-gene model for massive lymphoproliferation with autoimmunity in new mouse strain MRL. Fed. Proc. $\underline{36}$ : 1246.

Murphy, E.D., \& Roths, J.B. (1978): A single-gene model for massive lymphoproliferation with immune complex disease in new mouse strain MRL, Proc. $16^{\text {th }}$ Internat. Cong. Hematol. Excerpta Medica, Amsterdam: 58-61.

Nomenclature of Tocopherols and related compounds (1982): Eur. J. Biochem. 123: 473.

Netscher, T. (1996): Stereoisomers of Tocopherols-synthese and analytics. Chemia 50: 563567.

Pathania, V., Syal, N., Pathak, C.M., Khanduja, K.L. (1999): Vitamin E suppresses the induction of reactive oxygen spcies release by lipopolysaccaride, IL- $1 \beta$ and TNF- $\alpha$ in rat alveoral macrophages. J. Nutr. Sci. Vitaminol 46: 675-686.

Peters, J.H. (1992b): Cell Culture. In: Peters, J.H., Baumgarten, H. (eds.)Monoclonal antibodies, Springer Verlag, Berlin, Heidelberg, New York, S. 114-132.

Peters, J.H., Baumgarten, H. (1992): Monoklonale Antikörper, SPRINGER Verlag, Berlin.

Pollack, S.J., Jeferri, W.J., Schultz, P.G., (1986): Slective Chemical Catalysis by an Antibody. Science 234: 1570-1573. 
Russel, W.C., Newman, C., Williamson, D.H. (1975): A simple cytochemical technique for demonstration of DANN in cell infected with mycoplasmas and viruses. Nature 253: 461-462.

Satoh, M., Hamilton, K.J., Ajmani, A.K., Dong, X., Wang, J., Kanwar, Y.S., Reeves, W.H. (1996): Autoantibodies to ribosomal $\mathrm{P}$ antigen with immune complex glomerulonephritis in SJL mice treated with pristane. J. Immunol. 157: 3200-3206.

Santos, L.M., al-Sabbagh, A., Londono, A., Weiner, H.L. (1994): Oral tolerance to myelin basic protein induces regulatory TGF-beta-secreting T cells in Peyer's patches of SJL mice. Cell Immunol. 157: 439-447.

Satya-Murti, S., Howard, L., Krohel, G., Wolf, B., (1986): The spectrum of neurologic disorder from vitamin E deficiency. Neurologie 36: 917-921.

Schmitt, K., Däubener, W., Bitter-Suermann, D., Hadding, U. (1988): A safe and efficient method for elimination of cell culture mycoplasmas using ciprofloxacin. J. Immunol. Meth. 109: 17-25.

Schultz, P.G., Lerner, R.A., (1993): Antibody catalisis of Difficult Chemical Transformations. Acc. Chem. Res. 26: 391-395.

Seibel, J., (1997): Diplomarbeit, Göttingen.

Seibel, J., (2000): Dissertation, Göttingen.

Senozan, N.M., \& Landrum, J. (1981): Hemocyanin of the giant keyhole limpet, Megathura crenulata. In Invertebrate oxygen binding Proteins: structure, activ sites and function. Lamy J. and Lamy J., Editors, Marcel Dekker, New York: 703-717.

Simon, E.S., Cross, C.S., Milhorat, A.T. (1956): J. Biol. Chem. 221: 797-805.

Stocker, A., Fretz, H., Frick, H., Ruttimann, A., Woggon, W.D. (1996): The substrate specificity of tocopherol cyclase. Bioorg. Med. Chem. 4(7): 1129-1134. 
Tang, J.C., Ho, F.C., Chan, A.C., Srivastava, G. (1998): Cloning of lymphomas at multiple sites in SJL mice. Lab. Invest. 로: 205-212.

Tawfik, D.S., Chap, R., Green, B.S., Sela, M., Eshhar, Z. (1995): Unexpectedly high occurrence of catalytic antibodies in MRL/lpr and SJL mice immunized with a transition-state analog: Is there a linkage to autoimmunity? Proc. Natl. Acad. Sci. USA. 92: 2145-2149.

Tramontano, A., Janda, K.D., Lerner, R.A., (1986): Catalytic antibodies. Science 234:1566-1570.

Trost, B.M., (1995): Atomökonomische Synthesen- eine Herausforderung in der organishen Chemie. Angew. Chem. 107: 285-307.

Threlfall, D.R. (1971): The biosynthesis of vitamin E and K and related compounds. Vitam. Horm. 29: 153-200.

Towbin, H., Staehelin, T., Gordon, J. (1979): Electrophoretic transfer of proteins from polyacrylamide gels to nitrocellulose sheets: procedure and some applications. Proc. Natl. Acad. Sci. USA 므: 4350-4354.

Vatassery, G.T. (1989): Oxidation of vitamin E in red cell membranes by fatty acids, hydroperoxides and selected oxidants. Lipids. 24(4): 299-304.

Wassermann, M. (1993): Mycoplasma contamination in cell culture. Am. Biotechnol. Lab. 11: $10-12$.

Willett, W.C., Stampfer, M.J., Underwood, B.A., Taylor, J.O., Hennekens, C.H. (1983): Validation of a dietary questionaire with plasma carotenoid and alpha-tocopherol levels. Am. J. Clin. Nutr. 38: 559-566.

Winter, G., Griffiths, A.D. Hawkins, R.E., \& Hoogennboom, H.R. (1994): Making antibodies by phage display technology. Annu. Rev. Immunol. 12: 433-455.

Zola, H., Moore, H.A., Hunter, I.K., Bradley, J. (1984): Analysis of chemical and biochemical properties of membrane in situ by analytical flow cytometry with monoclonal antibodies, J. Immunol Meth. $\underline{74}$ : 65-67. 
Zhong, G., Shabath, D., List, B., Anderson, J., Sinha, S.C., Lerner, R.A., Barbas III, C.F., (1989): Katalytische enantioselektive Retro-Aldolreaktion: kinetische Racematspaltung von $\beta$-Hydroxylketonen durch Aldolase-Antikörper. Angew. Chem. 110: 2609-2612. 


\section{Danksagung}

Mein besonderer, innigster Dank gilt Herrn Prof. Dr. med. J. H. Peters, der mir dieses interessante Thema überließ, mich bei stetem Interesse am Fortgang dieser Arbeit in hilfreichen Diskussionen unterstützt und motiviert hat.

Mein herzlicher Dank geht an meinem Doktorvater, Herrn Prof. Dr. U. Grossbach, für seine anregenden Diskussionen und die sorgfältige Durchsicht des Manuskripts.

Herrn Prof. Dr. Dr. h. c. L. F. Tietze möchte ich für seine außerordentlich freundliche Unterstützung und sein anhaltendes Interesse an Fortgang dieser Arbeit herzlich danken.

Herrn Prof. Dr. med. O. Götze danke ich für die freundliche Aufnahme in die Abteilung für Immunologie, Zentrum Hygiene und Humangenetik.

Bei meinem Freund und Kollegen, Dr. J. Seibel bedanke ich mich für sein Interesse, besonders seine Ideen und Kreativitäten, die vor Nichts Halt machen und sein Engagement in der Fortführung dieses Projektes.

Herrn Dipl. Ing. H. Bayat Afshari danke ich für seine vielseitige Unterstützung bei den Computerarbeiten und täglich motivierenden Auseinandersetzungen zur Durchführung und Anfertigung der vorliegenden Arbeit.

Bei Frau Dipl. päd. E. Hossaini Tekihe und Frau Dipl.-Chem. Nicole Pöhlmann möchte ich mich für ihre Unterstützung trotz ihrer Zeitknappheit herzlich bedanken.

Frau D. Ostermeier, Frau A. Struck, Frau Dr. I. Schuberth und Frau E. Kühn danke ich für ihre wertvolle Hilfestellung und produktiven Diskussionen.

Allen Mitarbeitern der Abteilung für Immunologie gilt mein besonders herzlicher Dank für die angenehm freundliche und sterile Atmosphäre, an der sie stets besorgt waren, damit der Fortlauf dieser Arbeit nicht allzu ermüdend und kontaminiert war.

Meine tiefste und innigste Dankbarkeit gehört meiner Mutter, Frau M. Bayat Afshari, für ihr Immerdasein und ihre mütterlichen Besorgnisse, die mir in den Momenten, in denen nichts mehr geht, die Kraft zum Weitergehen verleihen.

Auch meinem verstorbenen Vater, Prof. Josef Djalali Bazzaz, möchte ich einen besonderen Dank aussprechen, der mir gelehrt hat, der Menschheit menschlich zu dienen, wofür er selber gelebt hat. Daher begleiten mich immer seine Gedanken und die unbeschreiblich schönen Momente mit ihm.

Nicht zuletzt danke ich meiner geliebten Frau, Hajar Rosana Sakhli, für ihre geduldige Akzeptanz, ihr Beistehen während meines ganzen Studiums und ihr verantwortungsvolles Bewußtsein und Verständnis für meine zuletzt andauernde Abwesenheit bei der Anfertigung dieser Arbeit. 


\section{LEBENSLAUF}

27.11.1961:

1968-1973:

1973-1976:

1976-1980:

1980:

1980-1982:

1982-1986:

Aug. 1986:

1988-1989:

WS 1989/90:

07. Apr. 1990:

14. Okt. 1992:

08. Okt. 1996:

Dez. 1995-Sep.96:

Nov. 1997-Sep. 2000:

20. Jan. 1999:

Seit 20. Nov. 1997:

Nationalität:
Geboren als Sohn des Universitätsprofessors, Josef Djalali

Bazzaz, und seiner Ehegattin, Frau Mansoureh Bayat Afshari, in Teheran/Iran.

Besuch der Grundschule „Nasser Khossrow“ in Teheran.

Besuch der privaten Orientierungsschule „Azar II“ in Teheran.

Besuch des privaten Gymnasiums „Azar II“ in Teheran.

Abitur in Naturwissenschaften in Teheran.

Absolvieren des Wehrdienstes in Teheran.

Aufnahme eines privaten Unternehmens

Einreise in die Bundesrepublik Deutschland und Besuch eines Sprachkurses

Besuch des niedersächsischen Studienkollegs in Hannover Beginn des Studiums in biologische Fakultät an der GeorgAugust-Universität zu Göttingen

Eheschließung mit Frau Hajar Sakhli in Latina/Italien

Diplomvorprüfung

Diplomprüfung

Diplomarbeit in der Abteilung für Immunologie der Universität zu Göttingen unter der Anleitung von Prof. Dr. med. J. H. Peters über das Thema „Charakterisierung eines oberflächenspezifischen Proteins auf in in vitro differenzierten humanen dendritischen Zellen“

Dissertation in der Abteilung für Immunologie der Universität zu Göttingen unter der Anleitung von Prof. Dr. U. Großbach und Prof. Dr. med. J. H. Peters über das Thema“ Geburt meines Sohnes, Damon Djalali Bazzaz, in Göttingen Angestellt als wissenschaftlicher Mitarbeiter der Universität zu Göttingen.

Seit Mär. 2000 Ir/De 